\title{
Drittes Kapitel: Normierung der materiellen Wiedergutmachung in der US-Zone (1945-1949)
}

\section{Deutsche und amerikanische Vorarbeiten}

\section{Deutsche Planungen: Wiedergutmachung aus eigener Initiative?}

Parallel zu den Anfängen der Fürsorge für ehemalige Verfolgte des Nationalsozialismus begannen auch bereits Planungen für die gesetzliche Wiedergutmachung der erlittenen Schäden. Dabei bestehen widersprüchliche Angaben darüber, inwieweit deutsche Stellen aus eigener Verantwortung um eine Lösung dieser Frage bemüht waren. Ein interner Bericht der OMGUS Information Control vom Februar 1946 erhob den Vorwurf, daß die deutschen Länderverwaltungen zwar umfassende Entwürfe zur Wiedergutmachung des nationalsozialistischen Unrechts verfaßt hätten, die amerikanische Militärregierung derartige Initiativen jedoch blockiert habe, da sie die Zeit noch nicht für reif erachte ${ }^{1}$. Ähnlich argumentierte Anfang der fünfziger Jahre vor dem Bundestag auch der SPD-Abgeordnete Adolf Arndt, der nach dem Krieg als Ministerialrat im hessischen Justizministerium tätig gewesen war: „Um der geschichtlichen Wahrheit willen darf ich feststellen, daß die Landesregierungen von Bayern, Hessen und WürttembergBaden 1945 sofort aus freien Stücken die Arbeiten an deutschen Rückerstattungs- und Entschädigungsgesetzen aufgenommen haben. Wenige wissen, daß die Militärregierungen dann diese Arbeit lange Zeit hindurch ausdrücklich verboten haben" 2 . Sind diese schweren Vorwürfe berechtigt? Verhinderte die amerikanische Militärregierung tatsächlich eine eigene Lösung dieser Fragen unter deutscher Regie?

Die Frage der Wiedergutmachung für Schäden aus nationalsozialistischer Verfolgung war, wie gezeigt, bereits vor Kriegsende auch auf deutscher Seite mehrfach aufgegriffen worden. Bald nach Kriegsende setzten dann deutsche Planungen auf Länderebene ein. Dabei gibt es aber kaum Beispiele für eine Kontinuität zu den Arbeiten aus der Kriegszeit. Die überlieferten frühesten Entwürfe sind überwiegend das Werk einzelner Persönlichkeiten in den Landesverwaltungen. In der US-Zone existierte bis zu den Landtagswahlen im Dezember 1946 keine Legislative, von der solche Initiativen hätten ausgehen können. Bis dahin war die gesetzgebende Gewalt den Ministerpräsidenten der US-Zone aufgrund der Proklamation Nr. 2 direkt durch die Militärregierung delegiert,

${ }^{1}$ OMGUS, Information Control, Intelligence Summary, (ICIS) N. 32, 23. 2. 1946, USNA, RG 59, 740.00119, Box 3483.

2 Deutscher Bundestag, 229. Sitzung am 11.9. 1952, Stenographische Berichte, Bd. 12, S. 10435. Zur Bedeutung Arndts für die Wiedergutmachung siehe auch Dieter Gosewinkel, Adolf Arndt. Die Wiederbegründung des Rechtsstaats aus dem Geist der Sozialdemokratie, Bonn 1991. 
die eine strenge Oberaufsicht behielt ${ }^{3}$. Zudem drängte die Militärregierung auch nach der Wahl von Volksvertretungen in den Ländern darauf, daß diese Materie weitgehend unter Ausschluß der Legislative behandelt wurde.

Bayern übernahm zunächst die Führung bei diesen Planungen ${ }^{4}$. Bereits am 8. August 1945 überreichte Justizminister Wilhelm Hoegner dem damaligen Ministerpräsidenten und späteren Bundesfinanzminister Fritz Schäffer einen Entwurf für ein Gesetz zur Wiedergutmachung nationalsozialistischen Unrechts, der auf seinen Vorarbeiten im Schweizer Exil basierte ${ }^{5}$. Dort behandelte er zunächst Schäden nicht-vermögensrechtlicher Natur. Alle politischen Handlungen gegen die nationalsozialistische Gewaltherrschaft sollten straffrei sein. Artikel 2 enthielt die zentrale Regelung, daß „Bayern, die wegen ihrer Rasse, Religion oder wegen ihres nicht-nationalsozialistischen Bekenntnisses unter der nationalsozialistischen Gewaltherrschaft bestraft oder sonst ihrer Freiheit beraubt und dadurch in ihrer Gesundheit erheblich und dauernd geschädigt worden sind, ... Anspruch auf Entschädigung nach billigem Ermessen " 6 hätten. Bemerkenswert daran ist, daß die nähere Bestimmung der nationalsozialistischen Verfolgung durch deren rassische, religiöse oder politische Motive erst in einem späteren Stadium dieses Entwurfes hinzugefügt worden war; offensichtlich wurde hier die von den Alliierten mitgebrachte Definition übernommen'. Zudem sticht die ausdrückliche Beschränkung der vorgesehenen Entschädigung auf bayerische Bürger ins Auge. Eine entsprechende Bestimmung fand sich in sämtlichen deutschen Entwürfen dieser Zeit. Die Zersplitterung Deutschlands unter der alliierten Besetzung führte so zu einer extremen Ausformung des Territorialitätsprinzips.

Weiter sah der erste Abschnitt vor, Ausbürgerungen rückgängig zu machen, entlassene Beamte zu entschädigen und Versicherungs- und Versorgungsansprüche ehemaliger Verfolgter wieder aufleben zu lassen. In einem zweiten Abschnitt behandelte Hoegner Vermögensschäden: Beschlagnahme, Einziehung und gegen die guten Sitten verstoßende Entziehung von Sachen und Rechten aller Art aus rassischen, religiösen oder politischen Gründen sollten rückgängig gemacht werden. Zur Finanzierung sah der Entwurf eine Wiedergutmachungskasse vor, gespeist aus dem aus Bereicherungen stammendem Vermögen früherer Mitglieder der NSDAP und ihrer Gliederungen. Solche Personen sollten darüber hinaus auch zur Wiedergutmachung durch Sonderbesteuerung, Sachund Arbeitsleistungen, Räumung von Wohnungen usw. herangezogen werden können $^{8}$. Das im Exil entwickelte Prinzip der Koppelung von Sühne und Wiedergutmachung hatte hier also seine Bedeutung behalten.

Eine gekürzte Fassung des Hoegnerschen Entwurfes wurde zusammen mit dem gleichfalls im Exil verfaßten Entwurf eines Gesetzes über die Sühne nationalsozialistischer Verbrechen am 18. Oktober der amerikanischen Militärregierung für Bayern zur

${ }^{3}$ Art. III, Proklamation Nr.2 der amerikanischen Militärregierung, 19.9. 1945, in: Amtsblatt der Militärregierung Deutschland, Amerikanische Zone, Ausgabe A, 1.6. 1946, S. 2 f.

+ Darauf wies bereits Walter Schwarz hin, doch übersah er dabei die frühesten Planungen. Vgl. ders., Rückerstattung nach den Gesetzen der Alliierten Mächte, München 1974, S. $28 \mathrm{ff}$.

5 Vgl. Frstes Kapitel, Abschnitt I. 4.

${ }^{6}$ Hoegner, Entwurf für ein Gesetz zur Wiedergutmachung des nationalsozialistischen Unrechts, 8. 8. 1945, BayHStA, MA 114240.

7 In einem etwas früheren Entwurf von ca. Juli 1945 wurde diese nähere Bestimmung nachträglich handschriftlich eingefügt. Vgl. IfZ-Archiv, NL Hoegner, ED 120, Bd. 354. Derselbe Vorgang läßt sich auch bei anderen frühen Wiedergutmachungs-Entwürfen deutscher Provenienz beobachten.

${ }^{8}$ Hoegner, Entwurf für ein Gesetz zur Wiedergutmachung des nationalsozialistischen Unrechts (Anm. 6). 
Genehmigung vorgelegt, als Datum des Inkrafttretens war der 1. November 1945 ins Auge gefaßt ${ }^{9}$. Vier Tage später bekräftigte Hoegner, der nach der Entlassung Schäffers durch die Militärregierung neuer Ministerpräsident geworden war, auch in seiner Regierungserklärung die dort festgelegten Prinzipien der Wiedergutmachung für Opfer der nationalsozialistischen Verbrechen ${ }^{10}$. Doch zur Enttäuschung Hoegners behandelte die Militärregierung seinen Antrag zunächst hinhaltend, um ihn dann auf Eis zu legen, bis er schließlich in Vergessenheit geriet ${ }^{11}$. Für diese dilatorische Behandlung läßt sich eine Reihe von Gründen vermuten. Erstens behandelte dieser Entwurf das Problem sehr stark aus bayerischer Perspektive, während vor allem im State Department die internationalen Aspekte der Wiedergutmachung eine große Rolle spielten. Zweitens ist anzunehmen, daß aufgrund von Plänen bei OMGUS, eine Regelung auf Kontrollratsbzw. auf US-zonaler Ebene anzustreben, kein Interesse an dieser allein auf Bayern begrenzten Initiative bestand ${ }^{12}$. Hier existierte eine Kluft zwischen den Dimensionen der nationalsozialistischen Verbrechen und den Möglichkeiten und Interessen eines einzelnen Landes. Zudem ist ungewiß, ob der Hoegnersche Entwurf überhaupt bis zur zuständigen OMGUS-Ebene weitergeleitet wurde oder bereits auf einer unteren Stufe hängenblieb. Dieses Beispiel war jedenfalls durchaus dazu geeignet, die Auffassung zu begründen, daß die amerikanische Militärregierung eigenständige deutsche Wiedergutmachungsinitiativen blockierte.

Doch auch in Württemberg-Baden und Großhessen begannen schon früh die Arbeiten an umfassenden Wiedergutmachungsregelungen. In Stuttgart verfaßte der Direktor der Wiedergutmachungsabteilung des Innenministeriums, Schöneck, einen Referentenentwurf. Seinem als Diskussionsgrundlage verstandenen Entwurf schickte er voraus, daß angesichts der Finanzlage der Länder die Mehrzahl der Geschädigten leer ausgehen müsse und nur die allerschwersten Fälle berücksichtigt werden könnten. „Der Kreis der eine Wiedergutmachung beanspruchenden Personen ist jedoch anderer Auffassung“, stellte Schöneck fest, der auch herausgefunden haben wollte, daß „Begehrensvorstellungen unbegründeter Art eine beträchtliche Rolle“ spielten; wieder einmal dränge sich der "vorlaute Spekulant ... in den Vordergrund “13. So ist es kein Wunder, daß von jüdischer Seite über die in den deutschen Ländern geschaffenen Entwürfe geklagt wurde: „Mit Schaudern empfinden wir den Geist, der sich hier zum Teil dokumentiert. “ ${ }^{14}$

Zusammenfassend hieß es zu Beginn des eigentlichen Entwurfes: „Wer durch Handlungen der nationalsozialistischen Parteiführung und ihrer Organe oder der Staatsführung des deutschen Reiches und seiner (verfassungsmässig) berufenen Vertreter seit

${ }^{9}$ Hoegner an OMGB, 18.10. 1945, anbei Gesetz zur Wiedergutmachung des nationalsozialistischen Unrechts, BayHStA, MA 114240.

${ }^{10}$ Regierungserklärung Hoegners, 22.10. 1945, in: Bayerisches Gesetz- und Verordnungsblatt (BayGVOBI), Nr. 4, 1.11. 1945, S.3.

1 Siehe dazu OMGB an Hoegner, o.Dat. (ca. Anfang November 1945), BayHStA, MA 114240; Hoegner an OMGB, 16. 11. 1945, ebenda; Sitzung des bayerischen Ministerrats vom 21.12. 1945 und vom 22.8. 1946, IfZ-Archiv, NL Hoegner, ED 120, Bd. 355 u. 359.

12 Anfang 1946 erhielt die deutsche Seite verschiedene Hinweise von OMGUS, daß die Angelegenheit der Rückerstattung zur Zeit vor dem Kontrollrat verhandelt würde. Vgl. etwa Staatssekretär Ehard an bayerisches Finanzministerium, 25. 1. 1946, BayMJ, 1101 a, H. 1.

13 Entwurf des Innenministeriums (Referent: Direktor Dr. Schöneck) zu einem Gesetz zur Wiedergutmachung des unter Hitler begangenen Unrechts (Wiedergutmachungsgesetz), Februar 1946, BadWürtHStA, EA 4/001, Bü. 35 .

14 Interessenvertretung der jüdischen Gemeinden und Kultusvereinigungen an alle Länderregierungen Deutschlands, 19.5. 1946, BadWürtHStA, EA 1/920, Bü. 709. 
dem 30. Januar 1933 aus politischen, religiösen oder rassischen Gründen einen erheblichen Schaden an Gesundheit, Freiheit oder Vermögen erlitten hat, besitzt einen nach billigem Ermessen festzusetzenden Anspruch auf Wiedergutmachung nach Maßgabe der Bestimmungen dieses Gesetzes. “ ${ }^{15}$ Es folgten umfassende Vorschläge zur Regelung der Rückerstattung, der Wiederherstellung von Rechten und aus der Sozialversicherung herrührender Forderungen, der Ansprüche verfolgter Beamten etc. Denunzianten sollten für die Folgen einer Anzeige persönlich haftbar gemacht werden können. Sofern aber kein persönlich haftender Schuldner herangezogen werden könne, müsse das Land Württemberg einspringen. Um die finanziellen Auswirkungen in Grenzen zu halten, bestimmte Schöneck, daß „nur Württemberger einen Anspruch besitzen können, da sonst der Ausbeutung durch gewissenlose Elemente nicht begegnet werden könnte. " 16 Erneut zeigt sich, daß die Entwicklung von Entwürfen auf der Ebene eines einzelnen Landes die Ausbildung eines besonders strengen Territorialitätsprinzips begünstigte. Außerdem sollten nicht nur nationalsozialistisch belasteten Personen, sondern auch „einem schwer vorbestraften Menschen, einem asozialen Individuum, einem Gewohnheitsverbrecher, Trunkenbold und ähnlichen Leuten nicht die Rechtswohltaten eines Gesetzes zukommen, das nur deshalb für seine Person Anwendung findet, weil der nationalsozialistische Staat eine summarische Ausmerzungstaktik geführt hat und ihn dadurch vor einer normalen Bestrafung nach gültigen Gesetzen bewahrt hat. " ${ }^{17}$ Die Diskussion um die Einbeziehung von Kriminellen und Asozialen, die ja, wie gezeigt, auch im Bereich der Verfolgten-Fürsorge in Württemberg-Baden mit besonderer Schärfe geführt worden war, fand also hier ihre Fortsetzung.

Eine Stellungnahme des Stuttgarter Finanzministeriums, der sich das Justizministerium weitgehend anschloß ${ }^{18}$, plädierte für weitere drastische Beschränkungen. $\mathrm{Da}$ es dem Prinzip der Demokratie widerstrebe, privilegierte Gruppen zu schaffen, dürften die vom Nationalsozialismus Geschädigten nicht anders behandelt werden als Kriegsbeschädigte bzw. Fliegergeschädigte. Anstelle der Opfer des Nationalsozialismus trat hier die übergreifende Kategorie der „Opfer des Systems“, der diese allesamt angehörten. Verbunden damit bestand nur eine geringe Bereitschaft, Verfolgungsmaßnahmen, die unter dem NS-Regime rechtens gewesen waren, nachträglich zu ächten. So sollten die Geschädigten keinen Anspruch auf Naturalrückerstattung erhalten, da sonst „die Rechtsstellung des neuen gutgläubigen Erwerbers missachtet "19 würde. Auch wurde eine Schadensersatzpflicht der Denunzianten abgelehnt, sofern es sich um Überzeugungstäter gehandelt habe. Ohnehin setzte die Stuttgarter Regierung zu dieser Zeit darauf, mit einer gesetzlichen Wiedergutmachung erst einmal abzuwarten. Finanzminister Fritz Cahn-Garnier schrieb mit Bezug auf den im Referentenstadium steckengebliebenen Entwurf Schönecks an das Innenministerium, „die juristische und finanzielle Regelung" müsse „zum mindesten für die ganze amerikanische Besatzungszone, besser aber für das gesamte Reichsgebiet einheitlich getroffen werden“ ${ }^{20}$.

Auch ein großhessischer Entwurf für ein Wiedergutmachungsgesetz, den Staatskom-

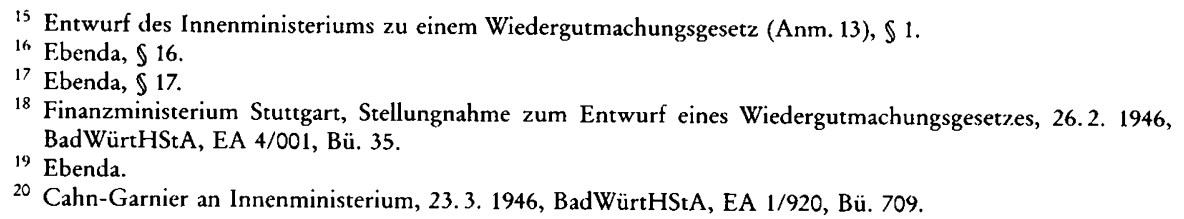


missar Epstein verfaßt hatte, übersprang nicht die Hürde des Ministerrats, der zunächst geklärt wissen wollte, wie hoch die Ansprüche seien, die in Betracht kämen, und welche Mittel dafür überhaupt zur Verfügung stünden. Zudem sei eine Regelung nur auf zonenweiter, wenn nicht gar vierzonaler Grundlage möglich. Da mittlerweile der Länderrat auf amerikanische Aufforderung hin mit der Arbeit an Wiedergutmachungsregelungen begonnen hatte, ließ sich dies nun umso leichter vertreten ${ }^{21}$. Damit war der großhessische Entwurf erst einmal Makulatur. Auch hier waren Rückerstattung, Entschädigung, Wiedergutmachung für Beamte etc. noch unter einem Dach zusammengefaßt worden. Der Entwurf des selbst rassisch verfolgten Staatskommissars ging recht weit zugunsten der Verfolgten, die aber wiederum auf Bürger Großhessens, die dort in der Zeit der nationalsozialistischen Herrschaft ansäßig gewesen waren, begrenzt wurden. (Eine Ausnahme wurde allerdings bei Emigranten gemacht ${ }^{22}$.) Dieser Entwurf bildete später auch die Grundlage für einen eigenen Vorschlag des bayerischen Staatskommissars für politisch Verfolgte Otto Aster ${ }^{23}$, der aber gleichfalls im politischen Vorfeld stecken blieb.

Damit läßt sich eine Antwort auf die eingangs gestellten Fragen geben: Mit Ausnahme des Hoegnerschen Entwurfes, der dem Desinteresse der amerikanischen Militärregierung zum Opfer fiel, scheiterten in Bayern, Württemberg-Baden und Hessen alle anderen nachgewiesenen frühen Versuche einer umfassenden Regelung auf deutscher Seite an der fehlenden Zustimmung der eigenen Regierungen. Aus Sorge vor unabsehbaren Kostenverpflichtungen, die die Möglichkeiten eines einzelnen Landes überstiegen, verlegten sich die Regierungen Württemberg-Badens und Hessens zunächst lieber auf das Abwarten.

Dennoch wurden einige Teilbereiche der Wiedergutmachung mit besonderer Priorität weiterverfolgt, wobei es zu ersten Regelungen kam. So trat in Bayern bereits am 15 . Oktober 1945 ein Gesetz über die sozialrechtliche Wiedergutmachung von Schäden infolge nationalsozialistischer Verfolgung in Kraft. Für einen Teil der Verfolgten wurden damit, wenn auch bescheidene, Rentenansprüche geschaffen. Körperliche Schäden infolge nationalsozialistischer Verfolgung wurden dort mit Betriebsunfällen gleichgestellt, und politisch Verfolgte mit mindestens 30-prozentiger Arbeitsbehinderung erhielten dadurch einen Rentenanspruch. Grundsätzliche Voraussetzung war aber, daß die Betroffenen den Schaden in Bayern erlitten hatten ${ }^{24}$.

Während dies eine bayerische Sonderentwicklung war, führten die eigentumsrechtlichen Unsicherheiten, die sich aus der Aufhebung nationalsozialistischer Gesetze mit vermögensrechtlicher Wirkung durch den Kontrollrat ergaben ${ }^{25}$, dazu, daß gleichzeitig in den Justizministerien Bayerns, Württemberg-Badens und Großhessens an der Rückerstattung des infolge der Verfolgung entzogenen, wiederauffindbaren Eigentums gear-

21 Beschluß-Protokoll über die Sitzung des großhessischen Kabinetts am 24.5. 1945, HessHStA, Abt. 502, Nr. 2772c.

22 Entwurf eines Gesetzes zur Wiedergutmachung nationalsozialistischen Unrechts, 26. 3. 1946, HessHStA, Abt. 502, Nr. 2772c.

${ }^{23}$ Entwurf für ein Gesetz zur Wiedergutmachung nationalsozialistischen Unrechts, 9.5. 1946, BayMJ, 1101a, H. 1.

${ }^{24}$ Gesetz Nr. 9 betreffend sozialrechtliche Wiedergutmachung von Schäden, die durch das nationalsozialistische System verschuldet worden sind, 15.10. 1945, in: BayGVOBI, Nr.3, 1.2. 1946, S.21; Mitteilungsblatt des Landesausschusses der politisch Verfolgten, Nr. 1, 1. 12. 1946, „Der Stand der Wiedergutmachung“.

25 Siehe dazu etwa Landrat von Hofheim an Regierungspräsidenten Würzburg, 13.9. 1945, BayMJ, 1101a, H. 1. 
beitet wurde. Auch auf diesem Teilgebiet war Bayern zunächst Schrittmacher. So begannen im dortigen Justiz- wie auch Finanzministerium bald nach Kriegsende Überlegungen zur vorläufigen Wiedergutmachung von Vermögensschädigungen. Im September 1945 nahm Walter Roemer, Ministerialrat im bayerischen Justizministerium, die Arbeit an einem Gesetzentwurf auf, und im Oktober sandte er einer Anzahl von Experten eine erste Version zur Begutachtung zu. Roemer unterstrich dabei die Notwendigkeit der Beseitigung der durch den Kontrollrat geschaffenen vermögensrechtlichen Unsicherheit. Zudem hob er die symbolische Bedeutung hervor, die darin liege, daß der sich bildende neue demokratische Staat gegenüber den inländischen Opfern als auch der übrigen Welt gegenüber seine Entschlossenheit zur Wiedergutmachung bezeuge $^{26}$.

In erster Linie sah Roemers Entwurf vor, daß noch vorhandene Sachen, Rechte und Vermögenswerte, die aus rassischen, religiösen und politischen Gründen entzogen oder beschlagnahmt worden waren, wieder zurückgegeben werden sollten. Soweit eine Wiedergutmachung auf diesem Wege nicht möglich sei, waren Leistungen aus einer Wiedergutmachungskasse vorgesehen, in die NS-Vermögen sowie erbenloses entzogenes Eigentum fließen sollten ${ }^{27}$. Doch im Januar 1946 stoppte die bayerische Staatskanzlei die Weiterarbeit an Roemers Entwurf mit der Begründung, daß die Angelegenheit nach amerikanischer Auskunft gerade beim Kontrollrat verhandelt würde ${ }^{28}$. Dagegen arbeiteten sowohl das württemberg-badische als auch das großhessische Justizministerium weiterhin an Entwürfen, in denen die Rückerstattung jüdischen Eigentums im Mittelpunkt stand ${ }^{29}$. Auch hier wurde dieses Problem als ein vorrangig zu behandelnder Sonderfall betrachtet. Bei all diesen Arbeiten fand ein ständiger Gedankenaustausch zwischen den einzelnen Ländern statt, ohne daß es dabei aber zu einer gemeinsamen Initiative gekommen wäre.

Ein weiterer Bereich, der frühzeitig in eine Sonderentwicklung einmündete, war die Wiedergutmachung für den öffentlichen Dienst. Ähnlich wie bei der Rückerstattung hatte auch hier die Aufhebung nationalsozialistischer Gesetze durch den Kontrollrat eine nach Klärung heischende Rechtsunsicherheit geschaffen, denn Kontrollratsgesetz Nr. 1 hatte das Gesetz zur Wiederherstellung des Berufsbeamtentums, das viele Beamte um ihre Arbeitsplätze gebracht hatte, aufgehoben ${ }^{30}$. Doch bestand in der Frage der Wiedergutmachung für den öffentlichen Dienst offensichtlich auch ein dringendes eigenes Anliegen der deutschen Seite. Hoegner hatte bereits im Schweizer Exil Grundzüge der Wiedergutmachung für Beamte entwickelt. Auch ergingen alle Regelungen auf dem Verordnungswege, um Konflikten mit der Militärregierung möglichst aus dem Wege zu gehen. Immerhin verfolgte ja die amerikanische Militärregierung bis

26 Roemer, Entwurf eines Gesetzes zur vorläufigen Wiedergutmachung der aus Gründen der Rasse, Religion oder des politischen Bekenntnisses zugefügten Vermögensschädigungen, 11.10. 1945, BayMJ, 1101a, H. 1.

27 Ebenda. Eine gesetzestechnische Interpretation dieses Entwurfes findet sich bei Schwarz, Rückerstattung nach den Gesetzen der Alliierten Mächte, S. 28-30.

28 Aktennotiz Walter Roemers an Staatskanzlei, 12.1. 1946 mit Antwort vermutlich von Staatssekretär Ehard vom 24. 1. 1946, BayMJ, 1101a, H. 1. Zu den Kontrollratsverhandlungen siehe unten, Abschnitt II. 3.

${ }^{29}$ Josef Beyerle an Wirtschafts- und Finanzministerium, 5. 3. 1946, BadWürtHStA, EA 4/001, Bü. 35; Vorentwurf zu einem Gesetz zur Wiedergutmachung von Vermögensschäden, ebenda; Entwurf einer Verordnung des großhessischen Justizministeriums vom 4.2. 1946 zur Wiedergutmachung nationalsozialistischen Unrechts bei rassisch Verfolgten, BadWürtHStA, EA 4/001, Bü. 35.

30 Kontrollratsgesetz Nr. 1 v. 20.9. 1945, in: Amtsblatt des Kontrollrats für Deutschland, Nr. 1, 29. 10. 1945, S. 6-8. 
Anfang der fünfziger Jahre das Ziel der Abschaffung des deutschen Berufsbeamtentums ${ }^{31}$.

Auch die Wiedergutmachung für den öffentlichen Dienst wurde zuerst in Bayern aufgegriffen. Ursprünglich sollte diese Frage, die Hoegner als selbst verfolgtem Beamten besonders am Herzen lag, im Rahmen seines Entwurfes für ein bayerisches Wiedergutmachungsgesetz geregelt werden. Nachdem das Projekt jedoch bei der Militärregierung auf Eis lag, beschloß der bayerische Ministerrat in seiner Sitzung vom 23. Januar 1946 eine Dienstanweisung, in der die Frage vorrangig geregelt wurde ${ }^{32}$. Ziel dieser Anweisung war "grundsätzlich Herstellung des beamtenrechtlichen Zustandes, der bestehen würde, wenn der Nationalsozialismus nicht zur Macht gekommen wäre“ ${ }^{33}$. Dies sollte in erster Linie durch die Wiedereinstellung der von den Nationalsozialisten entlassenen Beamten erfolgen. Die Stuttgarter Regierung überlegte, ob sie dem bayerischen Beispiel folgen sollte. Doch entschied sie sich schließlich zunächst dagegen, eine einzelne Gruppe vorweg zu behandeln und beließ es bei der bevorzugten Wiedereinstellung der geschädigten Beamten ${ }^{34}$. Auch in Hessen wurden 1947 eigene Richtlinien zur Wiedergutmachung für Beamte herausgegeben ${ }^{35}$.

Ein weiterer Sonderbereich war die Aufhebung von Verurteilungen mit nationalsozialistischem Hintergrund. In der US-Zone wurden einheitliche Gesetze zur Wiedergutmachung in der Strafrechtspflege erlassen, in denen die Straffreiheit von politischen Taten gegen den Nationalsozialismus bestimmt wurde ${ }^{36}$. Bereits die Kontrollrats-Proklamation Nr. 3 über Grundsätze für die Umgestaltung der Rechtspflege hatte die Aufhebung von Verurteilungen aus rassischen, religiösen und politischen Gründen bestimmt ${ }^{37}$. So waren diese US-zonalen Gesetze letztlich nur eine Umsetzung von Beschlüssen des alliierten Kontrollrats.

Welche grundsätzlichen Tendenzen zeichneten sich bei diesen frühesten Plänen aus Bayern, Württemberg-Baden und Großhessen ab? Welche Funktion wiesen sie der Wiedergutmachung für Verfolgte des Nationalsozialismus zu? Als eine erste Gemeinsamkeit läßt sich feststellen, daß alle diese Pläne zwar prinzipiell die Verantwortung des Staates anerkannten, aber nur subsidiär. Vorrangig sollten soweit als möglich die für die nationalsozialistischen Verbrechen direkt Verantwortlichen persönlich herangezogen werden. Die Vorschläge reichten von der Haftbarmachung von Denunzianten über die Verwendung des Vermögens der nationalsozialistischen Organisationen (die ohnehin

31 Vgl. dazu Wolfgang Benz, Versuche zur Reform des öffentlichen Dienstes in Deutschland 1945-1952. Deutsche Opposition gegen alliierte Initiativen, in: Vierteljahrshefte für Zeitgeschichte (VfZ) 29 (1981), S. 216-245.

32 Sitzung des bayerischen Ministerrats, 23. 1. 1946, IfZ-Archiv, NL Hoegner, ED 120, Bd. 356.

${ }^{33}$ Fritz Terhalle an bayerische Staatskanzlei usw., 17.6. 1946, Anlage: Gemeinsame Dienstanweisung sämtlicher Staatsministerien zur Beseitigung nationalsozialistischen Unrechts an Beamten, 23.1. 1946, BadWürtHStA, EA 1/014, Bü. 252.

${ }^{34}$ Protokoll der Sitzung des württemberg-badischen Staatsministerium am 6.11. 1946, BadWürtHStA, EA 4/ 001, Bü. 57 a.

35 Richtlinien für die Wiedergutmachung nationalsozialistischen Unrechts in Durchführung des Kontrollratsgesetzes Nr. 1 vom 20.9. 1945 vom 17.9. 1947, HessHStA, Abt. 502, Nr. 2773a; Entwurf der Richtlinien für die Wiedergutmachung nationalsozialistischen Unrechts auf dem Gebiet des Beamtenrechts, 8.11. 1947, (am 10. 12. 1947 v. Kabinett genehmigt), HessHStA, Abt. 503, Nr. 502.

${ }^{36}$ Gesetz Nr. 21 zur Wiedergutmachung nationalsozialistischen Unrechts in der Strafrechtspflege, 28. 5. 1946, in: BayGVOBl, Nr. 11, 4.7. 1946, S. 180ff.; Gesetz Nr. 29, in: Regierungsblatt der Regierung WürttembergBaden (WBRegBl), Nr. 17, 2. 8. 1946, S. 205 f. Darüber hinaus folgten mehrere Novellierungen zur Fristanpassung.

37 Amtsblatt des Kontrollrats in Deutschland, Nr. 1, 29.10. 1945, S. 22 f. 
bereits der Vermögenskontrolle unterlagen) sowie von NS-Verantwortlichen bis hin zu einer Sondersteuer für ehemalige Parteigenossen. Daneben wurde teilweise auch erbenloses Vermögen enteigneter Verfolgter als Finanzierungsquelle in Betracht gezogen. Damit besaß Wiedergutmachung zunächst ähnlich wie in vielen Plänen vor Kriegsende auch einen Sühnecharakter, wobei nicht kollektiv, sondern individuell gesühnt werden sollte.

Praktische Bedeutung bekam der Grundsatz der direkten Verantwortung durch das unter amerikanischer Anleitung entstandene "Gesetz zur Befreiung von Nationalsozialismus und Militarismus" vom 5. März 1946, das in Bayern, Württemberg-Baden und Großhessen die Entnazifizierung in deutsche Hände legte. Es bestimmte, daß die im Rahmen der Entnazifizierung verurteilten Personen mit ihrem Vermögen oder Sühneleistungen zur Finanzierung der Wiedergutmachung heranzuziehen seien ${ }^{38}$. Finanzminister Fritz Terhalle kommentierte dazu im bayerischen Ministerrat, daß „die Wiedergutmachungsansprüche der Juden usw. aus den durch die Urteile der Kammern hereinfließenden Summen gedeckt werden" müßten. Sein Ministerkollege Josef Baumgartner spitzte dies zu und forderte, „daß kein Nichtparteigenosse einen Pfennig für die Sache zahlen solle. Die Kosten müßten die Nazis selber aufbringen " ${ }^{39}$. Die Betonung der individuellen Verantwortung der Nationalsozialisten für die Wiedergutmachung ließ sich somit stets auch als ein Instrument zur Abwehr einer kollektiven finanziellen Belastung des deutschen Volkes einsetzen.

Eine Gegenüberstellung der frühen deutschen Pläne mit der vor allem von jüdischer Seite geäußerten Kritik ${ }^{40}$ verdeutlicht die grundsätzliche Problematik. Ähnlich wie auf amerikanischer Seite wurde auch seitens deutscher Politiker und Beamter die Pflicht zur Wiedergutmachung der den Verfolgten des Nationalsozialismus zugefügten Schäden überwiegend im Rahmen der Gesamtansprüche gegen das Deutsche Reich gesehen, was von vornherein eine Beschränkung der Leistungen bedeutete. Eine Konkurrenz entstand hierbei nicht nur aus den völkerrechtlichen Verpflichtungen zu Reparationen und äußeren Restitutionen, sondern in zunehmendem Maße auch aus den Ansprüchen anderer durch den Krieg in Not geratener Gruppen: Bombengeschädigte, Flüchtlinge, Vertriebene etc. Entgegen den Wünschen vieler Betroffener verfuhren deshalb alle Pläne nach dem Prinzip, daß nur ein Teil der Schäden wieder gutgemacht werden könne. Ein Entwurf der württembergischen Kultusvereinigung vom Mai 1946 zielte dagegen darauf, soweit als möglich die ganze gegen die Juden gerichtete Entwicklung seit 1933 wieder rückgängig zu machen ${ }^{41}$, weshalb die bekanntgewordenen deutschen Vorschläge als eine Entrechtung empfunden wurden ${ }^{42}$. Doch für eine vollständige Wiedergutmachung aller unter der nationalsozialistischen Herrschaft erlittenen Schäden war an keiner politisch maßgeblichen Stelle Bereitschaft vorhanden, weder auf deutscher, noch, wie zu zeigen sein wird, auf amerikanischer Seite.

38 BayGVOBl, Nr. 10, 1.7. 1946, S. 145 ff. Am 9.9. 1947 wurde es zum zoneneinheitlichen Gesetz erklärt.

39 Sitzung des bayerischen Ministerrats, 6.3. 1946, IfZ-Archiv, NL Hoegner, ED 120, Bd. 357.

40 Siehe etwa Israelitische Kultusvereinigung Stuttgart an Justizministerium Stuttgart, 14.4. 1946, BadWürtHStA, EA 4/001, Bü. 35.

${ }^{41}$ Israelitische Kultusvereinigung Württemberg an Reinhold Maier, 29.5. 1946, BadWürtHStA, EA 1/920, Bü. 709.

42 Interessenvertretung der jüdischen Gemeinden und Kultusvereinigungen an deutsche Länderregierungen, 19.5. 1946, BadWürtHStA, EA 1/920, Bü. 709. 


\section{Weichenstellungen in Washington und bei der amerikanischen Militärregierung}

Während die Betreuung der hilfsbedürftigen KZ-Überlebenden beim Einmarsch in Deutschland zu den vordringlichen Aufgaben der amerikanischen Militärregierung gehörte, bestanden dort zu diesem Zeitpunkt allenfalls rudimentäre Vorstellungen über das umfassendere Problem der Entschädigung der Verfolgten des Nationalsozialismus für das ihnen zugefügte Unrecht. Neben der in allgemeinen Formlierungen u. a. auch durch den Kontrollrat ausgedrückten grundsätzlichen Absicht, Maßnahmen in dieser Richtung zu ergreifen, stand als einziges konkretes Ergebnis der in Washington während des Krieges geführten Diskussionen die Anweisung Eisenhowers durch JCS 1067, das in Deutschland geraubte und entzogene Vermögen sicherzustellen und den rechtmäßigen Besitzern zurückzuerstatten ${ }^{43}$. Von Anfang an besaß dadurch die Rückerstattung einen gewissen Vorsprung.

Doch blieb es zunächst allein bei der Sicherstellung. Mit dem Vormarsch der alliierten Truppen auf deutschem Boden hatte das gemeinsame alliierte Oberkommando (SHAEF) in den besetzten Gebieten das Militärregierungsgesetz Nr. 52 in Kraft gesetzt, das die Kontrolle einer ganzen Reihe von Vermögenskategorien regelte. Darunter fiel auch das außerbalb der Grenzen des Deutschen Reiches geraubte Eigentum ${ }^{44}$, dessen Rückgabe die Alliierten bereits im Januar 1943 beschlossen hatten. Doch wurde in der US-Zone das Gesetz Nr. 52 nach dem Ende des gemeinsamen alliierten Oberkommandos dahingehend geändert, daß auch innerhalb Deutschlands geraubtes oder entzogenes Vermögen unter Kontrolle gestellt wurde ${ }^{45}$. Auf diese Weise glich Eisenhower den Umfang der Vermögenskontrolle der Formulierung in JCS 1067 an. Die Frage der Rückerstattung war damit aber noch offen.

Daran knüpften seit Kriegsende Tausende von Anfragen an das State Department und die amerikanische Militärregierung an. Insbesondere ehemalige deutsche Bürger in den USA versuchten, ihr aus rassischen oder anderen Gründen entzogenes oder geraubtes Eigentum zurückzuerhalten ${ }^{46}$. Daß es hier nun teilweise um die Eigentumsinteressen amerikanischer Staatsbürger ging, verschaffte der Frage der inneren Rückerstattung einen gewissen Aufmerksamkeitsbonus. So wies etwa der Political Adviser der amerikanischen Militärregierung, Robert Murphy, als er das State Department Anfang Juli um eine politische Direktive zur Frage der amerikanischen Vermögensinteressen in Deutschland bat, darauf hin, daß hierbei auch Maßnahmen zugunsten der Interessen naturalisierter Amerikaner notwendig seien, die aus rassischen und anderen Gründen ihr Eigentum durch die Nazis verloren hatten ${ }^{47}$. Die Grenzen zwischen innerer und äußerer Restitution waren hier also zum Teil fließend geworden.

Anfang September 1945 regte deshalb US-Außenminister James F. Byrnes an, die Sache baldigst im Kontrollrat zu regeln und spezielle Gerichte zu beauftragen, über die

43 JCS 1067, Abs. 48, in: Um den Frieden mit Deutschland. Dokumente zum Problem der deutschen Friedensordnung 1948, hrsg. v. W. Cornides u. H. Volle, Oberursel (Ts.) 1948, S. 58-73, hier: S. 72.

44 Military Government - Germany. Supreme Commander's Area of Control. Law No. 52, Blocking and Control of Property, Art. 1.2. , in: Handbook for Military Government in Germany prior to Defeat or Surrender (SHAEF), Dezember 1944, IfZ-Archiv, Dk 090.009.

45 Military Government Germany, United States Zone, Amendment to Law No. 52. Blockings and Control of Property, 14.7. 1945, in: Amtsblatt der Militärregierung Deutschland. Amerikanische Zone, hrsg. v. OMGUS, Ausgabe A, 1.6. 1946, S.27.

46 Siehe dazu USNA, RG 59, 462.11 E.W., Box 1925-1931; Rudolf Callmann (American Association of Jews from Central Europe) an Department of State, 30.8. 1945, ebenda, Box 1925.

47 Robert Murphy an James F. Byrnes, 3.7. 1945, USNA, RG 59, 462.11/7-345. 
Rückerstattung der im Zuge der nationalsozialistischen Verfolgung entzogenen Werte in Deutschland zu urteilen ${ }^{48}$. Diese Fragen wurden bei der amerikanischen Militärregierung einige Zeit ergebnislos diskutiert ${ }^{49}$, bis schließlich Captain Hemmendinger aus der Legal Branch am 18. September einen ersten Entwurf für ein derartiges Kontrollratsgesetz vorlegte. Allerdings hatte er sich nicht auf die Frage der Rückerstattung beschränkt, sondern zugleich auch das Problem der Entschädigung für Schäden der Gesundheit, der Arbeitskraft sowie des Vermögens aus Gründen der Rasse, der Nationalität, des religiösen Bekenntnisses oder der Gegnerschaft zur NSDAP berücksichtigt. Zugleich schlug Hemmendinger eine besondere Besteuerung derjenigen Personen vor, die sich an solchen Verfolgungsaktionen bereichert hatten ${ }^{50}$. Der Autor wechselte bald nach der Fertigstellung des Entwurfes nach Washington ins State Department, wo er mehrere Jahre lang für Wiedergutmachungsfragen zuständig war. Der Entwurf selbst ging als Unterlage in der nun in größerem Stil aufgenommenen Arbeit der OMGUSLegal Division an einer Kontrollrats-Vorlage auf.

Hier entstand eine ausführliche Bestandsaufnahme und Erörterung der aus der nationalsozialistischen Verfolgung herrührenden Forderungen, deren erste Fassung Ende Oktober/Anfang November nach Washington gekabelt wurde ${ }^{51}$. Sie basierte vor allem auf den insbesondere von jüdischer Seite gemachten Eingaben ${ }^{52}$. Die Bandbreite reichte dabei von Vermögensschäden verschiedenster Art bis hin zu allen erdenklichen persönlichen Schädigungen. Die Entschädigung der Verfolgten auf deutschem Boden erschien dabei relativ praktikabel, während Leistungen für diejenigen im Ausland komplizierte Transferprobleme aufwarfen. Die Ansprüche wurden nach Prioritäten geordnet, entscheidendes Kriterium war dabei die Frage der Finanzierbarkeit. Keinesfalls dürfe die Belastung zu einem Zusammenbruch der deutschen Wirtschaft führen, argumentierte die Legal Division, weil dann schließlich alle Ansprüche wertlos würden. Deshalb sollte die Finanzierung in erster Linie aus einem Pool erfolgen, in den deutsche Auslandsguthaben und das von den Nationalsozialisten geraubte und beschlagnahmte Vermögen einzubringen seien. Dabei dachte die Legal Division insbesondere auch an erbenloses Eigentum ermordeter Juden ${ }^{53}$.

Bei der Durchführung dieser Maßnahmen sollten die Deutschen unter strenge Aufsicht der Militärregierung gestellt werden. Das hierin zum Ausdruck kommende Mißtrauen speiste sich beispielsweise aus einer repräsentativen Umfrage unter der deutschen Bevölkerung in den vier Zonen von Berlin, die etwa ein halbes Jahr nach Kriegsende durchgeführt worden war. Von den Befragten befürworteten zwar immerhin 60 Prozent die Rückerstattung entzogenen Eigentums, aber nahezu jeder Befragte lehnte

48 Byrnes an Murphy, 4. 9. 1945, USNA, RG 59, 462.11/9-445.

49 Murphy an Byrnes, 7.9. 1945 sowie 18.9. 1945, USNA, RG 59, 462.11/9-745 u. 462.11/9-1845.

50 Capt. Hemmendinger, „Indemnities and Assessments for Acts During the National Socialist Regime“, 18. 9. 1945, IfZ-Archiv, MF 260, OMGUS-LD 17/56-2/21.

st Loyd V. Steere (OMGUS/POLAD) an Byrnes, 31.10. 1945, anbei Staff Study der Legal Division betr. "Claims for Damages or Injury Suffered as a Result of Nazi Persecution or Discriminatory Acts“, USNA, RG 59, 462.00R/10-3145; Murphy an Byrnes, 14. 11. 1945, ebenda. Ein bereits weiter ausgearbeiteter Entwurf vom 16.1. 1945 in IfZ-Archiv, MF 260, OMGUS, POLAD 730/58. Endgültige Fassung vom 15.1. 1946, Charles Fahy (Legal Advisor Clays) an Chief of Staff, IfZ-Archiv, MF 260, OMGUS, AG 1945-46/109/1.

52 Siehe etwa American Association of Former European Jurists an Edward R. Stettinius, 23. 3. 1945, "Instrument providing for the settlement of claims arising from Nazi and Fascist persecutions", USNA, RG 59, 462.11/3-2345. Am 12.6. 1945 wurde der Entwurf auch Eisenhower (SHAEF) zugesandt. Siehe IfZ-Archiv, MF 260, OMGUS-LD 17/56-2/21. Weitere Beispiele im Ersten Kapitel, Abschnitt II. 4.

${ }^{53}$ Ebenda. 
jegliche weitere Maßnahme zugunsten Verfolgter des Nationalsozialismus ab: schließlich hätten alle Deutschen unter Hitler gelitten ${ }^{54}$.

Washington ließ sich mit einer Stellungnahme gehörig Zeit. Am 15. März 1946 wurde OMGUS schließlich über das weitere Vorgehen in der Entschädigungsfrage instruiert $^{55}$, ohne daß der Entwurf der Legal Division damit eine offizielle Bestätigung erhalten hätte ${ }^{56}$. State und War Department befürworteten darin ausdrücklich die Rückerstattung von Eigentum bzw. die Entschädigung von Personen in Deutschland, die aus Gründen der Rasse, Nationalität, religiösen Anschauung oder ihrer Gegnerschaft zur NSDAP geschädigt worden waren. Über die Frage, was mit den Ansprüchen von Geschädigten, die jetzt außerhalb Deutschlands lebten, geschehen sollte, war man sich dort noch nicht schlüssig geworden. Dieses Telegramm stellte in mehrfacher Hinsicht die Weichen für die weitere Entwicklung: Der amerikanischen Militärregierung wurde nunmehr freie Hand gegeben, notfalls alleine in der US-Zone vorzugehen, falls der Weg zu einer alliierten Einigung im Kontrollrat zu lange dauern würde. Zugleich schrieb Washington die Reihenfolge der einzelnen Schritte vor. Als erstes sollte ein Programm zur Rückerstattung an Individuen erreicht werden, um sich erst dann der Frage der Rückerstattung an Organisationen und der Entschädigung für persönliche Schäden zuzuwenden. Rückerstattung und Entschädigung wurden hier also ausdrücklich getrennt.

Auf dieser Grundlage arbeitete der Property Disposition Board der amerikanischen Militärregierung die Einzelheiten des weiteren Vorgehens aus. In diesem Gremium waren neben der bislang federführenden Legal Division auch die Finance-, Economicund weitere Divisions vertreten. Am 26. März schlug der Ausschuß vor, den Stuttgarter Länderrat der US-Zone mit der Ausarbeitung der notwendigen Maßnahmen zu beauftragen. Dazu gehörte erstens ein Verfahren für die Übernahme der Vermögenskontrolle nach dem Militärregierungs-Gesetz Nr. 52 in die deutsche Verantwortung, zweitens die schleunige Rückerstattung von unter nationalsozialistischer Herrschaft entzogenem und wieder auffindbarem Vermögen und drittens eine vorläufige Entschädigungsregelung zum Zwecke der wirtschaftlichen Rehabilitierung ehemaliger Verfolgter, die zunächst aber nur Bedürftige einschließen sollte ${ }^{57}$. Der stellvertretende amerikanische Militärgouverneur Lucius D. Clay beschloß, auf diesem Weg in der US-Zone vorzugehen, anschließend wollte er versuchen, den Kontrollrat zur Übernahme des amerikanischen Modells zu bewegen ${ }^{58}$. Die Einwilligung Washingtons, trotz erklärter Präferenz einer alliierten Lösung notfalls auch unilateral vorzugehen, hatte also ermöglicht, daß OMGUS gar keinen Versuch mehr unternahm, eine Initiative auf Kontrollratsebene zu starten. Doch wurde dies auch mit praktischen Gründen entschuldigt: Der Property

${ }^{54}$ Fahy an Chief of Staff, 15.1. 1946 (Anm.51).

55 Siehe zum folgenden General Oliver P. Fchols (War Department/CAD) an OMGUS, 15. 3. 1946, IfZ-Archiv, MF 260, OMGUS, AG 45-46/109/1.

56 Hemmendinger an Finney, 10.4. 1946, Washington National Record Center, Suitland (WNRC), RG 94, Adjudant General's Office, Box 1129.

57 Das Memorandum des Property Disposition Board vom 26.3. 1946 war zwar unauffindbar, doch läßt sich sein Inhalt einigermaßen rekonstruieren. Siehe etwa Clay an War Department, 17.6. 1946, IfZ-Archiv, MF 260, OMGUS-CAD 3/159-3/19.

58 Clay an Echols, 28.3. 1946, IfZ-Archiv, MF 260, OMGUS, AG 45-46/109/1. 
Disposition Board sei ohne einen Vertreter beim Kontrollrat, der dort einen Entwurf hätte vorlegen können ${ }^{59}$.

Anfang April wurde der Stuttgarter Länderrat angewiesen, einen Sonderausschuss einzurichten. Er sollte gemäß dem Vorschlag des Property Disposition Board Entwürfe für die Übernahme der Vermögenskontrolle in deutsche Verantwortung, ein Rückerstattungsgesetz für wiederauffindbares Eigentum und ein vorläufiges Entschädigungsgesetz produzieren ${ }^{60}$. Im Hintergrund dieser Entscheidung spielte der Wunsch, sich der personal- und arbeitsintensiven Verwaltung der gesperrten Vermögen zu entledigen, eine wichtige Rolle ${ }^{61}$. Die Vermögenskontrolle in der US-Zone wurde durch eine ganze Reihe alliierter Anweisungen geregelt: Neben dem Militärregierungsgesetz Nr. 52, das alle Vermögensobjekte innerhalb des besetzten Gebietes, die Eigentum des Reiches oder nationalsozialistischer Organisationen waren bzw. der Kategorie des entzogenen und geraubten Vermögens angehörten, unter Verwaltung stellte, bestimmten die Kontrollratsgesetze Nr. 2, Nr. 9 und Nr. 10 die Kontrolle weiterer Vermögenskategorien ${ }^{62}$. Damit standen zugleich erhebliche Werte zur Disposition, über deren endgültiges Schicksal noch nicht entschieden war.

State und War Department stimmten dem Vorgehen zu und verwiesen dabei auf den zunehmenden Druck interessierter Personen und Organisationen, in dieser Sache endlich zu handeln ${ }^{63}$. Doch blieben dabei einige Fragen offen. Ein für Washington besonders wichtiger Punkt waren die von außerhalb Deutschlands, vor allem aus den USA, gestellten Forderungen. Oliver P. Echols gab Clay namens der Civil Administration Division des War Department zu bedenken, daß wohl kein Weg darum herumführe, diese Forderungen auf gleicher Grundlage wie diejenigen, die in Deutschland selbst erhoben würden, zu behandeln: „This matter is closely related to whole question of level of foreign investment in Germany and is difficult chiefly for that reason. It concerns many claimants now in the United States, many of them citizens. ${ }^{a 64}$ Clay pflichtete dem prinzipiell bei, aber nur unter der Bedingung, daß keine Devisen für diesen Zweck ausgegeben würden, so lange die USA noch finanzielle Hilfe für Deutschland leisteten ${ }^{65}$.

Von Anfang an war die Finanzierung einer der heikelsten Punkte. Die schon länger bestehende Idee eines Pools wurde zunächst weitergeführt, und auf Drängen Washingtons erörterte OMGUS die Möglichkeit, beschlagnahmtes Nazivermögen heranzuziehen $^{66}$. Clay zeigte sich dabei aber äußerst skeptisch gegenüber den Aussichten einer alliierten Einigung ${ }^{67}$, die hierfür erforderlich war. Dennoch wies OMGUS den Länderrat zunächst ausdrücklich darauf hin, daß die Lasten des Entschädigungsprogramms aus den im Rahmen der Vermögenskontrolle eingezogenen NS-Vermögen finanziert werden könnten ${ }^{68}$. Als eine zweite Quelle für diesen Pool wurden die erbenlosen und

59 Memorandum aus der OMGUS-Finance Division, 12.9. 1947, IfZ-Archiv, MF 260, OMGUS, POLAD 768/ 2.

60 James K. Pollock an Erich Rossmann, 9.4. 1946, in der Anlage Brief von Bryan L. Milburn (OMGUS) an RGCO, 3. 4. 1946, BayHStA, Bev. Stuttgart 71.

61 Steere an OMGUS, Legal Division, 5. 3. 1946, WNRC, RG 94, AG's Office, Box 1129.

62 Pollock an Rossmann, 9.4. 1946 (Anm. 60).

${ }^{63}$ Echols an Clay, 24. 4. 1946, IfZ-Archiv, MF 260, OMGUS-CAD 3/159-3/19.

${ }^{64}$ Ebenda.

${ }^{65}$ Clay an Echols, 8.3. 1946, IfZ-Archiv, MF 260, OMGUS-CAD, 3/159-3/19.

66 Echols an OMGUS, 15.3. 1946 (Anm. 55); Clay an Echols, 28.3. 1946 (Anm. 58).

67 Clay an Echols, 28. 4. 1946, IfZ-Archiv, MF 260, OMGUS, AG 45-46/109/1.

68 Milburn an RGCO, 3.4. 1946, BayHStA, Bev. Stuttgart 71. 
nichtidentifizierbaren Vermögen insbesondere jüdischer Herkunft diskutiert, die ja auch schon als eine der Finanzierungsquellen des Pariser Abkommens für nichtrepatriierbare Opfer des Nationalsozialismus aufgeführt worden waren ${ }^{69}$. Doch behielt sich Clay die endgültige Entscheidung bis zu den Beratungen mit dem Stuttgarter Länderrat vor $^{70}$.

Das Beharren auf der Finanzierbarkeit und die Rücksichtnahme auf die wirtschaftliche Stabilisierung der US-Zone prägten in dieser Phase Clays Politik in der Frage der Rückerstattung und Entschädigung für die ehemaligen Verfolgten. Nachdrücklich vertrat er die Auffassung, daß eine umfassende Entschädigung ausschließlich auf vierzonaler Ebene möglich sei. Entgegen den ursprünglichen Wünschen Washingtons hatte Clay weitergehende Entschädigungsmaßnahmen vorläufig abgelehnt. Nach seiner Auffassung mußten sich diese an die Ressourcen Deutschlands als Ganzes richten und konnten nicht allein aus dem Potential der US-Zone bestritten werden ${ }^{71}$. Von daher erklärte sich auch die Form des Auftrages an den Länderrat: zunächst nur ein begrenztes Entschädigungsprogramm mit Fürsorgecharakter, das den begrenzten Kapazitäten einer einzelnen Zone angemessen sein sollte, sowie ein Programm zur Rückerstattung wiederauffindbaren Vermögens, das prinzipiell kostenneutral war, da es sich ja nur um eine erneute Vermögensverschiebung handelte.

Walter Schwarz schrieb, daß Clay im Sommer 1945 durch eine bayerische Initiative zum Handeln gezwungen worden sei, blieb aber jeglichen Beleg dafür schuldig ${ }^{72}$. Tatsächlich findet sich in den Akten der amerikanischen Militärregierung kein Hinweis auf einen derartigen Zusammenhang. Wie gezeigt, begann die Militärregierung zunächst damit, die eingehenden Ansprüche zu sammeln und sie nach ihrer Realisierbarkeit zu sortieren. Als dann Washington im Frühjahr 1946 die prinzipielle Zustimmung zu einem unilateralen Vorgehen erteilte und zugleich die Reihenfolge der Schritte vorgab, ließ Clay den Länderrat anweisen, entsprechende Maßnahmen auszuarbeiten. Auch wenn seit Ende 1945 in der deutschen Administration der US-Zone gleichfalls an Entwürfen für Rückerstattungs- und Entschädigungsregelungen gearbeitet wurde, hatte dies das amerikanische Vorgehen bis dahin in keiner Weise beeinflußt.

\section{Der Beginn deutsch-amerikanischer Beratungen im Stuttgarter Länderrat}

Nachdem die amerikanische Militärregierung dem Stuttgarter Länderrat Anfang April 1946 den Auftrag erteilt hatte, einen Ausschuß einzusetzen, der neben einer Regelung für die Übernahme der Vermögenskontrolle in deutsche Verantwortung auch Maßnahmen zugunsten der Verfolgten des Nationalsozialismus ausarbeiten sollte, war die Phase, in der die deutsche und amerikanische Seite weitgehend unabhängig voneinander an diesen Fragen gearbeitet hatten, beendet. Am 24. April trat erstmals der Sonderausschuß für Eigentumskontrolle in der Villa Reitzenstein, dem Sitz des Länderrats in

\footnotetext{
${ }^{69}$ War Department an OMGUS, 18.3. 1946, IfZ-Archiv, MF 260, OMGUS-LD 17/251-2/17; Echols an Clay, 24. 4. 1946, ebenda, 3/159-3/19.

70 Clay an Echols, 9.5. 1946, IfZ-Archiv, MF 260, OMGUS 3/159-3/19.

${ }^{71}$ Clay signed McNarney an Echols, 28.4. 1946, IfZ-Archiv, MF 260, OMGUS, AG 45-46/109/1.

72 Walter Schwarz, Wie kam die Rückerstattung zustande? Neue Erkenntnisse aus den amerikanischen und britischen Archiven, in: Friedrich Biella usw., Das Bundesrückerstattungsgesetz, München 1981, S. $802 \mathrm{ff}$.
} 
Stuttgart, zusammen ${ }^{73}$. Neben den Delegierten Bayerns, Württemberg-Badens und Großhessens war dort auch eine Delegation der Militärregierung anwesend.

Diese hatte dem Länderrat ihre Wünsche detailliert erklärt: Zunächst war sie an der Rückerstattung von Vermögen an Einzelpersonen interessiert, gleichzeitig sollte aber auch die Rückerstattung an Organisationen erörtert werden. Da aber in vielen Fällen Personen durch die Rückerstattung für die unter der Naziherrschaft erlittenen Verluste nicht ausreichend entschädigt würden, sollte ein „Programm für die teilweise Befriedigung von Forderungen ... ausgearbeitet werden, damit diejenigen, die unter dem NaziRegime verfolgt wurden und verarmt sind, wirtschaftlich rehabilitiert werden können. Hierbei soll es sich jedoch nur um eine Notmaßnahme handeln, die die spätere Erfüllung aller Ansprüche nicht beeinträchtigt." Zur Finanzierung dieser vorläufigen Entschädigungsmaßnahmen stellte OMGUS in Aussicht, „daß den Landesregierungen eine genügende Anzahl der ... beschlagnahmten Vermögensobjekte zur Verfügung gestellt werden “74. Hier lag auch der Grund, weshalb die Übernahme der Vermögenskontrolle in deutsche Verantwortung und die Maßnahmen zugunsten der Verfolgten in einen Zusammenhang gestellt waren. Ein entsprechendes Programm sollte der Länderrat auf amerikanischen Wunsch bereits am 15. Mai vorlegen, damit es spätestens im Juli in Kraft treten konnte ${ }^{75}$.

Der Sonderausschuß für Eigentumskontrolle nahm die Arbeit an den geforderten Entwürfen unverzüglich auf. Dabei wurde streng zwischen Sofortmaßnahmen und endgültigen Maßnahmen unterschieden. Letztere wollte die deutsche Seite auf einen späteren Zeitpunkt, zu dem bestimmte Voraussetzungen wie insbesondere eine Währungsreform geschaffen seien, verschieben ${ }^{76}$. Auf einem Treffen der zuständigen Referenten der süddeutschen Länder am 21. Mai wurden drei Entwürfe für Sofortmaßnahmen ausgearbeitet und tags darauf im Sonderausschuß vorgelegt ${ }^{77}$. Der erste, der „Entwurf einer Verordnung zur Bildung eines Sonderfonds für Wiedergutmachungszwekke“, versuchte die vorläufige Entschädigung zu regeln. Aus Teilen der im Rahmen der geplanten Übernahme der gesperrten Vermögen in deutsche Verwaltung übergehenden Mittel sollte ein Fonds gebildet werden, aus dem vorläufige Leistungen an bedürftige Verfolgte gezahlt werden konnten. Darunter fielen nur Schäden, die auf dem Gebiet der drei Länder entstanden waren ${ }^{78}$. Dazu kamen Entwürfe eines „Gesetzes über den Wiedererwerb der deutschen Staatsangehörigkeit“ und einer „Verordnung über vordringliche Wiedergutmachungsmaßnahmen". Letzterer enthielt einen Vorschlag zur Regelung der Rückerstattung und basierte vor allem auf den bayerischen Vorarbeiten. In einer von Otto Küster und Walter Roemer redigierten Fassung überwies ihn der Rechtsausschuß des Länderrats an die amerikanische Militärregierung ${ }^{79}$.

Der Vorschlag des Länderrats zur Regelung der Rückerstattung sah vor, „Sachen

${ }^{73}$ Bericht über die Sitzung des Sonderausschusses für Eigentumskontrolle beim Länderrat am 24.4. 1946, BayMJ, 1101c, H. 1.

74 Milburn an RGCO, 3.4. 1946 (Anm. 68).

75 Pollock an Rossmann, 9.4. 1946 (Anm. 60).

76 Roemer an Höltermann, 19.5. 1946, Vorschläge über Sofortmaßnahmen und Endmaßnahmen zur Wiedergutmachung, BayMJ, 1101a, H. 1.

77 Niederschrift über die Sitzung des Sonderausschusses Eigentumskontrolle am 22.5. 1946, BayHStA, Bev. Stuttgart 71.

78 Ebenda, Anlage: Entwurf einer Verordnung über die Bildung eines Sonderfonds für Wiedergutmachungszwecke.

79 Henning von Arnim an Haller (RGCO), 29.5. 1946, Anlage: Entwurf eines Gesetzes über vordringliche Wiedergutmachungsmaßnahmen (Württemberg/Baden), 28.5. 1946, BA, Z 1, Bd. 1291. 
oder Rechte, die unter der nationalsozialistischen Herrschaft dem Berechtigten aus Gründen der Rasse, Religion, Weltanschauung oder des politischen Bekenntnisses entzogen worden waren“, zurückzuerstatten. Als entzogen galt hier ein Vermögensgegenstand nur dann, wenn ihn der Berechtigte durch einen staatlichen Hoheitsakt verloren hatte. Auch war die Rückerstattung auf Vermögensgegenstände beschränkt, „die zur Zeit dem Staat oder einer sonstigen öffentlichen Stelle zustehen ${ }^{\circ 0}$. Wie Justizminister Josef Beyerle auch gegenüber dem württemberg-badischen Ministerrat hervorhob, wurde hier zwar die Rückgabe von entzogenen Werten an religiöse, sportliche und gewerkschaftliche Organisationen erfaßt, nicht aber die Arisierungsfälle ${ }^{81}$. Damit hatte sich der Länderrat erst einmal vor der eigentlich heiklen Aufgabe gedrückt: Die vielfältigen Fälle, in denen sich Privatleute insbesondere an jüdischem Eigentum bereichert hatten, blieben ausgeklammert.

Der Property Disposition Board, das in dieser Frage maßgebliche OMGUS-Gremium, verwarf auf seiner Sitzung vom 7. Juni den Länderrats-Entwurf eines Rückerstattungsgesetzes $^{82}$. Ein von ihm beauftragter Arbeitsausschuß hatte einen neuen Entwurf verfaßt, der weit mehr Entziehungsfälle als der deutsche Vorschlag einschloß. Der Hauptunterschied war die Aufhebung der Beschränkung auf staatliche Entziehungsakte: auch private Maßnahmen sollten nun einbezogen werden. Damit zielte der amerikanische Entwurf auf die ganze Breite der Arisierungsfälle ${ }^{83}$. Aber auch für das Sonderfondsgesetz wurde ein US-Entwurf vorgelegt, der sich jedoch weitgehend an die deutsche Vorlage anlehnte ${ }^{84}$. Der Hauptunterschied war, daß die Finanzierung des Fonds modifiziert wurde: Im Gegensatz zum Länderrats-Entwurf wurden hier die Mittel aus dem Befreiungsgesetz als Hauptfinanzierungsquelle eingesetzt. Grund war der Optimismus des Property Disposition Board, daß reichlich Einnahmen aus der Entnazifizierung fließen würden. Zudem schienen ihm vorläufig die Absichten des Kontrollrats hinsichtlich der Verfügung über das gesperrte Vermögen der NSDAP und ihrer Gliederungen noch unsicher. Zusätzlich verwies er auf allgemeine Haushaltsmittel als Finanzquelle für den Sonderfonds. Den deutschen Entwurf für ein Gesetz zur Wiedererlangung der Staatsbürgerschaft verwarf der Property Disposition Board hingegen gänzlich, da die Angelegenheit ohnehin demnächst auf Kontrollratsebene geregelt würde ${ }^{85}$.

Diese Entscheidungen wurden dem Sonderausschuß „Eigentumskontrolle“ auf seiner nächsten Sitzung am 12. Juni vorgelegt und lösten dort einige Bestürzung aus ${ }^{86}$. Ministerialrat Hielscher, der das bayerische Finanzministerium im Sonderausschuß „Eigentumskontrolle“ vertrat, alarmierte den heimischen Ministerrat über die neue Entwicklung: „Wir wollten das eigentliche Problem der Restitution auf die Endmaßnahmen verschieben, die amerikanischen Teilnehmer erklärten aber, daß die Restitution jetzt, und zwar vollständig gelöst werden solle." Dahinter vermutete er zunehmende Aktivitäten der Verfolgtenorganisationen, denen er entgegenhielt: „Auch bei der wohlwollendsten Einstellung muß aber jede weitere Unruhe vom Wirtschaftsleben fernge-

80 Ebenda.

81 Niederschrift über die Sitzung des Staatsministeriums am 6.6. 1946, BadWürtHStA, EA 1/920, Bü. 709.

82 Minutes of the Meeting of the Property Disposition Board, 7.6. 1946, USNA, RG 59, 740.00119 E.W.

83 "Text of a Draft Law for Restitution Measures“, 7.6. 1946, Anlage zu Murphy an Byrnes, 19.6. 1946, USNA, RG 59, 740.00119 EW/6-1946.

84 "Text of a Draft Law on the Formation of a Special Fund for Interim Awards to Victims of Nazi Persecution and Discrimination", 7.6. 1946, ebenda.

85 Minutes of the Meeting of the Property Disposition Board, 7.6. 1946, USNA, RG 59, 740.00119.

${ }^{86}$ Bericht über die Sitzung des Sonderausschusses „Eigentumskontrolle“ am 12.6. 1946, BayMJ, 1101c, H. 1. 
halten werden. ${ }^{87} Z_{w a r}$ wurde auf dieser Sitzung das Sonderfondsgesetz zusammen mit den von OMGUS vorgenommenen Änderungen durch die Militärregierung vorläufig mündlich genehmigt und an die Kabinette zur Beschlußfassung überwiesen. Zugleich hatte OMGUS aber nun auch die Vorlage von Vorschlägen für eine endgültige Entschädigungsregelung gefordert, „während bisher“, so Hielscher, „der Ausschuß, wenn auch unausgesprochenermaßen, die Hoffnung hatte, daß es vorläufig bei den Sofortmaßnahmen sein Bewenden haben könnte." Die vorläufigen Ziele der deutschen Seite brachte Hielscher auf die Formel „Originalrestitution in glatten Fällen und ... Sofortmaßnahmen im Bedürftigkeitsfall." Alles weitere sollte auf unbestimmte Zeit aufgeschoben werden: „Für die Inkraftsetzung der Endmaßnahmen wäre die Geldreform abzuwarten. Ferner wäre anzustreben, den Wiedergutmachungsfonds als alleinigen Träger der Wiedergutmachung einzusetzen. " 88

Das Konzept der süddeutschen Länder, erst einmal nur Sofortmaßnahmen mit geringer Reichweite und wenig tiefen Einschnitten in die deutsche Gesellschaft anzustreben, war also seit der Mitteilung der neuen amerikanischen Forderungen auf der Sitzung des Sonderausschusses „Eigentumskontrolle“ vom 12. Juni 1946 geplatzt. Sie sahen sich nun gedrängt, umfassend für die Verbrechen des Deutschen Reiches geradezustehen, wogegen sie sich von Anfang an gesträubt hatten. Aber auch der amerikanische Plan, das gesamte geforderte Maßnahmenbündel bis zum Juli verabschieden zu können, war fürs erste hinfällig. Die weitere Entwicklung der vom Länderrat ursprünglich als Paket behandelten Entwürfe löste sich nunmehr in einzelne Stränge auf, die mit unterschiedlicher Priorität weiterverfolgt wurden.

\section{Die Regelung der Rückerstattung}

\section{Die Arbeit des Sonderausschusses "Eigentumskontrolle"}

Das Hauptgewicht bei der weiteren Ausarbeitung des Wiedergutmachungsprogramms durch den Länderrat galt zunächst der Regelung der Rückerstattung, wobei vorerst nur an das wiederauffindbare Vermögen gedacht wurde. Das lag einerseits daran, daß die amerikanische Militärregierung besonderen Nachdruck auf die vorrangige Regelung dieser Frage legte. Ein weiterer wichtiger Faktor war das starke Engagement der jüdischen Organisationen, da es sich bei der Rückerstattung vor allem um die Rückgängigmachung der „Arisierung“ handelte. Zum geringeren Teil fielen aber unter die geplante Rückerstattung auch die im Dritten Reich beschlagnahmten Vermögen von Parteien, Gewerkschaften, Konsumgenossenschaften etc. Ungefähr im Monatsrhythmus trafen im Sonderausschuß „Eigentumskontrolle“ in Stuttgart die deutschen und amerikanischen Experten sowie auch jüdische Interessenvertreter zusammen und berieten den Entwurf des Rückerstattungsgesetzes ${ }^{89}$. Parallel dazu diskutierte jeweils der OMGUS-Property Disposition Board die dort erzielten Ergebnisse und sorgte dafür, daß die Stellungnahmen der amerikanischen

\footnotetext{
${ }^{87}$ Hielscher, Vormerkung betr. Vermögenskontrolle und Wiedergutmachung vom 18.6. 1946, BayHStA, MA 114253.

${ }^{88}$ Ebenda.

89 Eine detaillierte Darstellung der einzelnen Stufen des Gesetzesentwurfes findet sich bei Schwarz, Rückerstattung nach den Gesetzen der Alliierten Mächte, S. 31-54.
} 
Militärregierung und aus Washington wieder in die Arbeit des Länderratsausschusses einflossen.

Hatten die Anstöße der jüdischen Organisationen bereits früher dafür gesorgt, das Thema im Bewußtsein der US-Administration und der amerikanischen Militärregierung zu verankern, so versuchten diese nunmehr direkt auf die Verhandlungen im Stuttgarter Länderrat Einfluß zu nehmen. Die führende Rolle übernahmen dabei fünf in den USA ansässige jüdische Organisationen, die ein gemeinsames Komitee bildeten. Dabei handelte es sich um den World Jewish Congress, das American Joint Distribution Committee, die Jewish Agency for Palestine, das American Jewish Committee und die American Jewish Conference (letztere schied allerdings später aus dieser Zusammenarbeit aus). Damit wurde die Kooperation jüdischer Organisationen, die schon im Vorfeld der Pariser Reparationskonferenz begonnen hatte, auf dem Feld der inneren Wiedergutmachung wirkungsvoll ausgebaut, was Chaim Weizmann und Nahum Goldmann bereits im Herbst 1945 angekündigt hatten ${ }^{90}$. Am 1. Februar 1946 nahm auch das Office of Indemnification des World Jewish Congress unter Leitung Nehemiah Robinsons seine Arbeit auf. Dort wurden Informationen gesammelt, politische Aktionen koordiniert und Entwürfe ausgearbeitet ${ }^{91}$. Alle diese Aktivitäten knüpften an die Vorarbeiten während des Krieges an.

Das Komitee der fünf jüdischen Organisationen versuchte sowohl auf dem Wege regelmäßiger Besprechungen mit den Verantwortlichen im State und War Department als auch bei der amerikanischen Militärregierung auf die Entwicklung einzuwirken. Unmittelbaren Einfluß gewann es durch die Einsetzung eines der OMGUS-Legal Division zugeordneten Internal Restitution Advisors ${ }^{92}$. Seit September 1946 nahm Max Lowenthal, der auf Vorschlag des Komitees der jüdischen Organisationen mit diesem Posten betraut worden war, an den Sitzungen des Länderrats-Sonderausschusses "Eigentumskontrolle“ teil und setzte sich dort für deren Interessen ein ${ }^{93}$. Parallel dazu agierten weitere internationale Organisationen, die gleichfalls - wenn auch nicht ausschließlich - jüdische Interessen vertraten. Insbesondere Bruno Weil mit seiner Axis Victims League wandte sich dabei gegen den durch das Komitee vertretenen Ansatz, der von einer gesonderten Vertretung der jüdischen Forderungen ausging. Von ihrer politischen Bedeutung her gesehen gelang es dieser und anderen Gruppierungen allerdings nie, mit dem Komitee der fünf jüdischen Organisationen gleichzuziehen.

Die Unterschiede in den Auffassungen der deutschen und der amerikanischen bzw. der jüdischen Seite in den Verhandlungen im Sonderausschuß „Eigentumskontrolle“ waren erheblich. Den Hintergrund vieler Konflikte bildete dabei der Umstand, daß ein Großteil der potentiellen Rückerstattungsberechtigten im Ausland lebte. Im Verlauf der Beratungen wurden Erwartungen geäußert, daß dies für

90 Vgl. Zweites Kapitel, Abschnitt I.

91 Vgl. Leon Kubowitzki, Unity in Dispersion. A History of the World Jewish Congress, New York 1948, S. $268 \mathrm{f}$.

92 Rabbi Philip S. Bernstein (Advisor on Jewish Affairs to the Theater Commander) an General Joseph T. McNarney, 1.7. 1946, IfZ-Archiv, MF 260, OMGUS, AG 45-46/109/1.

${ }_{93}$ Niederschrift über die Sitzung des Sonderausschusses „Eigentumskontrolle" am 19.9. 1946, BayHStA, Bev. Stuttgart 71 . 
95 Prozent der Ansprüche der Fall sein würde ${ }^{94}$; tatsächlich stellte diese Gruppe später immerhin ca. 80 Prozent $^{95}$ der Antragsteller.

Zu den zentralen Streitpunkten gehörte die Frage, welche Vermögensverschiebungen überhaupt unter die Rückerstattung fallen sollten. Die Deutschen zeigten sich daran interessiert, den in Frage kommenden Bereich so eng als möglich zu halten; umgekehrt versuchte die jüdische Seite, möglichst weite Kriterien durchzusetzen. Stein des AnstoBes war insbesondere die Frage des sogenannten „loyalen Erwerbs“. Sollte man gelten lassen, daß auch unter der nationalsozialistischen Herrschaft ein Verkauf unter redlicher Wahrung der Interessen eines verfolgten Verkäufers zustande gekommen sein konnte? Hier trafen gänzlich verschiedene Auffassungen über die Auswirkungen des nationalsozialistischen Terrors auf das Rechtsleben in Deutschland aufeinander.

Auf jüdischen Wunsch hin wurde der Schutz des guten Glaubens für einen Erwerber jüdischen Eigentums schon im Anfangsstadium der Verhandlungen weitgehend ausgeschlossen ${ }^{96}$. Zur direkten Verantwortung gezogen wurde jeweils der letzte Erwerber des betreffenden Eigentums. Am Ende galt prinzipiell jedes nach dem 15. September 1935 - dem Tag, an dem die Nürnberger Gesetze erlassen worden waren - abgeschlossene Geschäft mit Juden als anfechtbar, da von diesem Zeitpunkt an deren kollektive Verfolgung angenommen wurde. Um dieses Stichdatum hatte es auch intern bei OMGUS heftige Auseinandersetzungen gegeben. Im Gegensatz zur Legal Division, die auch hier den jüdischen Standpunkt unterstützte, hatten die Finance Division und die Property Control Branch übereinstimmend mit der deutschen Seite den November 1938, also die „Reichskristallnacht“, als Zäsur gefordert".

Auch um die Frage der Besetzung der Rückerstattungsgerichte wurde hart gerungen. Deutschen Richtern traute man im Ausland und zumal bei den Betroffenen in dieser Frage nur wenig Objektivität zu. Nehemiah Robinson, der Direktor des Office of Indemnification des World Jewish Congress, äußerte sich gleichfalls in diesem Sinne, als er Ende 1946 anläßlich eines Deutschland-Besuchs als Gast vor dem Sonderausschuß „Eigentumskontrolle“ um seine Meinung zum Entwurf des Rückerstattungsgesetzes gefragt wurde ${ }^{98}$. Auf deutscher Seite stieß das darin enthaltene Mißtrauen gegenüber der deutschen Justiz hingegen auf trotziges Unverständnis ${ }^{99}$. Zuletzt wurde ein Kompromiß erzielt: In erster Instanz sollten deutsche Gerichte entscheiden, doch wurde die Einrichtung einer amerikanischen Nachprüfungsstelle, des „Board of Review“, beschlossen ${ }^{100}$. Das war mehr, als die deutsche Seite zulassen wollte, aber eben soviel, wie OMGUS personell für machbar hielt.

Washington hatte dem schließlich mit dem Argument zugestimmt, daß dies die demokratischen Institutionen in Deutschland stärken würde, aber die Notwendigkeit

94 Rechtsanwalt Dr. Cahn, ebenda.

95 Bezogen auf das Gebiet der US-Zone. Vgl. Statistik in Schwarz, Rückerstattung nach den Gesetzen der Alliierten Mächte, S. 366.

96 Entwurf des Rückerstattungsgesetzes in der Fassung vom 29.7. 1946, wie es sich bei Annahme der Änderungsvorschläge der amerikanische Militärregierung ergeben würde, BayMJ, 1101a, H. 1.

${ }^{77}$ Minutes of the Meeting of the Property Disposition Board, 4. 4. 1947, IfZ-Archiv, MF 260, OMGUS-PCEA $17 / 1$.

${ }^{98}$ Niederschrift über die Sitzung des Sonderausschusses „Eigentumskontrolle“ am 17./18.12. 1946, BA, Z 1, Bd. 1290.

99 Siehe etwa Josef Andre (württ.-bad. Wirtschaftsminister) in der Sitzung des Sonderausschusses „Eigentumskontrolle“ am 19.9. 1946, BayHStA, Bev. Stuttgart 71.

$100 \$ 69$, Gesetz Nr.59 der amerikanischen Militärregierung (USREG), 10.11. 1947, in: Amtsblatt der amerikanischen Militärregierung Deutschlands, Ausgabe G, Nov. 1947, S. 1 ff. 
einer strengen alliierten Überwachung betont ${ }^{101}$. Clay, der stärker als seine vorgesetzten Stellen auch Rücksicht auf die deutschen Interessen nahm, bezog Washington gegenüber aus der erstinstanzlichen Bearbeitung der Rückerstattung durch die Deutschen ein zusätzliches Argument: Deren Wünsche sollten soweit als möglich akzeptiert werden, weil man sonst keine wirklich loyale Auslegung erwarten dürfe ${ }^{102}$. Dieses Argument erwies sich allerdings als Bumerang, denn als es den jüdischen Organisationen gelungen war, einige Bestimmungen in diesem Gesetz unterzubringen, die weit jenseits der deutschen Schmerzgrenze lagen, entwickelten sie auf Jahre hinaus erhebliche Ängste vor einer Ablösung der amerikanischen Nachprüfungsinstanzen.

Stand bei diesen Konflikten in erster Linie die deutsche Seite unter Druck, führte die Frage, was aus dem Eigentum derjenigen Menschen werden sollte, die durch die Verfolgung nicht nur ihr Vermögen, sondern überdies ihr Leben verloren hatten, auch zu schweren Auseinandersetzungen innerhalb der amerikanischen Militärregierung. Noch im Frühjahr 1946 bestand keine Klarheit über die künftige Verwendung des erbenlosen Eigentums ${ }^{103}$. Bis dahin wurde aber bei OMGUS noch der Gedanke favorisiert, diese Werte zur Hilfe für Verfolgte des Nationalsozialismus in Deutschland zu verwenden. Auch das State Department neigte einer solchen Lösung noch einige Zeit zu ${ }^{104}$. Die internationalen jüdischen Organisationen sahen dagegen endlich die Gelegenheit gekommen, ihr während des Krieges entwickeltes Konzept der kollektiven Anwartschaft auf das jüdische Erbe in Deutschland zu verwirklichen. Nachdem mit dem Pariser Reparationsabkommen bereits ein Präzedenzfall existierte, unternahmen sie nun große Anstrengungen, auch im Rückerstattungsgesetz der US-Zone eine entsprechende Regelung zu verankern. Über Rabbi Philip S. Bernstein, den Advisor on Jewish Affairs to the Theater Commander, intervenierte das Komitee der fünf jüdischen Organisationen Anfang Juli bei der amerikanischen Militärregierung. Bernstein protestierte gegen die ungenügende Berücksichtigung der spezifisch jüdischen Interessen in den bisherigen Planungen und insbesondere gegen die mögliche Verwendung des erbenlosen Vermögens zur Entschädigung aller Opfer des NS-Regimes ${ }^{105}$. Zuvor hatte sich bereits die American Jewish Conference in dieser Sache an Außenminister Byrnes gewandt und die Gründung einer Jewish Restitution Commission angeregt, in der die repräsentativen jüdischen Organisationen vertreten sein sollten ${ }^{106}$.

Die amerikanische Militärregierung sah sich nun zunehmend mit der Erwartung konfrontiert, daß das erbenlose jüdische Vermögen in Deutschland internationalen jüdischen Hilfsorganisationen zugeführt werde ${ }^{107}$. John French, seitens der OMGUSLegal Division maßgeblich mit der Angelegenheit betraut, stellte deshalb im September 1946 die rhetorische Frage, „ob dieses Vermögen an Agenturen übergeben werden soll, die anscheinend hauptsächlich Aktivitäten außerhalb Deutschlands betreiben, oder ob es nicht bedürftige Personen in Deutschland gibt, die ein gleiches, wenn nicht ein besseres Recht auf dieses Vermögen besitzen“108. Damit spielte French auf die zu

101 War Department an OMGUS, 19.7. 1946, IfZ-Archiv, MF 260, OMGUS-CAD 3/159-3/19.

102 Clay an Echols, 25.10. 1946, IfZ-Archiv, MF 260, OMGUS-LD 17/56-2/21.

103 Clay an Echols, 8. 5. 1946, IfZ-Archiv, MF 260, OMGUS-CAD 3/159-3/19.

104 War Department an OMGUS, 18. 7. 1946, IfZ-Archiv, MF 260, OMGUS-CAD 3/159-3/19.

105 Rabbi Bernstein an McNarney, 1.7. 1946 (Anm. 92).

${ }^{106}$ Henry Monsky (American Jewish Conference) an Byrnes, 19.6. 1946, USNA, RG 59, 740.00119 E.W.

107 John French an Alvin J. Rockwell, 11. 9. 1946, IfZ-Archiv, MF 260, OMGUS-LD 17/56-2/21.

108 Ebenda. 
diesem Zeitpunkt bei OMGUS noch nicht ad acta gelegten Pläne an, die vorläufigen Entschädigungsmaßnahmen in Deutschland aus diesen Werten mitzufinanzieren.

Daß nicht wie nach herkömmlichem Recht üblich der deutsche Staat - der vormalige Verfolger - in das Erbe eintreten sollte, wurde allgemein schnell akzeptiert. Auch daß nicht entfernte Verwandte von den Massenmorden profitieren sollten, fand weitgehend Zuspruch, da man keine „Auschwitz-Gewinnler“ schaffen wollte ${ }^{109}$. Größere Schwierigkeiten hatten die internationalen jüdischen Organisationen aber damit, den Grundsatz, jüdisches Vermögen nur für Juden zu verwenden, als auch die Ernennung von jüdischen Nachfolgeorganisationen durchzusetzen. Beträchtliche Spannungen entstanden daraus, daß diese den verbliebenen deutschen jüdischen Restgemeinden nicht die volle Anwartschaft auf das Vermögen der früheren deutschen Gemeinden zubilligen wollten, da diese nur noch etwa 30.000 von über 500.000 Juden in Deutschland vor dem Krieg umfaßten ${ }^{110}$.

So entwickelte sich auch ein innerjüdischer Konflikt um die Rückerstattung zwischen den ausländischen jüdischen Organisationen und den deutschen jüdischen Gemeinden, die bei den Beratungen in Stuttgart in Person des Repräsentanten der württembergischen Juden, Benno Ostertag, gleichfalls beteiligt waren. Bernard Bernstein, der im Auftrag des Komitees der fünf jüdischen Organisationen die Lage in Deutschland sondierte, berichtete im Sommer 1946 über seine Gespräche mit dortigen jüdischen Repräsentanten: „Consideration should be given to the possible dangers inherent in the situation of some small groups of Jews or half-Jews remaining in Germany claiming to be the successors to large amounts of Jewish communal property in Germany, or being willing to accept other provisions respecting restitution and indemnification that are not consistent with the other Jewish interests. " ${ }^{111}$ Dieser Konflikt, der letztlich mit der grundsätzlichen Frage nach der Rolle einer jüdischen Diaspora in Deutschland nach dem Holocaust zusammenhing, blieb noch lange Zeit virulent.

Ein zentrales Problem war dabei, ob das erbenlose Vermögen nur innerhalb oder auch außerhalb Deutschlands verwendet werden konnte, wie es die internationalen jüdischen Organisationen forderten. Dies hing auch eng mit der schon seit längerem diskutierten Frage zusammen, inwiefern künftig nach dem Ende der entsprechenden Kontrollratsverbote generell Wiedergutmachungsansprüche aus dem Ausland befriedigt werden könnten. Hier bestand auf amerikanischer Seite ein Dilemma. Die wirtschaftliche und reparationsrechtliche Situation Deutschlands setzte objektive Grenzen für einen Vermögenstransfer ins Ausland. Doch handelte es sich bei den Ansprüchen aus dem Ausland immerhin um die Hauptmasse, nicht zuletzt hatte diese Gruppe auf amerikanischer Seite mit den entscheidenden Anstoß zur Behandlung des Rückerstattungsproblems gegeben.

109 Vortrag Roemers vor dem Landesverband Bayern des Groß- und Einzelhandels, Bezirk Unterfranken, und unterfränkischen Juristen am 13.5. 1948 in Würzburg, BayMJ, 1091 I, H. 5.

110 Minutes of the Meeting of the Property Disposition Board, 16. 9. 1946, IfZ-Archiv, MF 260, OMGUSBICO 11/13-1/16.

111 Memorandum from Col. Bernard Bernstein Concerning Discussions in Germany on Problems of Restitution and Indemnification - August 29 - September 9, 1946, YIVO-Archiv, RG 347, AJC Records, GEN-10, Box 282. 


\section{Jüdische Interventionen in Washington und die Folgen}

Bis zum Herbst des Jahres 1946 hatte sich die Lage auf amerikanischer Seite soweit geklärt, daß die Ansprüche aus dem Ausland grundsätzlich anerkannt werden sollten, und auch das Prinzip der Nachfolgeorganisationen für erbenloses Eigentum hatte sich durchgesetzt und war im Länderratsentwurf des Rückerstattungsgesetzes verankert worden $^{112}$. Doch über die Frage, ob es sich dabei auch um internationale jüdische Nachfolgeorganisationen handeln konnte, war in den Diskussionen bei OMGUS und in Washington bis dahin noch keine Entscheidung gefallen. Jedenfalls war die amerikanische Militärregierung nun soweit mit dem bisherigen Verhandlungsergebnis zufrieden, daß Clay den mittlerweile sechsten Entwurf des Rückerstattungsgesetzes vom 18. Oktober des Jahres mit warmen Empfehlungen versehen nach Washington schickte und die Veröffentlichung des Gesetzes noch bis zum Jahresende für möglich hielt ${ }^{113}$. Während er dringend davon abriet, nochmals substantielle Änderungen vorzunehmen, um die Annahme des Entwurfes als deutsches Gesetz nicht zu gefährden, trug er aber selbst in der Folge nicht wenig eben dazu bei.

Ende November reiste Clay persönlich nach Washington und verhandelte bei dieser Gelegenheit auch mit einer hochrangigen Delegation des Komitees der fünf jüdischen Organisationen unter Leitung von Joseph M. Proskauer, dem Präsidenten des American Jewish Committee. Im Rahmen dieser Gespräche machte Clay einige weitreichende Zugeständnisse, deren Inhalt aber weder innerhalb der Militärregierung noch innerhalb der Washingtoner Administration in allen Einzelheiten bekannt wurden, was noch für etliche Verärgerung sorgen sollte. Unter anderem akzeptierte Clay nun auch, daß die Militärregierung und nicht etwa die Deutschen eine jüdische Nachfolgeorganisation bestimmen würde ${ }^{114}$. Damit wollten die jüdischen Organisationen die Möglichkeit deutscher Nachfolgeorganisationen ausschließen. Clay rechtfertigte sich später, in der Überzeugung gehandelt zu haben, der in Washington vorherrschenden politischen Stimmung entsprochen zu haben, während seine persönlichen Auffassungen eher in eine andere Richtung gegangen seien ${ }^{115}$.

Durch diese neuen Abmachungen wurde der Rahmen des bisher im Länderrat erzielten Konsenses gesprengt, weshalb sich alle Hoffnungen auf einen baldigen Erlaß des Rückerstattungsgesetzes als utopisch erwiesen. Die fünf jüdischen Organisationen sandten am 27. November ein Memorandum mit Änderungsvorschlägen an das State Department, in das auch die Abmachungen mit Clay eingearbeitet waren. Dort wurde die umfangreiche Wunschliste weitgehend gebilligt und an OMGUS weitergeleitet ${ }^{116}$, wo die erneuten Forderungen auftragsgemäß in den Länderrats-Ausschuß eingebracht wurden. Zwar gelang es der amerikanischen Delegation in weiteren Sitzungen des Sonderausschusses „Eigentumskontrolle“ Anfang 1947, die meisten dieser Wünsche in den Entwurf einzubauen, darunter auch die Bestimmung, daß internationale jüdische

112 Entwurf des Rückerstattungsgesetzes vom 18. 10. 1946, BayMJ, 1101a, H. 2.

113 Clay an Echols, 25. 10. 1946, IfZ-Archiv, MF 260, OMGUS-LD 17/56-2/21.

114 AJC Contributions to Postwar Economic Rehabilitation of Jewish Victims of Nazi Persecution, September 1965, AJC-Archiv, JSX, Subject Restitution 65-66. Vgl. auch Naomi W. Cohen, Not Free to Desist. A History of the American Jewish Committee 1906-1966. Introduction by Salo W. Barou, Philadelphia 1972, S. 278.

115 Clay an Daniel Noce (War Department), 7.2. 1948, IfZ-Archiv, MF 260, POLAD 793/46.

116 J.H. Hilldring (State Department) an Echols, 2.12. 1946, Anlage: Memorandum der fünf jüdischen Organisationen vom 27. 11. 1946, IfZ-Archiv, MF 260, OMGUS-CAD 3/174-1/17. 
Nachfolgeorganisationen zugelassen werden würden ${ }^{117}$. Doch hatte dies nur zur Folge, daß die ohnehin schon großen Vorbehalte auf deutscher Seite noch weiter zunahmen.

Vertreter aus deutschen Wirtschaftskreisen, die insbesondere im federführenden Bayern ausdrücklich aufgefordert waren, zu den Länderrats-Entwürfen Stellung zu nehmen, hatten diesen bereits von Anfang an kein gutes Zeugnis ausgestellt. In dem $\mathrm{Maße}$, in dem sich die Entwürfe zuungunsten der Pflichtigen verschärften, versteifte sich dort auch die Ablehnung. Zwar äußerten sich die befragten Wirtschaftsvertreter stets prinzipiell für die Rückerstattung, doch, wie Ludwig Kastl als Präsident des bayerischen Wirtschaftsbeirates formulierte, nur soweit, als der „versöhnliche Gedanke, der einer Wiedergutmachungsgesetzgebung im eigentlichen Sinne zugrunde liegen muß “118, nicht geschwächt werde. Hauptkritikpunkte waren daher die weitgehende Ausschaltung des gutgläubigen Erwerbs sowie die voraussichtlich einzonale Geltung des Gesetzes, die zu einer wirtschaftlichen Benachteiligung der US-Zone führe. Auch fehlte nicht der pharisäerhafte Hinweis, daß der Wirtschaftsbeirat den vorgesehenen Umfang der Rückerstattung gerade deshalb ablehne, weil „er das Aufkommen antisemitischer Strömungen jeglicher Art verhindern “119 wolle. In dieser beliebten Denkfigur wurden die Wiedergutmachungsansprüche der Juden zur eigentlichen Ursache des Antisemitismus. Die Münchener Bankenvereinigung forderte zudem die „Begrenzung der Rückerstattungsansprüche, um die notwendigerweise aus der Regelung des Rückerstattungs- und Wiedergutmachungsproblems sich ergebende Beunruhigung des öffentlichen und des privaten Wirtschaftslebens auf ein Mindestmaß zu beschränken “120. Die Ablehnung der Wirtschaftsorganisationen, deren Eigentumsinteressen hier bedroht wurden, war deutlich und lief schon seit Herbst 1946 auf eine klare Entscheidung hinaus: Sollte es nicht möglich sein, die inkriminierten Punkte aus den Entwürfen zu beseitigen, so wäre es vorzuziehen, „das Gesetz ... entweder der Militärregierung bezw. dem Kontrollrat zur Anordnung zu überlassen oder dem künftigen Landtag zu überweisen" ${ }^{\text {"121. }}$.

Diese Vorschläge aus Wirtschaftskreisen blieben nicht ohne Wirkung, enthielten sie doch im Prinzip dieselben Bedenken, die auch unter den an den Verhandlungen mit der Militärregierung beteiligten Deutschen verbreitet waren. Der Vorschlag des bayerischen Wirtschaftsbeirates fand im folgenden auch seine Entsprechung im weiteren Vorgehen der deutschen Delegation: Zunächst versuchte sie im Länderrats-Sonderausschuß verlorenes Terrain zurückzugewinnen und brachte eine Reihe von Änderungsvorschlägen ein, die darauf abzielten, „dem Gesetz die Zähne zu ziehen“122, wie es ein amerikanischer Beobachter formulierte. Als dies aber ohne Erfolg blieb und im Gegenteil im Januar 1947 neue Anweisungen aus Washington eintrafen, die weitere Verschärfungen mit sich brachten, änderten die Ministerpräsidenten der US-Zone die Taktik. Sie

11 Siehe Protokoll über die Sitzung des Sonderausschusses „Eigentumskontrolle“ am 20./21.1. 1947, BayMJ, $1101 \mathrm{a}$, H. 2; Entwurf des Rückerstattungsgesetzes in der Fassung vom 25.1. 1947, insbes. $\$ 6$, Abs. 6, ebenda; Niederschrift über die Sitzung des Sonderausschusses „Eigentumskontrolle ${ }^{\star}$ am 3.2. 1947, ebenda.

118 Denkschrift von Ludwig Kastl (Präsident des Wirtschaftsbeirats beim bayer. Wirtschaftsministerium), 9. 10. 1946, BayHStA, MA 130348. Kastl war 1925 bis 1933 geschäftsführendes Mitglied im Präsidium des Reichsverbandes der deutschen Industrie.

119 Kastl an Hoegner u. a., 7.11. 1946, BayHStA, MF 69409.

120 Albert Glaser u. Florian Witzmann, Münchener Bankenvereinigung, Leitung: Bayerische Hypotheken- und Wechsel-Bank, 9.11. 1946, BayMJ, 1101a, H. 2.

121 Kastl an Högner u.a., 7.11. 1946 (Anm. 119).

122 H. Marcuse an Rockwell, 25./26. 11. 1946, Report on Meeting of Restitution Committee of the Laenderrat, 20. 1. 1947, IfZ-Archiv, MF 260, OMGUS-LD 17/56-2/21. 
ließen die Militärregierung nunmehr wissen, daß die Anfang Dezember 1946 in Kraft getretenen Länderverfassungen und die nachfolgende Konstituierung der Landtage eine Verabschiedung des Rückerstattungsgesetzes ohne Beteiligung der Legislative unmöglich machten. Zugleich gab die deutsche Seite aber zu verstehen, daß dieses Gesetz in der vorliegenden Form keine Chance habe, in den Landtagen angenommen zu werden ${ }^{123}$.

Deshalb ermächtigte OMGUS die Länderkabinette dazu, das Gesetz zu verkünden, ohne die Landtage damit zu befassen ${ }^{124}$. Doch hüteten sich diese, die bittere Pille zu schlucken. Bezeichnend sind die Bedenken, die der frisch gewählte Ministerpräsident Hans Ehard am 1. Februar im bayerischen Ministerrat darlegte. Politisch gesehen bewege man sich in „einer feindlichen und mißtrauischen Atmosphäre“, in der es „keine Möglichkeiten gebe, sich einem Diktat gegenüber zu wehren“. In rechtlicher Hinsicht bezeichnete Ehard den Entwurf als „ein Musterbeispiel für ein raffiniertes Rechtsgewebe.“ Weiter verzeichnet das Protokoll die Äußerung Ehards, daß „mit Hilfe dieses Gesetzes ein Riesengeschäft gemacht werden (könne) und zweifellos gerade ein großer Teil derjenigen Werte, die wir so notwendig bräuchten, abwandern oder in ausländische Hände kommen“. Deshalb beabsichtigte er seine Unterschrift nur „auf schriftliche Weisung der Militärregierung ${ }^{\star 125}$ zu leisten. Freilich gab es auch mäßigende Stimmen. So wies der nunmehr stellvertretende Ministerpräsident Hoegner darauf hin, „man (dürfe) den Grundgedanken nicht aus dem Auge verlieren ..., daß nämlich eine Rückerstattung stattfinden müsse." Gleichwohl störte auch er sich an der konkreten Gestalt des Entwurfes, so besonders an der Ausschaltung jeglichen gutgläubigen Erwerbs sowie auch an der „in dem Gesetz vorgesehene(n) ausländische(n) Kollektivität, wobei der Begriff des jüdischen Volkes neu hereingebracht werde“. Und als Innenminister Seifried zu bedenken gab, daß man bei aller Kritik doch unbedingt an der Rückerstattungs- und Wiedergutmachungspflicht festhalten müsse, entgegnete ihm Ministerpräsident Ehard, dies „sei selbstverständlich, es komme aber auf das ,Wie“ an"126.

Am 11. März beriet der Länderrat abschließend über den Entwurf des Rückerstattungsgesetzes, der nunmehr in der Fassung vom 20. Februar vorlag. Statt ihn wie von der amerikanischen Militärregierung erhofft, endlich anzunehmen, übermittelte der Länderrat aber nur eine Entschließung an OMGUS, die verdeutlichte, daß die Ministerpräsidenten keine politische Verantwortung für den Entwurf in dieser Form übernehmen würden. Hauptgesichtspunkt der Erklärung war, wie der württemberg-badische Ministerpräsident Reinhold Maier seinen Ministern anderntags erläuterte, „daß sie nicht von der amerikanischen Presse als Ablehnung angegriffen werden kann" ${ }^{127}$. Der außenpolitische Erwartungsdruck, dem sich die deutsche Seite hier ausgesetzt sah, kommt auch in anderen Bekundungen zum Ausdruck. So hatte der maßgeblich an den Entwürfen beteiligte bayerische Ministerialrat Roemer den Entwurf vom 25. Januar zur Annahme empfohlen, „denn kleinere Bedenken ... müssen zurücktreten hinter der unbedingten moralischen Notwendigkeit, schwerstes Unrecht, soweit möglich, wieder

123 Rockwell an Chief of Staff, 27. 1. 1947, Report on the Meeting of Restitution Committee of the Laenderrat, 20. 1. 1947, IfZ-Archiv, MF 260, OMGUS 17/52-2/6.

124 Kurzprotokoll über die Sitzung des Sonderausschusses „Eigentumskontrolle“ am 3. 2. 1947, BayMJ, 1101a, H. 2.

125 Sitzung des bayerischen Ministerrats, 1. 2. 1947, IfZ-Archiv, NL Hoegner, ED 120, Bd. 362.

126 Ebenda.

127 Niederschrift über die Sitzung des Staatsministeriums am 12.3. 1947, BadWürtHStA, EA 4/001, Bü. 57a. 
gutzumachen, und hinter den politischen Notwendigkeiten, die sich namentlich aus den gegenwärtigen Friedensverhandlungen ergeben " ${ }^{128}$. Ähnlich argumentierte auch Direktor Hagel, der für Württemberg-Baden im Sonderausschuß „Eigentumskontrolle“ saß: „In allen Ländern der Erde sind solche Wiedergutmachungsberechtigte zum Teil in einflußreichen Positionen und größerer Zahl. “ ${ }^{129}$

So hieß es also in der Länderrats-Entschließung, daß die Ministerpräsidenten die Notwendigkeit einer unverzüglichen und umfassenden Rückerstattung bejahten. Zugleich baten sie die Militärregierung aber darum, einer Anzahl von Bedenken Rechnung zu tragen. Dabei nannten sie die in ihren Augen zu lange Anmeldefrist für Ansprüche sowie das zu weitreichende Anfechtungsrecht zugunsten der Geschädigten. In den Mittelpunkt ihrer Bedenken stellten sie aber das Argument, es sei nicht zu verantworten, eine derart schwerwiegende Regelung allein für die amerikanische Besatzungszone zu treffen ${ }^{130}$.

\section{Chancen und Scheitern einer alliierten Lösung}

Die Erklärung der Ministerpräsidenten der US-Zone vom 11. März war angesichts ihres geringen Handlungsspielraums taktisch sehr geschickt. Ihre unmittelbare Folge war, daß die inneren Gegensätze, die sich bei der amerikanischen Militärregierung in der Frage des Rückerstattungsgesetzes entwickelt hatten, nunmehr offen aufbrachen. Besonders im Property Disposition Board, der seit Frühjahr 1946 die zentrale Instanz zur Behandlung der Wiedergutmachungsfrage bei OMGUS war, hatten sich scharfe Fronten aufgebaut. Auf der einen Seite stand die Legal Division, wo insbesondere Alvin J. Rockwell maßgeblich dazu beitragen hatte, dem Entwurf seine jetzige harte, für die Deutschen unannehmbare Form zu geben. Daran hatten auch die Vertreter der jüdischen Organisationen, zuerst Max Lowenthal, später Irwin Mason, die der Legal Division als Internal Restitution Advisor beigegeben waren, kräftig mitgewirkt. Demgegenüber standen vor allem das Finance Directorate sowie die Property Control Branch, denen daran gelegen war, einerseits die Belastungen für die deutsche Wirtschaft gering $\mathrm{zu}$ halten und andererseits in Übereinstimmung mit den britischen und französischen Alliierten vorzugehen ${ }^{131}$.

Diese Gegensätze brachen erneut auf, als der Property Disposition Board am 4. April darüber beriet, wie man auf die neue Lage reagieren solle, die die Erklärung der Ministerpräsidenten geschaffen hatte ${ }^{132}$. Angesichts der Alternative - sofortiger Erlaß eines Militärregierungsgesetzes oder Aufnahme vierzonaler Verhandlungen - bildeten sich sogleich zwei Parteien. Die Vertreter der Finance Division, Bennett, Ball, Reinsel und Cassoday, traten vehement für Verhandlungen mit den anderen Alliierten ein, da ein einzonales Gesetz bei der Durchführung große Schwierigkeiten bereiten und zudem nur einen geringen Bruchteil des insgesamt betroffenen Vermögens erfassen würde.

\footnotetext{
128 Roemer an Högner, 29. 1. 1947, BayMJ, 1101a, H. 2.

129 Memorandum von E. Hagel, 27.2. 1947, BadWürtHStA, EA 1/920, Bü. 709.

130 Text der Entschließung des Länderrats vom 11.3. 1947 in Schreiben Arnims an Roemer, 17.3. 1947, BayHStA, Bev. Stuttgart 71.

131 Vgl. dazu „Complications in Connection with the Enactment of the Restitution Law in the U.S.-Occupied Zone of Germany“, 18.4. 1947, YIVO-Archiv, RG 347, AJC Records, GEN-10, Box 291.

132 Siehe zum folgenden Minutes of the Meeting of the Property Disposition Board, 4. 4. 1947, IfZ-Archiv, MF 260, OMGUS, PCEA 17/1.
} 
Ebenso bestimmt sprachen sich die Vertreter der Legal Division, Rockwell, Schopler, Marcuse und Mason, für den sofortigen Erlaß eines Militärregierungsgesetzes aus, da Eile geboten sei und alliierte Verhandlungen ohne Erfolgsaussichten seien. Der Vertreter der jüdischen Organisationen hob dabei besonders auf die Sogwirkung eines schnellen unilateralen Handelns ab: „The enactment of this law on a zonal basis would act as a shot in the arm to the other Nations and would result in the adoption by them of similar laws. “ ${ }^{133}$ Der Ausschuß einigte sich schließlich auf einen Kompromiß: Er beschloß, Clay vorzuschlagen, daß der Erlaß eines unilateralen Militärregierungsgesetzes für 60 Tage aufgeschoben werden sollte, um in der Zwischenzeit die Möglichkeit eines alliierten Arrangements zu prüfen.

Dieser Vorschlag setzte sich aus einer Reihe von Gründen bei OMGUS und auch in Washington durch: Clay befürchtete, daß ein unilaterales Militärregierungsgesetz die US-Zone gegenüber den anderen Zonen benachteiligen würde und zudem wohl kaum auf große Loyalität der ausführenden deutschen Behörden zählen dürfe ${ }^{134}$. Bei der Stelle des Political Advisors betonte man, daß nur etwa 15 bis 20 Prozent des jüdischen Eigentums in Deutschland in der US-Zone lägen. Zudem wurden dort auch die starken Bedenken von französischer und britischer Seite gegen ein einzonales Gesetz angeführt, auf die Rücksicht genommen werden sollte ${ }^{135}$. So reichten die amerikanischen Kontrollratsvertreter am 10. April einen US-Entwurf in der Property Control Commission ein, den der OMGUS-Property Disposition Board auf der Grundlage des NovemberEntwurfs des Länderrats angefertigt hatte ${ }^{136}$.

Das Komitee der fünf jüdischen Organisationen in New York reagierte auf diese Entwicklung höchst beunruhigt. Es erwartete, daß aus alliierten Verhandlungen erhebliche Verzögerungen resultierten, vor allem aber rechnete es damit, daß es ihm dort im Gegensatz zu den Beratungen in der US-Zone nicht gelingen würde, seinen Standpunkt geltend zu machen. So befürchtete es einen alliierten Kompromiß, der auf Kosten der jüdischen Interessen gehen würde. Auch ein weiterer Aspekt bereitete ihm Sorgen: Es hatte erfahren, daß bei OMGUS Bestrebungen bestanden, die 60-tägige Frist auch zu erneuten Verhandlungen mit den Deutschen zu nutzen. Von derartigen Gesprächen erwarteten die jüdischen Organisationen eine Abschwächung des letzten LänderratsEntwurfs durch ein Entgegenkommen an die Deutschen, das diesen die Zustimmung ermöglichen sollte.

So sahen sich die jüdischen Organisationen nun zwischen der Skylla eines verwässerten mehrzonalen Gesetzes, in dem auf die Interessen der Juden als der schwächsten Partei keine Rücksicht genommen würde, und der Charybdis eines einzonalen, von den deutschen Interessen geprägten Gesetzes. Zusätzlich erschwert war die Lage durch Konflikte mit den deutschen Juden, da „sich die deutsche jüdische Führung in Deutschland anscheinend ängstlich um Gehorsam gegenüber den deutschen Behörden bemüht". Auch der Council for the Protection of the Rights and Interests of Jews from Germany in London, der unter Leitung Leo Baecks, dem ehemaligen Vorsitzenden der

133 Ebenda.

134 Clay an War Department, 8.4. 1947, IfZ-Archiv, MF 260, OMGUS, AGTS 62/1-4.

135 R. Heath (stellv. Political Advisor) an Secretary of State, 11.4. 1947, IfZ-Archiv, MF 260, OMGUS, POLAD 768/1.

136 Allied Control Authority (ACA), Finance Directorate, Propekty Control Committee, Draft of Restitution Law (Proposal by U.S. Member), DFIN/CB/P(47)11, 10.4. 1947, IfZ-Archiv, MF 260, OMGUS-ACA 2/ 122-1/14; Political Advisor an State Department, 29.4. 1947, IfZ-Archiv, MF 260, OMGUS, POLAD 768/1. 
Reichsvereinigung der Juden in Deutschland, stand, hatte sich "gegen das US-zonale Gesetz und zugunsten einer bi- oder trizonalen Regelung ausgesprochen “137. Ziel des Komitees war dagegen die schleunige unilaterale Verabschiedung des US-zonalen Entwurfes, woran sich Bemühungen anschließen sollten, diese Regelungen auch in den anderen Zonen durchzusetzen.

Das stärkste Druckmittel, das dem Komitee der fünf jüdischen Organisationen in dieser Situation verblieben war, bestand darin, General Clay auf seine bei den Gesprächen in New York im November 1946 abgegebenen Zusagen festzulegen. Davon wurde in den folgenden Monaten ausgiebig Gebrauch gemacht. Derart von seinem Jewish Advisor Rabbi Bernstein bedrängt, bat Clay um Verständnis dafür, daß es in der gegenwärtigen politischen Gesamtsituation zu riskant sei, das Gesetz entgegen den deutschen Wünschen per Erlaß zu verkünden. Er benötige eine Frist von 60 Tagen, um die Zustimmung aller vier Militärregierungen zu einem Rückerstattungsgesetz zu erlangen. Doch als Gegenleistung gab Clay Bernstein die ausdrückliche Versicherung, daß "falls er nicht in der Lage sei, ein überzeugendes Abkommen zu erreichen oder falls kein derartiges Abkommen am Ende dieser 60 Tage in Sicht sei, er bereit sei, unilateral vorzugehen ${ }^{\alpha 138}$. Den jüdischen Organisationen blieb angesichts der ausdrücklichen Billigung der vierzonalen Verhandlungen durch das State Department und dem starken inneren Widerstand bei OMGUS gegen ein unilaterales Militärgesetz gar nichts anderes übrig, als diesen Kompromiß zu akzeptieren.

Zu dem Zeitpunkt, als der US-Entwurf eines Rückerstattungsgesetzes im Kontrollrat eingebracht wurde, hatte man dort bereits seit einiger Zeit über diese Frage diskutiert. Dabei sind zwei Stränge zu unterscheiden: Erstens beriet das Property Control Committee seit Februar 1946 über die Verwendung des Eigentums, das infolge des Kontrollsratsgesetzes Nr. 2 sowie der Kontrollratsproklamation Nr. 2 gesperrt worden war. Darunter fielen das Vermögen der NSDAP und damit in Verbindung stehender Organisationen einschließlich der paramilitärischen und militärischen ${ }^{139}$. In diesem Zusammenhang war auch die Frage der Rückerstattung aufgetaucht, da ein Teil dieses gesperrten Vermögens aus beschlagnahmtem Eigentum der früheren Parteien, Gewerkschaften, Genossenschaften oder sonstigen demokratischen Organisationen bestand bzw. aus solchen Vermögenswerten, die Fürsorge- und Wohltätigkeitszwecken sowie religiösen oder humanitären Zielen gedient hatten.

Der Kontrollrat einigte sich darauf, diese Vermögenswerte an die früheren Eigentümer bzw. an Nachfolgeorganisationen, die den früheren Organisationen ähnlich waren, zurückzuerstatten. Dies betraf also vorrangig die Rückerstattung an Organisationen, die im Zuge der Auflösung oder Gleichschaltung ihr Eigentum verloren hatten, bis auf Ausnahmefälle aber nicht die Rückerstattung an Individuen ${ }^{140}$. Anders als es bei Rainer Hudemann anklingt, der kurz auf die Vorgeschichte dieser Direktive eingeht, war dies

137 Complications in Connection with the Enactment of the Restitution Law, 18.4. 1947 (Anm. 131).

138 American Jewish Committee, Bericht über Treffen der fünf jüdischen Organisationen mit Rabbi Bernstein, 21. 4. 1947, YIVO-Archiv, RG 347, AJC Records, GEN-10, Box 291.

139 Kontrollratsgesetz Nr. 2, Auflösung und Liquidation der Naziorganisationen, in: Amtsblatt des Kontrollrats in Deutschland, Nr. 1, 29. 10. 1945, S. 19-21; Kontrollrats-Proklamation Nr. 2, ebenda, S. 8-19.

140 ACA, Finance Directorate, Property Control Committee, „Disposition of Property Taken under Control According Control Council Law No. 2 and Proclamation No. 2“, DFIN/CB/P (46) 22, 2nd rev., 17. 7. 1946, IfZ-Archiv, MF 260, OMGUS-Bico, Dec. 11/13-1/16. 
keine Einigung quasi in letzter Minute ${ }^{141}$, sondern ein Grundsatz, der bereits ein Jahr vor Erlaß des Gesetzes feststand. Im September 1946 ging die Behandlung dieses Entwurfs vom Property Control Committee, das dem Finance Directorate zugeordnet war, auf das Legal Directorate über. Dort wurden im wesentlichen nur noch geringfügige rechtstechnische Änderungen vorgenommen ${ }^{142}$, aber erst am 29. April 1947 setzte schließlich der Kontrollrat den Entwurf als Direktive Nr. 50 in $\mathrm{Kraft}^{143}$.

Ein zweiter Entwicklungsstrang hängt schließlich direkt mit den seit Sommer 1946 in der amerikanischen Zone betriebenen Planungen für ein Gesetz zur Rückerstattung wiederauffindbaren Eigentums zusammen. Am 20. Juni 1946 reagierten die Briten im Finance Directorate auf die jüngst von den Amerikanern in ihrer Zone forcierten Planungen und regten eine gemeinsame Kontrollratsinitiative für diesen Bereich an. Dieser sollte demzufolge gemeinsame Prinzipien der Rückerstattung und Entschädigung für Opfer der nationalsozialistischen Verfolgung erarbeiten und sodann eine deutsche Kommission mit der Ausarbeitung und Durchführung dieser Grundsätze beauftragen. Ähnlich wie bei den amerikanischen Vorschlägen war auch hier zunächst an die Rückerstattung wiederauffindbaren Vermögens an Personen innerhalb Deutschlands und ihre Erben als Sofortmaßnahme gedacht. Langfristig sollte dies dann durch einen Plan „zur Rückerstattung einer begrenzten Kategorie von Gegenständen und zur Entschädigung an Personen innerhalb und außerhalb Deutschlands" ergänzt werden ${ }^{144}$.

Das Finance Directorate überwies auch dieses Papier an das Property Control Committee $^{145}$, wo nun wiederum monatelang über alliierte Grundsätze in der Frage der Rückerstattung für Verfolgte des Nationalsozialismus verhandelt wurde ${ }^{146}$. Dabei war das Komitee ausdrücklich angewiesen, die Entwicklung in den einzelnen Zonen zu berücksichtigen. Im Februar 1947 passierte ein Zwischenbericht des Ausschusses ohne Veränderungen das Finance Directorate ${ }^{147}$. Dies war zugleich der letzte Stand der alliierten Beratungen über die Rückerstattung, als auf amerikanischer Seite der Entschluß fiel, nunmehr die Anstrengungen, die bislang vorrangig in ihrer eigenen Zone betrieben worden waren, auf den Kontrollrat zu verlagern.

Am 10. April legte die US-Delegation ihren auf dem Länderrats-Entwurf basierenden Vorschlag im Property Control Committee des Kontrollrats vor. Kurz danach reichten auch die Franzosen einen Entwurf ein, der auf den in ihrer Zone geleisteten Vorarbeiten beruhte ${ }^{148}$. Mehrere Wochen lang diskutierten die alliierten Vertreter den amerikani-

141 Vgl. Rainer Hudemann, Anfänge der Wiedergutmachung. Französische Besatzungszone 1945-1950, in: Geschichte und Gesellschaft 13 (1987), S. 200 f.

142 Siehe zu den Verhandlungen im ACA-Legal Directorate IfZ-Archiv, MF 260, OMGUS-ACA 2/113-3/1, 2/ 113-1/10-14, 2/125-1/5-7, 2/125-2/2-7.

143 Direktive Nr. 50: Verfügung über Vermögenswerte, die den in der Kontrollratsproklamation Nr. 2 und im Kontrollratsgesetz Nr.2 aufgeführten Organisationen gehört haben, in: Amtsblatt des Kontrollrats in Deutschland, Nr. 15, 31.5 1947, S. 275-278.

144 ACA, Directorate of Finance, „Victims of Nazi Oppression (British proposal) ${ }^{\star}$, DFIN/P(46)89, 20. 6. 1946, IfZ-Archiv, MF 260, OMGUS-ACA 2/111-2/12-15.

145 ACA, Directorate of Finance, Minutes of the 35th Meeting, 9. 7. 1946, IfZ-Archiv, MF 260, OMGUS-ACA 2/111-1/7-12.

146 Die Protokolle des ACA-Property Control Committee sind leider nicht in der OMGUS-Verfilmung vorhanden.

147 ACA, Directorate of Finance, Minutes of 60th-63rd. Meetings, 10.-13.2. 1947, IfZ-Archiv, MF 260, OMGUS-ACA 2/111-1/7-12.

148 ACA, Finance Directorate, Property Control Committee, DFIN/CB/P(47)12, French Proposal, 22. 4. 1947, IfZ-Archiv, MF 260, OMGUS-ACA 2/122-1/14. 
schen Entwurf, wobei es zunächst so aussah, als würden sich die Briten diesem anschließen, während mit der französischen und der sowjetischen Delegation keine Einigung in Reichweite sei. Deshalb meldete OMGUS Ende Mai nach Washington, daß im Juni eine letzte Anstrengung im Finanz-Direktorium des Kontrollrats unternommen würde, die Zustimmung der Alliierten zu den amerikanischen Vorstellungen zu erlangen $^{149}$. Damit folgte man dem Wunsch der Briten, die abgelehnt hatten, ein gemeinsames Gesetz zusammen mit den Amerikanern zu erlassen, solange es sich nicht als unmöglich erwiesen habe, sich im Kontrollrat zu einigen.

Clay befand sich dadurch in einer Zwickmühle: Er wollte das Rückerstattungsgesetz unbedingt zusammen mit den Briten veröffentlichen, was auch aussichtsreich schien, mußte aber dazu erst den von ihm erwarteten negativen Ausgang der Kontrollratsverhandlungen abwarten. Zugleich hatte er sich aber gegenüber Rabbi Bernstein festgelegt, unilateral vorzugehen, falls die alliierten Verhandlungen nicht innerhalb von 60 Tagen zu einem Erfolg führen sollten. Da nun diese Frist ohne Resultat verstrichen war, bat er seine vorgesetzten Stellen in Washington, vor der Aufnahme der weiteren Verhandlungen einen erneuten Aufschub bei den amerikanischen jüdischen Organisationen zu erwirken, bis es ihm gelungen sei, wenigstens ein gemeinsames Gesetz für die britische und amerikanische Zone zu erreichen ${ }^{150}$.

Auch in Washington herrschte die Überzeugung vor, daß der Stand der bizonalen Vereinigung kein einseitiges Vorgehen erlaube ${ }^{151}$. So begannen im Juni wiederum mehrmonatige Verhandlungen im Finanz-Direktorium des Kontrollrates, die einen 48 Paragraphen umfassenden Entwurf des Property Control Committee zum Gegenstand hatten, der auf dem amerikanischen Vorschlag basierte. Angesichts dieses Umfanges hatte sich das Finanz-Direktorium eine Zusammenfassung der strittigen Punkte erbe$\operatorname{ten}^{152}$. Über die darin genannten neun offen gebliebenen Fragen beriet es anschließend mehrere Monate lang. Bis Mitte Juli war es gelungen, eine ganze Reihe von Streitpunkten auszuräumen, so daß OMGUS nach Washington meldete, bei dem Versuch, eine vierseitige Einigung zu erzielen, seien größere Fortschritte erzielt worden, als man für möglich gehalten hätte ${ }^{153}$. Als einzige ungelöste Frage von Gewicht erschien zu diesem Zeitpunkt nur noch die Verwendung des erbenlosen Eigentums ${ }^{154}$. Der amerikanische Vorschlag, diese Werte einer jüdischen Nachfolgeorganisation zu überlassen, stieß bei den drei anderen Alliierten auf massive Ablehnung.

Hier wurden die unterschiedlichen gesellschaftspolitischen Konzeptionen besonders deutlich: Die Sowjetunion wollte das erbenlose Eigentum den deutschen Ländern überlassen, die damit Hilfsmaßnahmen zugunsten aller Verfolgten auf ihrem Territorium finanzieren sollten. Dagegen argumentierten die westlichen Alliierten, gegenwärtig bestünde noch keine ausreichende Gewähr dafür, daß die deutschen Länder diese Mittel

149 Keating (OMGUS) an Adjudant General War Department for War Department Special Services Civil Affairs Division, 26.5. 1947, USNA, RG 165, WDCAD, Box 356.

150 Clay an Adjudant General War Department to War Department Civil Administration Division, 16.6. 1947, IfZ-Archiv, MF 260, OMGUS-COS 3/177-2/2.

151 Memorandum v. J.J. Gorman (War Department), ca. 7.7. 1947, USNA, RG 165, War Dept., General and Special Staff, Box 356.

152 Verbatim Notes on the 76th Meeting of the Finance Directorate, 27.6. 1947, IfZ-Archiv, MF 260, OMGUSACA 17/8212/5.

153 Clay an Adjudant General War Department for War Department Special Services Civil Affairs Division Economics, 13. 7. 1947, USNA, RG 165, WDCAD, Box 356.

154 Keating an Adjudant General War Department for War Department Special Services Civil Affairs Division, 21.7. 1947, USNA, RG 165, Box 356. 
wirklich im Sinne der Verfolgten verwenden würden ${ }^{155}$. Der Delegierte der UdSSR, W.K. Sitnin, bestand dagegen darauf, daß im sowjetischen Machtbereich alle Erscheinungen des Nationalsozialismus vollkommen beseitigt seien und deshalb den Deutschen dort volles Vertrauen zu schenken sei. Sitnin störte sich auch daran, daß es sich bei den von den USA vorgeschlagenen Nachfolgeorganisationen um amerikanische Organisationen handeln sollte, die daran interessiert sein würden, das von ihnen geerbte Vermögen außerhalb Deutschlands zu verwenden. Dies sah er im ausdrücklichen Gegensatz zum Interesse der UdSSR an der Fähigkeit Deutschlands, Reparationen zu zahlen. Vom sowjetischen Standpunkt aus hing die Frage der Entschädigung und Rückerstattung unlösbar mit dem Problem der Reparationen zusammen ${ }^{156}$, von daher erklären sich viele Differenzen insbesondere zum amerikanischen Standpunkt.

Das berührte sich auch mit der nachdrücklichen sowjetischen Forderung, nur Verfolgte zu entschädigen, die sich innerhalb Deutschlands befänden; die Entschädigung von Verfolgten im Ausland sollte erst später im Zusammenhang aller deutschen Auslandsverbindlichkeiten diskutiert werden ${ }^{157}$. In diesem Punkt einigten sich aber die anderen Delegierten darauf, daß es ungerecht sei, deutsche Verfolgte prinzipiell auszuschließen, nur weil sie nicht mehr in Deutschland lebten. Über die praktischen Konsequenzen bestand allerdings noch Unklarheit, verboten die alliierten Bestimmungen doch jeglichen deutschen Kapitaltransfer ins Ausland ${ }^{158}$.

Bezüglich des erbenlosen Eigentums wünschte Frankreich wiederum eine nichtkonfessionelle Nachfolgeorganisation, die unterschiedslos allen Verfolgten des Nationalsozialismus helfen sollte. Der französische Delegierte Paul Leroy-Beaulieu bezeichnete den Vorschlag, jüdische Nachfolgeorganisationen zu gründen, als eine Art Neuauflage der Nürnberger Rassengesetzgebung: „It seems to me that if we create certain organizations like Catholic organizations, or Jewish organizations, we are doing the same thing as Hitler did." 159 Leroy-Beaulieu monierte hier einen inneren Widerspruch, da die Alliierten entgegen ihren eigentlichen Absichten die Strukturen des nationalsozialistischen Verfolgungssystems tradierten: „Once and for all the Germans must understand that there is only one category of German. “ 160

Die Briten hatten ursprünglich die amerikanische Position akzeptiert, bevor sie dann auf die französische Linie umschwenkten ${ }^{161}$. Der Grund dafür lag in den verschärften Spannungen im Nahen Osten. So befürchteten die Briten, daß eine jüdische Nachfolgeorganisation den jüdischen Aufstand in Palästina gegen das britische Mandat finanziell unterstützen würde. Den unmittelbaren Auslöser dieser Schwierigkeiten bildeten die Vorgänge um das jüdische Flüchtlingsschiff „Exodus“, die im Juli 1947 die Weltöffent-

155 Verbatim Notes of the Continuation of the 77th Meeting of the Directorate of Finance, 15.7. 1947, IfZArchiv, MF 260, OMGUS-ACA 17/8212/5.

156 Siehe dazu ein Gespräch Col. Bernard Bernsteins (American Jewish Conference) mit dem sowjetischen Kontrollratsdelegierten Sitnin, in: Memorandum from Col. Bernstein Concerning Discussions in Germany on Problems of Restitution and Indemnification (Anm.111).

157 Ebenda; ACA, Finance Directorate, Minutes of the 77th Meeting of the Directorate, 11., 15. u. 22. 7. 1947, IfZ-Archiv, MF 260, OMGUS-ACA 2/111-1/7-12.

158 Siehe dazu etwa Verbatim Notes of the Continuation of the 77 th Meeting of the Directorate of Finance, 15. 7. 1947, IfZ-Archiv, MF 260, OMGUS-ACA 17/8212/5.

159 Ebenda. Vgl. auch Hudemann, Anfänge der Wiedergutmachung, S. 202.

160 Verbatim Minutes of the Second Session of the 81st Meeting, 9.9. 1947, IfZ-Archiv, MF 260, OMGUS 17/ $8212 / 5$.

161 Keating an War Department, 21.7. 1947, USNA, WDCAD, RG 165, Box 356. 
lichkeit aufwühlten ${ }^{162}$. Dadurch rückte auch die Einigung mit den Briten, die der amerikanischen Militärregierung schon zum Greifen nah erschienen war, zeitweilig wieder ins Ungewisse ${ }^{163}$.

Da die Frage der Verwendung des erbenlosen Eigentums ein solches Gewicht für die weiteren Verhandlungen bekommen hatte, Clay in diesem Punkt aber gegenüber den amerikanischen jüdischen Organisationen im Wort stand, traf General Hilldring, der nach seiner Tätigkeit als Direktor der Civil Administration Division des War Departments nunmehr Staatssekretär im State Department war, Anfang August mit deren Repräsentanten zusammen. Er beabsichtigte, die jüdischen Organisationen zu einem Kompromiß zu bewegen, der eine mehrzonale Lösung ermöglich sollte bzw. Clay von seinem Versprechen zu entbinden, im Falle des Scheiterns der alliierten Verhandlungen unilateral vorzugehen ${ }^{164}$. Nolens volens willigten diese zwar ein, weitere Bemühungen um eine alliierte Einigung abzuwarten, unterstrichen aber erneut, daß sie einen baldigen unilateralen Erlaß des US-zonalen Entwurfes wünschten, worauf Anstrengungen folgen sollten, Großbritannien und Frankreich, und vielleicht sogar die Sowjetunion, zur Übernahme dieser Regelung zu bewegen. Umgekehrt hatte die britische Botschaft in Washington am 22. Juli energisch gegen ein mögliches einzonales Rückerstattungsgesetz in der US-Zone protestiert und damit auf entsprechende Drohungen von amerikanischer Seite reagiert. Das State Department kündigten den Briten daraufhin einen amerikanischen Alleingang für den Fall an, daß bis zum 1. Oktober keine mehrzonale Lösung erreicht sei ${ }^{165}$.

Tatsächlich schwenkten die Briten in der Frage der Nachfolgeorganisationen wieder auf eine moderatere Linie ein, und ebenso wie die Franzosen zeigten sie sich bereit, den von den Amerikanern vorgeschlagenen Kompromiß zu akzeptieren, daß jedem Zonenkommandanten die Ernennung einer Nachfolgeorganisation seiner Wahl überlassen bleiben solle. Frankreich und Großbritannien sollten auf diese Weise in ihren Zonen nichtkonfessionelle Nachfolgeorganisationen bestimmen können ${ }^{166}$. Die sowjetische Delegation dagegen hielt in dieser Frage unverrückbar an ihrem ablehnenden Standpunkt fest.

Bis Ende September hatte sich im Finanz-Direktorium herauskristallisiert, daß es neben der Frage der Verwendung des erbenlosen Eigentums nur noch zwei Punkte gab, über die sich keine Einigung herstellen ließ. Der erste betraf die Frage der Verteilung der Gewinne, die die im Zuge der nationalsozialistischen Verfolgung entzogenen Betriebe während des Krieges abgeworfen hatten. Die amerikanische Delegation stand hier mit ihrem Vorschlag alleine, daß auch die entgangenen Gewinne den ursprünglichen Eigentümern zurückerstattet werden sollten. Alle anderen Delegationen störten sich hingegen daran, daß auf diese Weise ehemalige Verfolgte von Kriegsgewinnen profitieren könnten. Sie schlugen deshalb vor, die Gewinne aus dieser Zeit in einen Fonds einzubringen, aus dem eine größere Zahl von Verfolgten Zuwendungen erhalten könnte ${ }^{167}$.

\footnotetext{
162 Vgl. David A. Charters, The British Army and Jewish Insurgency in Palestine, 1945-1947, London 1989, S. $70 \mathrm{ff}$.

163 Clay an War Department, 30.7. 1947, USNA, WDCAD, RG 165, Box 356.

164 Memorandum v. Gorman (War Department), 8. 8. 1947, USNA, WDCAD, RG 165, Box 356.

165 War Department an OMGUS, 24. 8. 1947, IfZ-Archiv, MF 260, OMGUS-Co ORG. PROGR. 5/359-3/8.

166 George P. Hays an War Department, 13.9. 1947, IfZ-Archiv, MF 260, OMGUS, POLAD 768/2.

167 Eine Zusammenfassung der Argumente findet sich in ACA, Directorate of Finance, Restitution to Victims of
} 
Unterschiedliche Auffassungen herrschten auch über den Umfang der Anfechtungsmöglichkeit von Verkäufen seitens rassisch verfolgter Personen. Hier war die Sowjetunion mit ihrer Position isoliert. Die amerikanischen, britischen und französischen Delegierten stimmten darin überein, daß alle Veräußerungen rückgängig gemacht werden können sollten, sofern sie nicht auch ohne den Nationalsozialismus stattgefunden hätten bzw. der Käufer die Interessen des Verkäufers berücksichtigt hatte. Dabei stimmten die westlichen Alliierten auch darin überein, daß der Zwang in den späteren Jahren größer gewesen sei als zu Beginn der nationalsozialistischen Herrschaft. Darüber, von welchem Zeitpunkt an ein allgemeiner Zwang geherrscht habe, gingen die Auffassungen aber auseinander: bereits von 1935 an mit den Nürnberger Gesetzen, wie der US-Delegierte vertrat, oder erst seit 1938, mit den Gesetzen zur Ausschaltung der Juden aus dem Wirtschaftsleben, wie die britischen und französischen Delegierten vorschlugen? Der sowjetische Delegierte lehnte dagegen generell eine Rückerstattung $a b$, sofern ein angemessener Preis bezahlt worden war ${ }^{168}$. Die Schwelle einer planmäßigen wirtschaftlichen Diskriminierung sah er dabei im Jahre 1938, vorher hätten alle wirtschaftlichen Transaktionen einen freiwilligen Charakter besessen ${ }^{169}$. Da nach sowjetischer Auffassung zumindest in ihrer Besatzungszone alle, die sich unrechtmäßig an jüdischem Eigentum bereichert hatten, im Gefängnis säßen und nun die deutschen Antifaschisten die Macht in den Händen hielten, sei es falsch, das deutsche Volk kollektiv zu bestrafen ${ }^{170}$. So folgte aus der sowjetischen Antifaschismuskonzeption eine recht eingeschränkte Definition der Rückerstattung. Demgegenüber hatte insbesondere die amerikanische Auffassung des Privateigentums eine sehr weitgehende Regelung zur Konsequenz.

Als das Kompromißpotential des Finanz-Direktoriums schließlich erschöpft war, faßten die alliierten Vertreter die verbliebenen drei strittigen Punkte in einem Brief zusammen, um sie dem Koordinierungs-Ausschuß des Kontrollrats zur Entscheidung vorzulegen ${ }^{171}$. Doch als die Delegierten in der Sitzung vom 12. November die Weiterleitung des Schreibens offiziell beschlossen, teilte der US-Delegierte Ball seinen Kollegen förmlich mit, daß die amerikanische Militärregierung vor zwei Tagen in ihrem Bereich ein unilaterales Rückerstattungsgesetz in Kraft gesetzt habe. Der französische Delegierte Davost setzte hinzu, daß am selben Tag auch in der französischen Zone ein entsprechender Schritt erfolgt sei. Namens der sowjetischen Delegation protestierte Sitnin heftig dagegen, daß diese Maßnahme bereits vor der Beratung durch den Koordinierungs-Ausschuß erfolgt sei ${ }^{172}$. Dennoch wurde dort im Januar 1948 die Vorlage des Finanz-Direktoriums beraten. Allerdings beharrten alle Seiten auf den zuletzt eingenommenen Positionen, und so wurde der Entwurf nach gegenseitigen Schuldzuweisun-

Nazi Persecution, Draft Submission to the Coordinating Committee, DFIN/P(47)214/1, 26.9. 1947, IfZArchiv, MF 260, OMGUS-ACA 2/111-1/7-12.

168 Ebenda.

169 Verbatim Minutes of the 81st Meeting of the Finance Directorate, 15. 9. 1947, IfZ-Archiv, MF 260, OMGUS 17/8212/5.

170 Verbatim Notes of the Continuation of the 77th Meeting of the Directorate of Finance, 15.7. 1947, IfZArchiv, MF 260, OMGUS-ACA 17/8212/5.

171 Verbatim Minutes of the 87th Meeting of the Finance Directorate, 24.10. 1947, IfZ-Archiv, MF 260, OMGUS 17/8212/5; Draft Submission to the Coordinating Committee (Anm. 167).

172 ACA, Directorate of Finance, Minutes of the 89th Meeting, 12.11. 1947, IfZ-Archiv, MF 260, OMGUSACA 2/111-1/7-12. 
gen schließlich endgültig von der Tagesordnung genommen ${ }^{173}$. Was war auf amerikanischer Seite geschehen? Weshalb wurde dort der Ausgang der alliierten Verhandlungen nicht abgewartet und statt dessen nun doch ein auf dịe eigene Zone beschränktes Gesetz erlassen?

\section{Das amerikanische Militärregierungsgesetz $\mathrm{Nr} .59$}

Parallel zu den Gesprächen auf Kontrollratsebene verhandelte die amerikanische Militärregierung auch bilateral mit den Briten. Eine Einigung mit ihnen schien vordringlich und auch machbar. Doch obwohl die sachlichen Differenzen zuletzt mininimal waren, zögerten die Briten eine endgültige Zusage immer wieder heraus. Dies wurde auf amerikanischer wie auch auf jüdischer Seite vermutlich zu Recht als Hinhaltetaktik empfunden; anscheinend wollten die Briten dabei die Klärung der Verhältnisse in Palästina bis zu einer endgültigen Entscheidung abwarten ${ }^{174}$. Schließlich hatte das State Department den Briten, wie oben berichtet, eine letzte Frist eingeräumt: Sollten sie sich bis zum 1. Oktober nicht zum Mitmachen entschlossen haben, würden die Vereinigten Staaten in ihrer Zone alleine handeln.

Clay machte seiner Umgebung deutlich, daß ein unilaterales Rückerstattungsgesetz seiner persönlichen Überzeugung vollkommen zuwiderlaufe. Es sei unfair, „seinen“ siebzehn Millionen Deutschen ein Gesetz aufzuerlegen, daß für die anderen fünfzig Millionen zu hart sei, und die deutschen Gerichte würden es deshalb auch nicht loyal durchsetzen. Auch wären die Briten ungehalten über ein einseitiges Vorgehen. Sorge bereitete Clay zudem, daß die öffentliche Meinung eher den Briten als den Amerikanern recht geben würde. Dennoch war er bereit, ein einzonales Gesetz zu erlassen, wenn bis zum ersten Oktober keine Einigung mit den Briten erreicht sei, da er zu seinem Versprechen stehen wollte ${ }^{175}$. Schließlich machte Clay die Entscheidung von einer letzten Besprechung mit den Briten abhängig, die für den 29. September angesetzt war.

Doch auch diese letzte Frist verstrich ohne Resultat. Und als die Briten statt dessen am 2. Oktober mitteilten, daß es mehrere Wochen dauern würde, bis sie ihre endgültige Zustimmung geben könnten, beschritt Clay schließlich schweren Herzens den Weg zu einer unilateralen Lösung ${ }^{176}$. Walter Schwarz irrt, wenn er behauptet, daß Clay „unbeirrt auf die unilaterale Lösung zu(steuerte) ${ }^{\star 177}$. Bereits am Tag darauf ließ OMGUS bei den Ministerpräsidenten der US-Zone anfragen, ob sie nunmehr bereit seien, in ihren Ländern ein Gesetz zu erlassen, das auf dem Länderrats-Entwurf basieren sollte, in den einige Änderungen eingearbeitet waren, die aus den alliierten Verhandlungen resultierten. Andernfalls würde das Rückerstattungsgesetz durch die Militärregierung verkündet werden ${ }^{178}$. Ausdrückliches Ziel Clays zu diesem Zeitpunkt war, das Rückerstattungsgesetz in einer Form durchzusetzen, die die mit den Briten bzw. den anderen

173 ACA, Coordinating Committee, Minutes of the 147th Meeting, 15. u. 19.1. 1948, IfZ-Archiv, MF 260, OMGUS-ACA 2/108-1/1-18.

174 Memorandum of Telephone Conversation between Eli Rock and Irwin Mason, ca. 3. 10. 1947, YIVOArchiv, RG 347, AJC Records, GEN-10, Box 293.

175 Louis E. Levinthal an Col. Bernstein, 4. 10. 1947, ebenda.

176 Hays an War Department, 7. 10. 1947, IfZ-Archiv, MF 260, OMGUS, POLAD 768/2.

177 Schwarz, Wie kam die Rückerstattung zustande, S. 808.

178 Clay an RGCO Stuttgart, 3.10. 1947, IfZ-Archiv, MF 260, OMGUS, AG 1947/188/1; Charles D. Winning (RGCO) an Rossmann, 3. 10. 1947, BayMJ, 1101a, H. 3. 
Alliierten erreichten Gemeinsamkeiten soweit als möglich berücksichtigte. Auch wenn OMGUS nun aufgrund der gegenüber den amerikanischen jüdischen Organisationen abgegebenen Verpflichtungen einen Alleingang unternahm, sollten auf keinen Fall die Chancen für eine spätere ähnliche Regelung insbesondere in der britischen Besatzungszone gefährdet werden ${ }^{179}$. Diese Ausgangssituation reduzierte in der folgenden Schlußphase der Verhandlungen den Spielraum für weitere Änderungen des Entwurfes auf ein Minimum.

Das bekamen nun auch die amerikanischen jüdischen Organisationen zu spüren. Am 5. Oktober sandte der Internal Restitution Advisor Mason einen Alarmruf nach New York. Erschrocken berichtete er über ein Gespräch mit Rockwell und Ball aus der OMGUS-Finance-Division, bei dem sie ihm in harten Worten ihre Ablehnung des Prinzips der jüdischen Nachfolgeorganisationen erklärt hatten. Ball, der eben diesen Grundsatz in seiner Eigenschaft als amerikanischer Delegierter im Finanz-Direktorium des Kontrollrats hartnäckig verteidigen mußte, erklärte gegenüber Mason, daß er schon immer gegen diese Idee gewesen sei. Er bezeichnete dies als einen politischen Fehler der jüdischen Organisationen, denn gegenüber der Weltöffentlichkeit hätte es ihnen besser zu Gesicht gestanden, wenn sie bereit gewesen wären, diese Werte in einen nichtkonfessionellen Fonds zugunsten aller Opfer einzubringen. Überdies hatten diverse Äußerungen jüdischer Funktionäre bei Ball die Überzeugung verfestigt, daß die Nachfolgeorganisationen alles Mögliche unternehmen würden, um Werte ins Ausland zu transferieren sowie in der ganzen Welt Ansprüche von Flüchtlingen aufzukaufen. Ball kündigte an, alles in seiner Macht stehende zu tun, um sie an der Ausführung eines solchen Programmes zu hindern ${ }^{180}$.

Tatsächlich war Ball bei den Verhandlungen mit den Alliierten wiederholt gezwungen, gegen die in seiner eigenen Abteilung herrschenden Auffassungen zu argumentieren. Intern stimmten die Fachleute der OMGUS-Finance Division gerade in den zentralen Streitpunkten oft mehr mit der Position der anderen Alliierten überein als mit den von Ball vertretenen offiziellen amerikanischen Standpunkten. Dort war man der Ansicht, daß die Chance einer mehrzonalen Einigung aus zweifelhaften Gründen vergeben worden sei: „To sacrifice the chance of obtaining quadripartite agreement mainly because of our position on heirless property seems very ridiculous ... Strange as it may seem, our position on the question of heirless properties as well as other questions was never too clearly defined in any cables received from Washington and it would seem as though these were commitments of a purely personal type. " 181 Indirekt und häufig auch direkt wurde Clay aus seiner eigenen Administration vorgeworfen, daß er durch persönliche Absprachen mit den jüdischen Organisationen den Spielraum für eine Übereinkunft mit den anderen Alliierten entscheidend verringert habe ${ }^{182}$.

Die Befürchtungen der amerikanischen jüdischen Organisationen waren also nicht aus der Luft gegriffen. Sie versuchten deshalb, die bedrohliche Lage durch eine Intervention auf höchster Ebene zu entschärfen. Dazu arrangierten sie für den 16. Oktober erneut ein Treffen mit Clay, der sich gerade einige Tage in Washington aufhielt. Sie

179 Hays an War Department, 7.10. 1947 (Anm. 176).

180 Mason an Bernstein, 5. 10. 1947, YIVO-Archiv, RG 347, AJC Records, GEN-10, Box 293.

181 Memorandum der OMGUS-Finance Division vom 12.9. 1947, IfZ-Archiv, MF 260, OMGUS, POLAD $768 / 2$.

182 Siehe dazu etwa W.C. Haraldson an James W. Riddleberger u. Chase, 10.2. 1948, IfZ-Archiv, MF 260, OMGUS, POLAD 793/46. 
erhofften sich davon eine ähnliche Wirkung wie von dem Gespräch ein Jahr zuvor, bei dem Clay die Zusagen abgegeben hatte, die ihm jetzt so zusetzten. Drei Dinge wünschten die jüdischen Organisationen hier zu erreichen: Erstens wollten sie die durch die amerikanischen Verhandlungen mit den Alliierten erreichten Veränderungen so weit als möglich wieder aus dem US-Entwurf tilgen; allein der letzte Länderrats-Entwurf erschien ihnen als angemessen. Zweitens wünschten sie zur Absicherung gegen Sabotage durch deutsche Stellen bei der Durchführung des Gesetzes den Erlaß von Durchführungs-Bestimmungen seitens der Militärregierung. Und drittens forderten sie die endgültige Anerkennung der von den jüdischen Organisationen gegründeten Jewish Restitution Commission als rechtmäßige Nachfolgeorganisation für erbenloses jüdisches Vermögen ${ }^{183}$.

Diesmal blieb Clay hart. Er akzeptierte bei dem Gespräch zwar prinzipiell den Gedanken einer amerikanischen Durchführungsverordnung, wobei er die Anerkennung der Jewish Restitution Commission aber noch von der Zustimmung Washingtons abhängig machte. Im übrigen lehnte Clay aber jede weitere Zurücknahme von Änderungen, die auf die Verhandlungen mit den Alliierten zurückgingen, ab. Wie die jüdischen Organisationen bereits erwartet hatten, verwies Clay hierbei auf die Dringlichkeit einer nachfolgenden Einigung mit den Briten, weshalb der erreichte Konsens nicht gefährdet werden dürfe ${ }^{184}$. Doch auch der Spielraum für erneute Verhandlungen mit dem Stuttgarter Länderrat war sowohl sachlich als auch zeitlich äußerst beschränkt. Nach den mehrmonatigen Verzögerungen war Clay nun wild entschlossen, das Rückerstattungsgesetz schleunigst durchzusetzen und dabei die Ergebnisse der alliierten Verhandlungen unangetastet zu lassen. Als die Ministerpräsidenten Ehard (Bayern), Maier (Württemberg-Baden), Stock (Großhessen) sowie der Bremer Senatspräsident Kaisen am 7. Oktober über die von OMGUS formulierte Alternative - deutsches Gesetz oder Militärregierungsgesetz - berieten, sahen sie sich nicht in der Lage, einen Entschluß zu treffen. Zwar herrschte die Stimmung vor, daß dieses Gesetz nun unbedingt nötig sei, aber zugleich wollten die Ministerpräsidenten für ein Gesetz in der vorliegenden Form nicht die politische Verantwortung übernehmen. Hauptkritikpunkt war weiterhin der nur einzonale Geltungsbereich. So beschlossen sie schließlich, den Gesetzentwurf sowie die neuen von amerikanischer Seite vorgelegten Änderungen dem zuständigen Länderrats-Ausschuß „zur Prüfung vorzulegen, die Angelegenheit in den Kabinetten zu beraten und nach Anhörung des Parlamentarischen Rates auf der nächsten Länderratstagung die endgültige Stellungnahme abzugeben “185. Das hieß also letztlich, daß die Ministerpräsidenten versuchten, die politische Verantwortung abzuwälzen. Die amerikanische Militärregierung fand Verständnis für dieses Vorgehen, schloß aber daraus, daß der angestrebte Zeitplan auf diese Weise nicht eingehalten werden könne ${ }^{186}$. Clays Stellvertreter, General Hays, telegraphierte deshalb seinem Chef, der sich noch in Washington befand, es sei unwahrscheinlich, daß der Länderrat jemals einem unilateralen Gesetz zustimmen würde. Deshalb würde gegenwärtig die Heraus-

${ }^{183}$ Main Topics of the Meeting with General Clay on October 16, 1947, YIVO-Archiv, RG 347, AJC Records, GEN-10, Box 276.

184 Eugene Hevesi an Joel Wolfsohn, 23.10. 1947, YIVO-Archiv, RG 347, AJC Records, GEN-10, Box 291; Clay an Chief of Staff, US Army, 29. 10. 1947, IfZ-Archiv, MF 260, OMGUS, AG 47/188/1.

185 Auszug aus dem Protokoll der Internen Länderrats-Sitzung am 7. 10. 1947, BayHStA, MA 130348.

186 RGCO an Legal Division, OMGUS, 11. 10. 1947, IfZ-Archiv, MF 260, OMGUS, AGTS 62/1-4. 
gabe eines Militärregierungsgesetzes vorbereitet ${ }^{187}$. Auf amerikanischer Seite bestand jetzt keine Neigung mehr, an dieser deutschen Haltung noch etwas zu ändern.

Am 29. Oktober meldete der mittlerweile nach Berlin zurückgekehrte Clay nach Washington, er beabsichtige nun, den Entwurf als Militärregierungsgesetz Nr. 59 am 10. November $z u$ erlassen ${ }^{188}$. Vor dem Hintergrund dieses Beschlusses wurde dem Länderrat am 3. November ein letztes Ultimatum gestellt. OMGUS teilte mit, man könne noch über einige Veränderungen diskutieren, falls der Länderrat bereit sei, doch noch ein deutsches Gesetz zu verkünden. Nachdem der Parlamentarische Rat beschlossen hatte, daß aus außenpolitischen Gründen versucht werden sollte, dem Entwurf noch eine Fassung zu geben, in der er als deutsches Gesetz erlassen werden könnte, erfolgte tatsächlich noch einmal eine letzte Anstrengung des Länderrats, zu einem derartigen Kompromiß zu gelangen ${ }^{189}$. Unter großem Zeitdruck verfaßte der Sachverständigenausschuß für das Rückerstattungsgesetz am 5. und 6. November einen neuen Entwurf, in den diejenigen Änderungen eingearbeitet waren, die die Annahme als deutsches Gesetz ermöglichen würden ${ }^{190}$. Zwei Tage später, am 8 . November, traf die Antwort der amerikanischen Militärregierung ein, die den Großteil der geforderten Änderungen ablehnte. Insbesondere vier Hauptpunkte des deutschen Entwurfes erklärte OMGUS als unannehmbar: Erstens sah dieser vor, daß die Nachfolgeorganisationen für erbenloses jüdisches Vermögen unter deutscher Staatsaufsicht stehen und ihren Sitz in Deutschland haben sollten. Zweitens enthielt der deutsche Entwurf eine Härteklausel für Arisierungen vor 1938. Drittens sollte ein loyaler späterer Erwerber eines arisierten Objektes nicht unter allen Umständen einem Hehler gleichbehandelt werden. Und viertens wollte der deutsche Entwurf einen loyalen Erwerber nicht mit der Haftung dafür belasten, wenn der von ihm seinerzeits bezahlte Kaufpreis von der Gestapo beschlagnahmt worden war oder das Objekt durch Kriegseinwirkung an Wert verloren hatte ${ }^{191}$. Ein Kompromiß in diesen Punkten durch die amerikanische Militärregierung hätte das ganze komplizierte Gerüst an Abmachungen und Verhandlungsergebnissen mit den jüdischen Organisationen wie auch den Briten und den anderen Alliierten zum Einsturz gebracht. Ein weiteres Nachgeben war deshalb ausgeschlossen.

Als einzige Möglichkeit, den Erlaß in Form eines Militärregierungsgesetzes noch zu verhindern, wurde den Ministerpräsidenten eingeräumt, daß sie auf der noch am selbigen Tag stattfindenden Länderratssitzung beschließen könnten, binnen einer Woche ein deutsches Rückerstattungsgesetz zu den amerikanischen Bedingungen zu verkünden. Darauf ließ sich der Länderrat jedoch nicht ein: Die Ministerpräsidenten hielten an dem überarbeiteten Entwurf des deutschen Sachverständigenausschusses fest ${ }^{192}$, der jedoch zwei Stunden später von der Militärregierung endgültig abgelehnt wurde ${ }^{193}$. Statt dessen veröffentlichte diese zwei Tage später, am 10. November 1947, nach an-

187 Hays an Clay, 14. 10. 1947, IfZ-Archiv, MF 260, OMGUS, AGTS 62/1-4.

188 Clay an Chief of Staff, US Army, IfZ-Archiv, MF 260, OMGUS, AG 47/188/1.

189 Protokoll der Internen Länderrats-Sitzung am 3./4.11. 1947, BayMJ, 1101 a, H. 3.

190 Niederschrift über die Sitzung des Sachverständigenausschusses für das Rückerstattungsgesetz am 5./6.11. 1947, BayMJ, 1101a, H. 3.

191 Antwort der Militärregierung, übergeben in Stuttgart, 8.11. 1947, BayMJ, 1101a, H. 3.; Darstellung Otto Küsters auf der Pressekonferenz am 11. 11. 1947, BayMJ, 1101a, H. 4.

192 Protokoll der Internen Länderratssitzung, 8.11. 1947, BA, Z 1, Bd. 1293.

193 Darstellung Küsters auf der Pressekonferenz am 11.11. 1947 (Anm. 191). Vgl. auch Schwarz, Rückerstattung nach den Gesetzen der Alliierten Mächte, S. $53 \mathrm{f}$. 
derthalbjährigem Tauziehen das Rückerstattungsgesetz zu ihren Bedingungen als Militärregierungsgesetz Nr. $59^{194}$.

\section{Reaktionen in Deutschland und USA}

Auf deutscher Seite herrschte teils Erleichterung, teils Verbitterung darüber, daß die Rückerstattung schließlich doch in Form eines Militärregierungsgesetzes geregelt worden war. Ministerpräsident Maier teilte seinem Kabinett mit: „Den beteiligten Kreisen ist damit mehr gedient als mit einem deutschen Gesetz. ${ }^{195} \mathrm{Zu}$ den Enttäuschten gehörte dagegen insbesondere Otto Küster, der auf württemberg-badischer Seite an der Ausarbeitung des Entwurfes teilgenommen hatte. Auf einer Pressekonferenz am Tage nach der Veröffentlichung des Rückerstattungsgesetzes der amerikanischen Besatzungszone klagte er: „Es ist tief bedauerlich, daß die amerikanische Militärregierung um relativ geringer materieller Differenzen willen den deutschen Regierungen die Chance aus der Hand geschlagen hat, die Rückerstattung im Einklang mit der deutschen Rechtsüberzeugung auf Grund eines selbst gegebenen Gesetzes durchzuführen." 196

Walter Schwarz urteilte dazu später: „Hätten die Amerikaner den deutschen Ländern freie Hand gegeben, dann wäre ebenfalls ein REG entstanden, das vielleicht in wenigen Punkten weniger hart gewesen wäre als das USREG. Hätte man länger zusammengesessen, würde man sich gewiß geeinigt haben. ${ }^{197}$ Dies geht jedoch an der Sache vorbei. Tatsächlich hatte keine Chance für eine nochmalige Änderung des Entwurfs bestanden. Wie gezeigt existierte tatsächlich weder ein zeitlicher noch ein sachlicher Spielraum für weitere Verhandlungen. Daß sich der Länderrat im Verlaufe der Verhandlungen zu einer Rückerstattung in einem Ausmaß bereit gefunden hatte, das weit über das hinausging, was von deutscher Seite ursprünglich selbst entwickelt worden war, ist nicht zu übersehen. Doch war auch dies das Ergebnis ständiger Interventionen der Militärregierung und der jüdischen Organisationen. Zwar schrieb Schwarz über die Verhandlungen im Länderrats-Auschuß, daß „sich bald ein echtes Teamwork zwischen Amerikanern und Deutschen“ ${ }^{198}$ entwickelt habe. Demgegenüber sprach ein Memorandum aus der OMGUS-Finance Division davon, daß im Verlaufe der Beratungen immer stärker die Legal Division den Ton bestimmt habe. Im Bezug auf den Entwurf vom Februar 1947 hieß es dort: „While theoretical this draft was supposed to reflect the suggestions of the Germans, it really contained what the representatives of the Legal Division told the Germans to write into it. ${ }^{199}$

Eine Schlüsselstellung kam dabei Clay selbst zu, der zwar nicht an den Details des Entwurfes beteiligt war, aber die Verantwortung für eine Reihe zentraler Entscheidungen trug. Damit hatte er sich auch gegen erhebliche Bedenken aus seiner eigenen Administration durchgesetzt. Clay rechnete fest damit, daß ihm die öffentliche Meinung der USA für den Erlaß eines unilateralen Rückerstattungsgesetzes schlechte Zensuren erteilen würde. Auch hier war der Grund, daß es eine Anzahl von Bestimmungen enthielt,

\footnotetext{
194 Militärregierungsgesetz Nr. 59 (USREG) (Anm. 100).

195 Niederschrift über die Sitzung des Staatsministeriums am 12.11. 1947, BadWürtHStA, EA 4/001, Bü. 57a.

196 Darstellung Küsters auf der Pressekonferenz am 11.11. 1947 (Anm. 191).

197 Schwarz, Wie kam die Rückerstattung zustande, S. 802.

198 Ebenda.

199 Memorandum der OMGUS-Finance Division, 12.9. 1947 (Anm. 181).
} 
die von den übrigen Alliierten und auch von einem Teil seiner eigenen Administration als unglücklich empfunden wurden. Er erwartete, daß die amerikanische öffentliche Meinung in den Streitpunkten den jüdischen Standpunkt ablehnen würde ${ }^{200}$. Dies verdroß Clay umso mehr, als er eigentlich gerne zu einer einvernehmlichen Lösung zumindest mit den Briten gekommen wäre. So war die Art und Weise, in der der amerikanische Militärgouverneur in den vorangegangenen Monaten seinen Kurs vertreten hatte, nicht ohne selbstquälerische Züge.

Die jüdischen Organisationen hatten diese Stimmungslage sorgenvoll beobachtet, befürchteten sie doch ständig, Clay könnte von seinen Versprechungen abrücken. Ende September hatte Levinthal nach New York telegraphiert, es sei unbedingt nötig, daß der Ankündigung eines unilateralen Rückerstattungsgesetzes „enthusiastisch zustimmende Reaktionen " 201 in den USA folgten. Derselben Auffassung war auch der Internal Restitution Advisor Mason, der hoffte, daß das Rückerstattungsgesetz in der US-Presse günstig beurteilt würde, damit General Clay „sich in der Angelegenheit wohlfühle, und auch um dazu beizutragen, daß sich bei ihm eine wohlwollende Einstellung" gegenüber den Vertretern der amerikanischen jüdischen Organisationen entwickle ${ }^{202}$.

Das Komitee der fünf jüdischen Organisationen übernahm daraufhin die Aufgabe, eine positive Kommentierung und lobende Stellungnahmen in den amerikanischen Medien zu organisieren. Die praktische Durchführung dieser Kampagne wurde dem dafür am besten gerüsteten Public Relations Department des American Jewish Committee übertragen ${ }^{203}$. Am 18. November legte es eine Bilanz dieser Bemühungen vor: Es war gelungen, eine zustimmende Bewertung des Rückerstattungsgesetzes der US-Zone in den USA zu erreichen. Unter anderem hatte das American Jewish Committee einen Kommentar in der New York Times vom 11. November mit dem Titel „An Act of Justice“ inspiriert, bei der Nachrichtenagentur International News Service einen an 600 Zeitschriften verteilten Bericht untergebracht, und eine vorbereitete Radiomeldung wurde von den Stationen der NBC, der ABC, AP Radio News (mit alleine 856 Stationen) und WOR gesendet. Die Präsidenten der American Federation of Labor (AFL), William Green, sowie des Congress of Industrial Organization (CIO), Philip Murray, hatten sich bereit erklärt, zustimmende Telegramme an Clay zu schicken, deren Text gleichfalls das American Jewish Committee entworfen hatte. Auch der „Federal Council of Churches“ wollte das Material des American Jewish Committee für seine Medienarbeit übernehmen ${ }^{204}$.

Die Berichterstattung der amerikanischen Medien über das Rückerstattungsgesetz war also in einem hohen Ausmaß durch die jüdischen Organisationen angeregt worden, um Clay davon zu überzeugen, daß der Erlaß eines stark von ihren Forderungen beeinflußten Gesetzes in der US-Zone richtig war. Hier stellt sich die Frage nach der Reichweite bisheriger Versuche, die Bedeutung der öffentlichen Meinung in den USA für die Wiedergutmachung zu erforschen. Alle bisher vorliegenden Ansätze in dieser

200 Hevesi an Slawson, 3. 10. 1947, YIVO-Archiv, RG 347, AJC Records, GEN-10, Box 291.

201 Ebenda.

202 Memorandum of Telephone Conversation between Col. Bernstein and Irwin Mason, 29.9. 1947, YIVOArchiv, RG 347, AJC Records, GEN-10, Box 293.

203 American Jewish Committee, Enactment of the Restitution Law in the US Zone of Germany, 7. 11. 1947, AJC-Archiv, Blaustein Library, Restitution \& Indemnification - Germany, AJC.

$20+$ Summary of Promotion of the Restitution Law by the American Jewish Committee, 18. 11. 1947, AJCArchiv, Blaustein Library, Restitution \& Indemnification - Germany, AJC. 
Richtung gehen von einer Auswertung der erschienenen Berichterstattung aus, ohne der Frage nachzugehen, welche Interessen binter einer Veröffentlichung standen ${ }^{205}$. Darüber hinaus bestätigt diese Medienkampagne, daß die Auseinandersetzung um die Rückerstattung des in der nationalsozialistischen Zeit entzogenen Eigentums zwar eine elementare moralische Dimension besaß, sich aber weitgehend in den Formen der Interessenpolitik vollzog.

\section{Der Weg zur Entschädigung}

\section{Zwischenlösung: Vorläufige Entschädigung im Sonderfondsgesetz}

Die amerikanische Militärregierung hatte vom Stuttgarter Länderrat neben der Rückerstattung wiederauffindbaren Eigentums auch Schritte zur Entschädigung der persönlichen, gesundheitlichen, beruflichen und finanziellen Nachteile, die die Verfolgten des Nationalsozialismus erlitten hatten, gefordert. Vorrang besaß zunächst aber eine provisorische Regelung dieser Ansprüche. Gleichzeitig mit der Arbeit am Rückerstattungsgesetz beriet der Sonderausschuß für Eigentumskontrolle deshalb auch das vorläufige Entschädigungsgesetz zugunsten bedürftiger Verfolgter in der US-Zone. Damit sollte deren Betreuung auf eine gesetzliche Grundlage gestellt und so der bisherige Zustand verändert werden; denn nach Ansicht der Militärregierung beschworen unklare Betreuungskompetenzen und mangelhafte staatliche Leistungen die Gefahr der Bildung von Interessengruppen der Verfolgten herauf.

Wie geschildert hatte OMGUS bereits in der Sitzung des Länderrats-Sonderausschusses „Eigentumskontrolle“ vom 12. Juni 1946 den Entwurf eines solchen vorläufigen Entschädigungsgesetzes mündlich genehmigt. Im Gegensatz zu der Annahme Kreikamps entstand also auch das Sonderfondsgesetz als zonale Initiative ${ }^{206}$. Der Entwurf sah vor, Leistungen an rassisch, religiös und politisch Verfolgte in der US-Zone zu vergeben, sofern sie sich in einer wirtschaftlichen Notlage befanden. Dazu gehörten insbesondere befristete Renten, Kosten für Heilbehandlungen und berufliche Ausbildungen sowie Existenzgründungsdarlehen. Die Maßnahmen zielten also primär auf die zügige Rehabilitierung und Integration notleidender Verfolgter, was notwendig schien, um aus deren Not und Sonderbetreuung keinen Dauerzustand entstehen zu lassen; schließlich dachte die amerikanische Seite bei der Verfolgtenbetreuung an eine soziale Initialzündung und nicht an eine dauerhafte Alimentierung. Die Finanzierung sollte vorrangig aus den bei der Durchführung des Befreiungsgesetzes anfallenden Mitteln erfolgen. Offen gehalten war die Einbringung anderer nationalsozialistischer Vermögenswerte bzw. der Rückgriff auf allgemeine Haushaltsmittel ${ }^{207}$.

Als der Sonderausschuß am 9. Juli wieder zusammentraf, bemängelte Reinsel aus der OMGUS-Finanzabteilung, daß sich inzwischen allein das württemberg-badische Kabinett mit dem Entwurf beschäftigt hatte. Auf seine Veranlassung hin wurde er dem

205 Vgl. insbesondere Michael Wolffsohn, Die Wiedergutmachung und der Westen - Tatsachen und Legenden, in: Aus Politik und Zeitgeschichte, B 16-17 (1987), S. 19-28; Norbert Frei, Die deutsche Wiedergutmachungspolitik gegenüber Israel im Urteil der öffentlichen Meinung der USA, in: Wiedergutmachung in der Bundesrepublik Deutschland, hrsg.v. Ludolf Herbst u. Constantin Goschler, München 1989, S. 215-230.

$206 \mathrm{Vgl}$. Hans-Dieter Kreikamp, Zur Entstehung des Entschädigungsgesetzes der amerikanischen Besatzungszone, in: Herbst/Goschler (Hrsg.), Wiedergutmachung, S.61.

207 Bericht über die Sitzung des Sonderausschusses „Eigentumskontrolle“ am 12.6. 1946, BayMJ, 1101c, H. 1. 
gerade tagenden Länderrats-Direktorium zur Entscheidung vorgelegt und bei dieser Gelegenheit auch angenommen ${ }^{208}$. Daraufhin stimmten die Kabinette in Bayern und Großhessen dem Entwurf gleichfalls $z^{209}$. Neue Verzögerungen entstanden jedoch auf amerikanischer Seite. Das State Department störte sich daran, daß das Prinzip der auf Not begründeten Zahlungen gegenüber dem Rechtsanspruch auf Leistungen zu sehr im Vordergrund stünde. Bei der Zustimmung zu diesem Programm sollte also unbedingt klar gestellt werden, daß es sich nur um eine vorläufige Teillösung handle. Völlige Gerechtigkeit sei zwar unmöglich, doch sah „es das State Department ... als nützlich für das Ansehen der Vereinigten Staaten an, wenn die US-Zone die Führung bei der Entschädigung für Verletzungen persönlicher Rechte ebenso wie von Vermögensrechten übernehmen könnte, auch wenn diese nur teilweise und beschränkt sei“ ${ }^{210}$. Die OMGUS-Internal Affairs \& Communications-Division monierte überdies, weder sei ausreichend definiert, was unter „Bedürftigkeit“, noch was unter „Personen, die unter der NS-Herrschaft gelitten haben“, zu verstehen sei ${ }^{211}$. Die Präzisierung dieser Begriffe in einer Ausführungsbestimmung wurde deshalb bei der Genehmigung des Gesetzes am 2. Oktober zur Bedingung gemacht. Außerdem teilte OMGUS mit, daß das Sonderfondsgesetz nur als vorläufige Maßnahme verstanden werden dürfe und sich dadurch der Erlaß eines endgültigen Entschädigungsgesetzes nicht erübrige ${ }^{212}$.

In den folgenden Monaten machte sich der Länderrats-Ausschuß daran, die geforderte Ausführungsverordnung auszuarbeiten. Auch wurde das Gesetz selbst nun auf erneutes amerikanisches Drängen ${ }^{213}$ Ende des Jahres auch in Großhessen und Württemberg-Baden veröffentlicht, nachdem Bayern diesen Schritt bereits früher getan hatte ${ }^{214}$. Wegen fehlender Ausführungsbestimmungen erlangte das Sonderfondsgesetz aber erst im Verlaufe des Jahres 1947 allmählich eine praktische Bedeutung. Doch legte OMGUS ohnehin im Januar 1947 eine eigene Fassung des Sonderfondsgesetzes vor, in die die geforderten Ausführungsbestimmungen bereits mit eingearbeitet waren. Ziel war nunmehr gleich ein neues, zoneneinheitliches Gesetz. Um das Verfahren zu beschleunigen, erklärte OMGUS, daß es nicht nötig sei, die im Dezember gewählten Landtage damit zu befassen ${ }^{215}$. Auch hier vermied die amerikanische Militärregierung das Risiko einer substantiellen Veränderung ihrer Pläne im Zuge einer parlamentarischen Beratung.

Am 11. März stimmte der Länderrat dem Entwurf schließlich zu. Die Verabschiedung verzögerte sich noch durch einige Änderungsanträge von württemberg-badischer

208 Bericht über die Sitzung des Sonderausschusses „Eigentumskontrolle“ am 9. 7. 1946, BayMJ, 1101c, H. 1.

${ }^{209}$ In Hessen in der Kabinettssitzung am 10.7. 1946. Vgl. Brill an Epstein, 11.7. 1946, HessHStA, Abt. 502, Nr.2773b. In Bayern am 1.8. 1946. Vgl. Sitzung des bayerischen Ministerrats, 27.9. 1946, IfZ-Archiv, NL Hoegner, ED 120, Bd. 360.

210 War Department an OMGUS, 18.7. 1946, IfZ-Archiv, MF 260, OMGUS-CAD 3/159-3/19.

211 Minutes of the Meeting of the Property Disposition Board, 16. 9. 1946, IfZ-Archiv, MF 260, OMGUS-Bico, Dec., 11/13-1/16.

212 Arnim an die Justizminister Bayerns, Großhessens u. Württemberg-Badens, 15. 10. 1946, BayMJ, 1101c, H. 4.

213 Niederschrift über die Sitzung des Sonderausschusses „Eigentumskontrolle“ am 25./26.11. 1946, BayHStA, MF 69409.

214 Bayern: Gesetz Nr. 35 v. 1.8. 1945, BayGVOBl, Nr. 17, 1.10. 1946, S.258f. Württemberg-Baden: Gesetz Nr. 133, 13.6. 1946, WBRegBl Nr.24, 28.11. 1946, S. 273-275. Großhessen: Gesetz über Bildung eines Sonderfonds zum Zwecke der Wiedergutmachung v. 10.7. 1946, Gesetz- und Verordnungsblatt für GroßHessen (HessGVOBl), Nr. 32/33, 30.11. 1946, S.226f. Die Gesetze wurden unter dem jeweiligen Datum ihrer Annahme durch die Kabinette veröffentlicht, obwohl sie erst erheblich später in Kraft traten.

215 Protokoll über die Sitzung des Sonderausschusses „Eigentumskontrolle ${ }^{\alpha}$ am 20./21.1. 1947, 1947, BayMJ, 1101a, H. 2. 
Seite, gegen die wiederum Bayern protestierte ${ }^{216}$. In der Hauptsache ging es dabei um die Auslegung des Wohnsitzprinzips bei den Ansprüchen der Geschädigten. Zuvor war im Sonderausschuß beschlossen worden, daß Leistungen nur Geschädigten zustünden, die ihren Wohnsitz zur Zeit des ihnen zugefügten Unrechts in der US-Zone hatten. Darüber hinaus sollten aber auch Geschädigte, die beim Eintritt der Verfolgung in den abgetrennten Ostgebieten gelebt hatten, jetzt aber in der US-Zone wohnten, einen Anspruch erhalten ${ }^{217}$. Das zielte auf die Flüchtlinge und Vertriebenen, die mit ihren Ansprüchen nicht mehr an ihren Heimatstaat verwiesen werden konnten.

Otto Küster und sein Chef, der württemberg-badische Justizminister Beyerle, setzten sich dagegen dafür ein, daß die Leistungen aus dem Sonderfondsgesetz „mindestens in Härtefällen auch solchen Personen zugewendet werden können, die aus anderen Zonen oder aus den nach dem 1. Jan. 1938 angegliederten oder in Kontrolle genommenen Gebieten in unsere Länder zugewandert sind “218. Das bayerische Finanzministerium wandte sich aber gegen diese Ausweitung der Leistungen, da sie nicht explizit von der Militärregierung verlangt worden sei. Vergeblich protestierte Beyerle, die Wiedergutmachung sei keine Angelegenheit, bei der der deutsche Gesetzgeber notgedrungen den Wünschen der Militärregierung folge, sondern entspringe eigenen Antrieben ${ }^{219}$.

Der Streit ging darauf zurück, daß es infolge des Krieges eine gewaltige deutsche Binnenwanderung gegeben hatte, so daß der Grundsatz, nur solchen Verfolgten zu helfen, die Bürger des eigenen Landes waren, zu vielen Ungerechtigkeiten führte. Daß in den Anfängen der Entschädigung ein extremes Territorialitätsprinzip entwickelt wurde, war natürlich vor allem eine Folge des finanziellen Selbstschutzes der Länder sowie der offenen Frage der Verantwortung für die Verbindlichkeiten des Deutschen Reiches. Auch bei OMGUS wurde bedauert, daß das Sonderfondsgesetz enge Kriterien hinsichtlich der Nationalität und des Wohnortes setzte, doch erschien dies als notwendiger Preis einer solchen landesrechtlichen Regelung 220 .

Im Juli/August wurde das revidierte Sonderfondsgesetz als zoneneinheitliches Gesetz in Bayern, Württemberg-Baden und Großhessen erlassen ${ }^{221}$. Bis zum Inkrafttreten eines allgemeinen Entschädigungsgesetzes blieb es die Hauptgrundlage für die Befriedigung von Entschädigungsansprüchen der Opfer des Nationalsozialismus in der USZone. Die Hauptwirkung bestand darin, daß diese Gruppe nunmehr aus dem Rahmen der allgemeinen Fürsorge sowie der aus Eigeninitiativen der Verfolgten entstandenen Selbsthilfeorganisationen herausgenommen wurde und ein auf deren spezielle Bedürfnisse zugeschnittenes Instrument bestand, das in staatlicher Hand lag. Dabei sollte die zügige Integration und Rehabilitierung notleidender Verfolgter erreicht werden und weniger der Ausgleich tatsächlich entstandener Schäden.

216 Rossmann an die Mitglieder des Länderrats-Direktoriums, 17.4. 1947, BadWürtHStA, EA 1/014, Bü. 253.

217 Protokoll über die Sitzung des Sonderausschusses „Eigentumskontrolle ${ }^{\alpha}$ am 20.121.1. 1947, BayMJ, 1101a, H. 2.

218 Beyerle an Ministerpräsident Ehard, 28.4. 1947, BadWürtHStA, EA 1/920, Bü. 715.

219 Ebenda.

220 Marcuse an Rockwell, 27. 12. 1946, Report on the Meeting of Restitution Committee of the Laenderrat, 17./ 18. 12. 1946, IfZ-Archiv, MF 260, OMGUS-LD 17/56-2/21.

221 Bayern: Gesetz Nr. 75 über die Bildung eines Sonderfonds zum Zwecke der Wiedergutmachung, 1. 8. 1947, in: BayGVOBl 1947, Nr.13, 26.8. 1947, S. 164 f. Württemberg-Baden, Gesetz Nr.169, 9.7. 1947, in: WBRegBl, Nr. 11, 2.9. 1947, S. 74-77. Großhessen: Gesetz über die Bildung eines Sonderfonds zum Zwecke der Wiedergutmachung vom 24.7. 1947, in: HessGVOBI, Nr. 7, 15.7. 1947, S. $39 \mathrm{f}$. 


\section{Das Entschädigungsgesetz der US-Zone}

a) Endgültige Regelung oder weiteres Provisorium?

Ursprünglich hatte OMGUS bereits in der Sitzung vom 12. Juni 1946 den Sonderausschuß „Eigentumskontrolle“ dazu aufgefordert, nunmehr gleichfalls einen Entwurf für ein endgültiges Entschädigungsgesetz vorzubereiten ${ }^{222}$. Ministerialrat Roemer aus dem bayerischen Justizministerium legte daraufhin gute zwei Wochen später einen von ihm verfaßten Entwurf vor ${ }^{223}$. Die Beratung wurde dann zunächst nur bis Anfang September aufgeschoben, doch wurde aus dem geplanten kurzen Aufschub nahezu ein ganzes Jahr. Verantwortlich für diese Unterbrechung war, daß in dieser Zeit die Arbeit am Rückerstattungsgesetz sowie in geringerem Ausmaß auch am Sonderfondsgesetz alle Kräfte der damit befaßten Personen auf deutscher wie auf amerikanischer Seite beanspruchte. Washington drängte jedoch wiederholt, daß bald auch ein allgemeines Entschädigungsgesetz auf den Weg gebracht werde ${ }^{224}$. Namentlich im State Department spielten dabei auch die internationalen Wirkungen der nationalsozialistischen Verfolgung weiterhin eine besondere Rolle. Zentral waren in dieser Sichtweise die nichtrepatriierbaren Personen ${ }^{225}$, deren Existenz die Völkergemeinschaft mit erheblichen Kosten belastete. Deshalb hatten die USA auch bereits deren Einbeziehung in das Pariser Reparationsabkommen gefördert, das allerdings bei weitem keine ausreichende Lösung dieses Problems schaffen konnte.

Doch bremste OMGUS zunächst die Forderungen Washingtons nach einer schnellen Regelung der endgültigen Entschädigung unter Hinweis auf die finanziellen Konsequenzen von Leistungen auch ins Ausland ${ }^{226}$. Das ständige Drängen Washingtons, die endgültige Entschädigung in Angriff zu nehmen, konterte OMGUS ebenso beharrlich mit dem Argument, daß dazu erst eine gesamtdeutsche Finanzreform nötig sei: „We feel since final claims law would involve for the most part claims against the Reich it is integrally connected with plan for financial reform and must wait upon adoption for latter. “227 Gegenüber Washington, wo die internationalen Aspekte des Problems deutlicher wahrgenommen wurden, nahm OMGUS eine mehr innenpolitische Betrachtungsweise ein. Deshalb wurde zum einen stärker auf die finanzielle Belastbarkeit der USZone Rücksicht genommen und zum anderen das Sonderfondsgesetz in den Vordergrund gestellt, da dies von unmittelbarer Bedeutung für die sozialen Verhältnisse in diesem Gebiet war. Ende des Jahres 1946 regte das State Department jedoch an, daß dennoch bereits jetzt ein Entwurf verfaßt werden sollte, selbst wenn man bis zum Inkrafttreten eines allgemeinen Entschädigungsgesetzes die Währungsreform abwarten müsse ${ }^{228}$. Für endgültige Klarheit auf amerikanischer Seite sorgten schließlich die neuen Richtlinien der Joint Chiefs of Staff, die am 15. Juli 1947 an Clay ergingen und JCS 1067 ablösten. Die neue Direktive JCS 1779 führte nunmehr neben der Rückerstattung auch

222 Vgl. oben, Abschnitt I. 3.

${ }^{223}$ Niederschrift über die Sitzung des Sonderausschusses „Eigentumskontrolle“ am 29.7. 1946, BayHStA, Bev. Stuttgart 71; Entwurf eines Wiedergutmachungsgesetzes nach dem Stande vom 29.7. 12.9. 1946, BayMJ, $1101 \mathrm{~b}, \mathrm{H} .1$.

224 War Department an OMGUS, 18.7. 1946, IfZ-Archiv, MF 260, OMGUS-CAD 3/159-3/19.

225 Siehe dazu etwa Minutes of the Meeting of the Property Disposition Board, 16. 9. 1946, IfZ-Archiv, MF 260, OMGUS-Bico, Dec., 11/13-1/16.

226 Ebenda.

227 Clay an Echols, 6.11. 1946, IfZ-Archiv, MF 260, OMGUS-Bico, Dec., 11/13-1/16.

${ }^{228}$ Hilldring an Echols, 2. 12. 1946, IfZ-Archiv, MF 260, OMGUS-CAD 3/174-1/17. 
die Entschädigung persönlicher Schäden in deutscher Währung unter den offiziellen Zielen der amerikanischen Militärregierung auf ${ }^{229}$.

Mittlerweile hatte aber der Länderrat die Arbeit am Entwurf des allgemeinen Entschädigungsgesetzes bereits aus eigener Initiative wieder aufgenommen. Dies hatte Otto Küster vorgeschlagen, nachdem der Sonderausschuß „Eigentumskontrolle“ seine Arbeit am Rückerstattungsgesetz im April 1947 vorläufig abgeschlossen hatte. Zugleich regte er die Bildung eines neuen Ausschusses an, der sich vor allem aus Vertretern der Justiz- und Finanzministerien der US-zonalen Länder zusammensetzen sollte ${ }^{230}$. Daraufhin entbrannte unter diesen eine Auseinandersetzung um die Frage der Stimmführung. Vor allem das bayerische Finanzministerium stellte sich dabei auf den Standpunkt, daß die Auswirkungen auf die Staatshaushalte bei der Beratung des Entschädigungsgesetzes stärker im Vordergrund stünden „als die mehr rechtlichen Erwägungen des Justizministeriums", und forderte deshalb die Stimmführung für sein Ressort ${ }^{231}$. Dagegen protestierte Wilhelm Hoegner, der zu dieser Zeit bayerischer Justizminister war, mit dem Argument, es handle sich hier „um Verpflichtungen zum Schadensersatz, die aus sitten- und rechtswidrigen Staatsakten und aus unerlaubten Handlungen herrühren. Die Feststellung der Schadensersatzpflicht ist daher eine reine Rechtsfrage“, meinte Hoegner und forderte deshalb die Federführung der Justizministerien ${ }^{232}$.

Die prinzipielle Alternative lautete: Entschädigung für Verfolgte des Nationalsozialismus als Teilregelung des Reichsschuldenproblems oder moralisch vorrangige rechtliche Verpflichtung zum Schadensersatz. Dies war in der Tat eine entscheidende Weichenstellung, implizierte die erste Lösung doch eine Relativierung der möglichen Leistungen durch den Bezug auf die ungeheuren Gesamtforderungen gegen das Deutsche Reich, während die zweite Lösung eine exzeptionelle Stellung der Entschädigung annahm, die auf der besonderen moralischen Qualität dieser Forderungen beruhte. Herrschte etwa im bayerischen Finanzministerium der Standpunkt, daß es sich bei der Entschädigung für Verfolgte eigentlich um die Pflicht eines gesamtdeutschen Staates handele und die Länder mit dieser Aufgabe überfordert seien, widersprach umgekehrt der bayerische Staatskommissar Auerbach der Verknüpfung der Ansprüche der Opfer des Nationalsozialismus mit der allgemeinen Reichsschuld, die für ihn Ansprüche sui generis darstellten ${ }^{233}$. Küster wiederum akzeptierte zwar den Zusammenhang der Entschädigung mit dem Reichsschuldenproblem, forderte aber die Priorität der Bearbeitung für die Wiedergutmachung ${ }^{234}$. Das Direktorium des Länderrats entschied sich in diesem Konflikt dafür, daß jedes Land zwei stimmberechtigte Vertreter haben solle, je einen des Justiz- und Finanzministeriums ${ }^{235}$. Zu Recht stellt Kreikamp fest, daß hiermit „der Konflikt zwischen moralisch-rechtlicher Würdigung einerseits und Finanzierbarkeit andererseits geradezu vorprogrammiert" ${ }^{\text {" }}{ }^{236}$.

\footnotetext{
229 Text der JCS 1779 in: Um den Frieden mit Deutschland, S. 100-105, hier: S. 103.

230 Küster an Finanzministerium Stuttgart, 2.5. 1947, BayMJ, 1101b, H. 1.

231 Vormerkung Hartmann (bayer. Finanzministerium), 6.6. 1947, BayHStA, MF 69410. Siehe auch Finanzminister Müller an bayerisches Justizministerium, 24.6. 1947, BayMJ, 1101b, H. 1.

232 Hoegner an bayerisches Finanzministerium, 11.7. 1947, BayMJ, 1101b, H. 1.

233 Protokoll über die Sitzung des Sonderausschusses für das Entschädigungsgesetz am 30.7. 1947, BayMJ, 1101b, H. 1.

234 Küster an Finanzministerium Stuttgart, 2.5. 1947 (Anm. 230).

235 Arnim an die Justizministerien Bayerns, Hessens, Württemberg-Badens etc., 25. 7. 1947, BayMJ, 1101b, H. 1.

236 Kreikamp, Entstehung des Entschädigungsgesetzes, S. 64.
} 
Ein bedeutender Unterschied zur Entstehung des Rückerstattungsgesetzes ergab sich auch bei der Vertretung der Verfolgteninteressen. Dort hatten die amerikanischen jüdischen Organisationen eine wesentliche Rolle gespielt. Beim Entschädigungsgesetz blieben diese zunächst weitgehend unbeteiligt, erst in der Schlußphase - davon wird noch die Rede sein - griffen diese dann erneut in das Geschehen ein. Zwar war in manchen Sitzungen der Rechtsberater der Jewish Agency anwesend, er verfügte aber anders als der Internal Restitution Advisor der jüdischen Organisationen über keinen Sonderstatus bei der Militärregierung, sondern nahm nur als Gast teil. Statt dessen engagierten sich nun bei der Entschädigung die deutschen Verfolgten mit großer Energie. Die jüdischen Gemeinden waren wie bereits beim Rückerstattungsgesetz durch Benno Ostertag vertreten. Doch meldeten sich vor allem auch die politisch Verfolgten, die ja die Mehrzahl der deutschen Verfolgten in der US-Zone stellten, zu Wort. Als Grundlage für eine Interessenvertretung bildete sich in den deutschen Ländern die "Vereinigung der Verfolgten des Naziregimes" (VVN), so im Januar 1947 in Bayern $^{237}$, im Februar in Großhessen ${ }^{238}$ und im Mai in Württemberg-Baden ${ }^{239}$. Im März 1947 wurde auch ein gemeinsames Interzonensekretariat der VVN gegründet, in dem alle vier Besatzungszonen vertreten waren ${ }^{240}$. Die VVN war zunächst eine umfassende, überparteiliche Vertretung deutscher rassisch, religiös und politisch Verfolgter in den vier Zonen, wobei aber die politisch Verfolgten schon rein quantitativ von Anfang an dominierten.

In den Verhandlungen des Sonderausschusses für das Entschädigungsgesetz konnte die VVN der US-Zone ihren Einfluß insbesondere über die Staatskommissare für rassisch, religiös und politisch Verfolgte geltend machen, die gleichfalls als Delegierte teilnahmen. Vor allem Philipp Auerbach, der sich einige Zeit in der bayerischen VVN engagierte, setzte sich energisch für deren Interessen ein. In einigen Sitzungen war die VVN aber auch durch einen eigenen Vertreter repräsentiert ${ }^{241}$. Nicht $z u$ vergessen ist, daß zugleich eine Anzahl von prominenten Politikern, die selbst zu den politisch Verfolgten zählten, zumindest anfangs der VVN nahestanden. Dazu gehörten neben Wilhelm Hoegner in Bayern auch Werner Hilpert und Hermann Brill in Großhessen. Nennenswerten Einfluß besaß die VVN allerdings nur in der ersten Zeit ihres Bestehens, in die auch die Anfänge des Entschädigungsgesetzes fielen.

Die amerikanische Militärregierung hielt sich hingegen bis zur Schlußphase sehr stark mit ihrer Einflußnahme auf das Entschädigungsgesetz zurück, wenngleich sie bei den Beratungen stets präsent war. Sie war ja - im Unterschied zu den Deutschen weiterhin stark mit den alliierten Verhandlungen um das Rückerstattungsgesetz beschäftigt. Dagegen versuchte ein Vertreter der Preparatory Commission for the International Refugee Organization (PCIRO) die Interessen der ihm anvertrauten Displaced Persons bei der Entschädigung geltend zu machen. Alles in allem waren aber die

237 Protokoll der Gründungsversammlung der VVN Bayern am 26.1. 1947 in München, IfZ-Archiv, NL Hoegner, ED 120, Bd. 327.

238 Vgl. Jörg Ehret, Gründung der Vereinigung der Verfolgten des Naziregimes, in: Als der Krieg zu Ende war, hrsg.v. Ulrich Schneider u. a., Hessen 1945: Berichte und Bilder vom demokratischen Neubeginn, Frankfurt a.M. 1980, S. $139 \mathrm{f}$.

239 Protokoll der Landes-Delegierten-Konferenz der Vereinigung der Verfolgten des Naziregimes (VVN) Württemberg-Baden am 17.5. 1947 in Stuttgart, VVN/BW-Archiv, Geschichte/Dokumente der VVN.

240 Protokoll der 1. Interzonalen Länderkonferenz der VVN vom 15.-17.3. 1947 in Frankfurt a.M., VVN/BWArchiv, Geschichte/Dokumente der VVN.

241 Z.B. Karl Keim, Vorsitzender der VVN, Stuttgart. 
Gespräche im Sonderausschuß für das Entschädigungsgesetz zunächst weitgehend eine deutsche Angelegenheit - sehr im Gegensatz zum Rückerstattungsgesetz.

b) Die Auseinandersetzung um den Umfang der Entschädigung

Am 30. Juli 1947 nahm der Sonderausschuß für das Entschädigungsgesetz seine Beratungen wieder auf, die zunächst auf einer revidierten Fassung des im Sommer 1946 vorgelegten bayerischen Entwurfs basierten. Eine der zentralen Fragen war, welcher Personenkreis überhaupt entschädigungsberechtigt sein sollte. In der bisherigen Entwicklung hatte sich bereits eine Basisdefinition der nationalsozialistischen Verfolgung ergeben; sie umfaßte die aus rassischen, religiösen und politischen Gründen verfolgten Personen. Unumstritten fielen darunter in dieser Zeit insbesondere Juden, aber auch Kommunisten, Sozialdemokraten und Mitglieder anderer verfolgter Parteien sowie Zeugen Jehovas.

Ursprünglich fand sich in diesem Ausschuß eine Mehrheit für die Auffassung, daß der „Anspruch auf Wiedergutmachung ... durch den Aufenthalt in einem deutschen $\mathrm{KZ}$ begründet “ ${ }^{242}$ werde. Doch wurde dies in zweierlei Hinsicht eingeschränkt. Bei einer Anzahl von durch den Nationalsozialismus Geschädigten war umstritten, inwieweit sie in das Schema der rassischen, religiösen und politischen Verfolgung hineinpaßten. Dabei handelte es sich insbesondere um die Zwangssterilisierten, die Euthanasieopfer, „übermäßig hart bestrafte“ Verbrecher, „Asoziale“ sowie Deserteure - allesamt Gruppen, die in jüngerer Zeit als „vergessene Opfer“ thematisiert wurden. Offenbar „vergaß“ man diese Gruppen keineswegs einfach, ihr weitgehender Ausschluß aus der Entschädigung war vielmehr eine Folge gezielter politischer Handlungen. Für den weitgehenden Einschluß derartiger Gruppen hatten sich insbesondere Otto Küster sowie sein Chef, Justizminister Beyerle, eingesetzt. Dabei stand auch ein so unbedingter Verfechter der Wiedergutmachung wie Küster vor dem Konflikt, wo die Grenze zu einer spezifisch nationalsozialistischen Verfolgung gezogen werden müsse. Beispielsweise gab er bei einem Vortrag vor einer CDU-Versammlung in Stuttgart zu erkennen, daß er „aus soldatischem Empfinden“ Schwierigkeiten habe, etwa Deserteure als Verfolgte des Nationalsozialismus zu akzeptieren ${ }^{243}$.

Gegner der Einbeziehung von Zwangssterilisierten, Euthanasieopfern, „Asozialen“ und Fahnenflüchtigen in das Entschädigungsgesetz fanden sich auf zwei Seiten: Einmal vor allem in den Finanzministerien, deren Beweggründe leicht nachzuvollziehen sind: Sie widersetzten sich jeder möglichen Ausweitung des entschädigungsberechtigten Kreises aus Kostengründen ${ }^{244}$. Zum anderen fanden sich aber die Gegner auch unter den Verfolgten selbst. Als es etwa im Sonderausschuß für das Entschädigungsgesetz um die mögliche Einbeziehung der Zwangssterilisierten ging, wandten sich die Verfolgtenvertreter dagegen. Sie sprachen dieser Gruppe zwar nicht grundsätzlich die Entschädigungsansprüche $a b$, wollten aber, daß diese in einem eigenen Gesetz geregelt werden sollten $^{245}$. Beyerle schwächte deshalb den von seinem Delegierten Küster vorgebrachten

242 Protokoll über die Sitzung des Sonderausschusses für das Entschädigungsgesetz am 30.7. 1947, BayMJ, $1101 b$, H. 1.

${ }^{243}$ Aufzeichnung Heusels über Vortrag Küsters vor CDU-Versammlung in Stuttgart, 12.1. 1949, VVN/BWArchiv, Wiedergutmachung - Entschädigungsgesetz.

244 Siehe dazu etwa Protokoll über die Sitzung des Sonderausschusses für das Entschädigungsgesetz am 30.7. 1947, BayMJ, 1101b, H. 1.

245 Ebenda. OMGUS hatte zuvor bereits einen Vorstoß der jüdischen Organisationen in den USA abgeblockt, 
Vorschlag auf Einbeziehung der oben genannten Personenkreise in das Entschädigungsgesetz ab, so daß nur noch "unschuldig Verfolgte" einbezogen werden sollten ${ }^{246}$. Der Länderratsausschuß beschloß nun, zusätzlich zu dem Kriterium der rassischen, religiösen und politischen Verfolgung auch demjenigen einen Anspruch auf Entschädigung zuzubilligen, der „unter Mißachtung der Menschenrechte verfolgt worden“ $\operatorname{sei}^{247}$. Dieser Zusatz wurde aber dann im Verlaufe der weiteren Ausschuß-Beratungen wieder gestrichen, doch auf Wunsch Württemberg-Badens schuf ein neuer Paragraph (\$50) die Möglichkeit einer landesrechtlichen Regelung der damit bezeichneten Ansprüche ${ }^{248}$. Die starke Fixierung der politisch Verfolgten auf die Hervorhebung der aktiven Kämpfer, wie sie noch in den Betreuungskriterien für die Verfolgtenfürsorge zum Ausdruck gekommen war $^{249}$, übernahm der Sonderausschuß jedoch nicht mehr. Damit entfiel aber auch die Betonung der gesellschaftlichen Anerkennung des Widerstandes gegen das nationalsozialistische Regime, die die politisch Verfolgten als Bestandteil der Entschädigung gefordert hatten.

Beyerle hatte sich bissig zu den Empfindlichkeiten der Verfolgtenverbände geäußert: „Es besteht wohl Einigkeit darüber, daß die Aufgabe des Entschädigungsgesetzes nicht die ist, Widerstandskämpfer zu prämieren, sondern Verfolgte zu entschädigen. Es besteht, wie wir hoffen, auch Einigkeit darüber, daß es ganz allgemein nicht Aufgabe der Gesetzgebung sein kann, sachlich zusammengehöriges deswegen in verschiedenen $\mathrm{Ge}$ setzen zu regeln, weil die interessierten Personenkreise an die Gesetzesoptik aus Prestigegründen besondere Ansprüche stellen. “250 Für einen Teil der Betroffenen war dies aber gerade das Problem. Sie wollten nicht unterschiedslos als Opfer einer gemeinsam erlittenen Katastrophe behandelt werden, und so wurde es etwa als Schande empfunden, mit „Asozialen“ oder Kriminellen zusammen in einem Gesetz aufgeführt zu werden. Bei den politisch Verfolgten trat überdies häufig die Empfindung dazu, daß sie als diejenigen, die aktiven Widerstand gegen die Nationalsozialisten geleistet hatten, gegenüber den Juden, die meist passive Opfer gewesen seien und zum Teil, wenn auch letztlich vergeblich, den Ausgleich mit dem Regime gesucht hätten, eine herausragende Rolle besäßen ${ }^{251}$. Der von jüdischer Seite (vor allem im Ausland) vertretenen These, die Juden seien die ersten und bedeutendsten Opfer des NS-Regimes gewesen ${ }^{252}$, stand zumindest in Ansätzen ein entsprechender Anspruch der politisch Verfolgten gegenüber, zumal sie die nationalsozialistische Herrschaft aktiv bekämpft hätten.

Dieser Konflikt um die Kategorien der nationalsozialistischen Verfolgung überlagerte sich zum Teil mit einem zweiten Problem bei der Bestimmung des entschädigungsberechtigten Kreises. Sollten auch verfolgte DP's, d. h. also nichtdeutsche Verfolgte, in die geplante Entschädigung einbezogen werden? Diese Frage bejahten nachdrücklich die

dic ein exklusives Rückerstattungsgesetz für jüdische Ansprüche gewünscht hatten. Siehe Clay an Echols, 6. 11. 1946, IfZ-Archiv, MF 260, OMGUS-Bico, Dec., 11/13-1/16.

246 Beyerle an Roemer, 26.8. 1947, BayMJ, 1101b, H. 1.

247 Niederschrift über die Sitzung des Sonderausschusses für das Entschädigungsgesetz am 5. 9. 1947, BayMJ, $1101 b$, H. 1.

248 Stellungnahme des erweiterten Sonderausschusses für Wiedergutmachung zu den vom Direktorium des Länderrats in der Sitzung vom 19.8. 1948 aufgeworfenen Fragen (Ergebnis der Besprechung vom 26.8. 1948), BayMJ, 1101b, H. 2.

249 Vgl. dazu Zweites Kapitel, Abschnitt III. 2.

250 Beyerle an Roemer, 26.8. 1947 (Anm. 246).

251 Siehe dazu etwa Ausführungen Wallers (Stuttgart) in Protokoll über die Sitzung des Sekretariats der VVN Württemberg-Baden am 30.10. 1947, VVN/BW-Archiv, Geschichte/Dokumente der VVN.

252 Vgl. dazu Erstes Kapitel, Abschnitt II. 
Vertreter der PCIRO wie auch der Jewish Agency. Im Sonderausschuß für das Entschädigungsgesetz fand sich zunächst eine Mehrheit bereit, auch rassisch, religiös und politisch verfolgten DP's einen Anspruch einzuräumen. Dies hatte der Ausschuß an die Bedingung geknüpft, daß der durch die Verfolgung Geschädigte „am 1. Januar 1947 sich in einem DP-Lager der amerikanisch besetzten Zone aufhielt und sich spätestens innerhalb eines Jahres nach dem Inkrafttreten dieses Gesetzes in die Rechts- und Wirtschaftsordnung des Landes ... eingegliedert hat oder auswandert ${ }^{* 253}$.

Als das Länderrats-Direktorium im September 1948 abschließend über den Entwurf des Sonderausschusses debattierte, gehörte aber der Abschnitt über die Einbeziehung verfolgter DP's zu einer ganzen Reihe von Bestimmungen, die nunmehr finanziellen Erwägungen geopfert werden sollten; davon wird noch die Rede sein ${ }^{254}$. Doch auch hier waren es nicht allein die Vertreter der Finanzbehörden, die Widerspruch angemeldet hatten, sondern auch die der Verfolgten. Benno Ostertag, der Vertreter der deutschen Juden im Sonderausschuß, erklärte dort, daß sich unter den DP's ,vielfach Menschen befunden haben, die im Dienste der SS die Insassen der KZ-Lager bewacht hätten und sich heute schwindelhaft auch als Verfolgte ausgeben "255. Ähnliche Vorwürfe erhob auch die VVN, die zudem selbst bei einer Aussiebung der unwürdigen Elemente die Ansprüche der DP's als eine untragbare Belastung für die deutsche Bevölkerung ansah $^{256}$. Auch hier stößt man also auf das Phänomen, daß ein Teil der Verfolgten einem anderen die Ansprüche bestritt, denn auch wenn die DP's keinesfalls pauschal zu dieser Gruppe gezählt werden konnten, so steht doch außer Zweifel, daß ein erheblicher Teil dieser Menschen unter rassischer, religiöser oder politischer Verfolgung gelitten hatte. Diese begrenzte Solidarität hatte jedoch viel damit zu tun, daß die Verfolgten des Nationalsozialismus keine sozial, politisch oder auch nur national homogene Gruppe bildeten. Vielmehr waren sie als solche nur durch die Verfolgung definiert, wodurch das identitätsstiftende Merkmal eine letzte Mitgift der nationalsozialistischen Weltanschauung war.

Die Frage, welche Schadenskategorien im Entschädigungsgesetz behandelt werden sollten, war hingegen weitgehend unumstritten. Prinzipiell galt der Grundsatz, daß all das, was das Rückerstattungsgesetz nicht berücksichtigte, nun hier geregelt werden sollte. Drei große Kategorien bildeten sich dabei heraus, die im zweiten Teil des Entwurfes festgelegt wurden. Unter die erste fielen Schäden an Leben, Körper, Gesundheit und Freiheit. Die zweite betraf Schäden an Eigentum und Vermögen, die dritte Schäden im wirtschaftlichen Fortkommen, worunter zuletzt auch noch die Wiedergutmachung der Schäden im Bereich der Sozialversicherung gefaßt wurde ${ }^{257}$.

Ein Bezug auf das Rückerstattungsgesetz bestand aber auch in anderer Hinsicht.

${ }^{253} \$ 6$, Abs.3, Entwurf eines Gesetzes zur Wiedergutmachung nationalsozialistischen Unrechts (Entschädigungsgesetz), Fassung vom 26. 8. 1948, BayMJ, 1101b, H. 2.

254 Vgl. unten, S. 142.

255 Protokoll über die Sitzung des Sonderausschusses für das Entschädigungsgesetz am 8. 10. 1947, BayMJ, 1101b, H. 1.

256 Diskussionsgrundlage zur Ablehnung des Entschädigungsgesetzes des Süddeutschen Länderrates durch OMGUS, 22.3. 1949, VVN/BW-Archiv, Wiedergutmachung - Entschädigungsgesetz. Auch Auerbach sprach davon, daß sich unter den DP's Kollaborateure und KZ-Lagerwachen befänden. Vgl. Rundschreiben Auerbachs, 22.9. 1947, BayMJ, 1101b, H. 1.

257 Gesetz zur Wiedergutmachung nationalsozialistischen Unrechts (Entschädigungsgesetz), 12.8. 1949, in: BayGVOBI, Nr. 20, 29. 8. 1949, S. 195-204, hier: S. 197-203. 
Dieses wurde auf deutscher Seite - sowohl bei Verfolgten als auch bei Nicht-Verfolgten - häufig als eine Bevorzugung insbesondere ausländischer Juden und zugleich der Kapitaleigner empfunden. Die Bemühungen des Sonderausschusses für das Entschädigungsgesetz besaßen deshalb auch einen starken Antrieb darin, ein Gegengewicht vor allem zugunsten der deutschen politischen Verfolgten zu schaffen, die zumeist weniger in ihrem Vermögen als in ihrer Person und Arbeitskraft geschädigt worden waren ${ }^{258}$. Besonders stark ausgeprägt war dieser Wunsch natürlich bei den deutschen politischen Verfolgten selbst. Deshalb versuchte Philipp Auerbach, mit ihrer Unterstützung eine vorrangige Regelung der Haftentschädigung zu erreichen. Dies mündete in eine Initiative zugunsten eines eigenständigen „Gesetzes über vordringliche Entschädigung für politische Haft“. Auerbach forderte dort, daß ehemalige KZ-Häftlinge, die sich über sechs Monate in einem Lager befunden hatten, pro Tag ihrer Haft zehn RM erhalten sollten $^{259}$. Noch bevor genaue Zahlen über die möglichen finanziellen Konsequenzen eines derartigen Gesetzes bekannt waren, herrschte unter den Finanzverwaltungen Übereinstimmung, daß die Kosten nicht tragbar seien ${ }^{260}$.

Als die Zahlen vorlagen, verringerten sich die Besorgnisse keineswegs: Für Bayern ging man von etwa 55.000 Anspruchsberechtigten aus, für Württemberg-Baden und Großhessen von je ca. 10.000. Daraus ergab sich eine geschätzte Gesamtbelastung von etwa 300 Mio. Mark ${ }^{261}$. Der Sonderausschuß für das Entschädigungsgesetz empfahl dem Länderrat am 13. November, das Haftentschädigungsgesetz zu verabschieden, regte aber zugleich an, daß der Entwurf zuvor von den Finanzministern der US-Zone auf seine Auswirkungen geprüft werde ${ }^{262}$. Dabei wies er noch einmal auf die angesichts der Rückerstattungsregelung besondere Bedeutung einer vorläufigen Entschädigung für diejenigen, die eine Haft erlitten hatten, hin: „Es würde andernfalls der Eindruck entstehen, daß die Wiedergutmachung von Kapitalschäden wichtiger sei als diejenige der Freiheitsschäden, obschon die Kapitalschäden mehr auf die passiven Opfer, dagegen die Freiheitsschäden auf die aktiven Kämpfer der Gewaltherrschaft (sic!) entfallen." 263

Auerbach, der sich hier auch ein persönliches Denkmal setzen wollte, glaubte aber vergeblich, bereits am Ziel zu sein ${ }^{264}$. Das Länderrats-Direktorium vermochte sich in seiner Sitzung vom 12. Februar 1948 nicht über den Entwurf zu einigen. Während Württemberg-Baden und Bremen bereit waren, das Gesetz anzunehmen, war Großhessen kategorisch dagegen und schlug vor, den Gesetzeszweck durch eine Erweiterung des Sonderfondsgesetzes zu verfolgen. Bayern wiederum wollte die Haftentschädigung nicht als eigenes Gesetz von der allgemeinen Entschädigung abkoppeln und wünschte

258 Siehe etwa Auerbach an das Direktorium des Länderrats, 12.8. 1948, BA, Z 1, Bd. 1297.

259 Niederschrift über die Sitzung des Sonderausschusses für das Entschädigungsgesetz am 5.9. 1947, BayMJ, $1101 \mathrm{~b}$.

${ }^{260}$ Siehe etwa Ringelmann an Hans Kraus (bayer. Finanzminister), 23. 9. 1947, BayHStA, MF 69410.

261 Statistische Auswertung der Voranmeldungen zum Entschädigungsgesetz, Bayerisches Staatskommissariat für rassisch, religiös und politisch Verfolgte, BayMJ, 1101b, H. 1; Küster an Trabold (württ.-bad. Finanzministerium), 15. 11. 1947, BayHStA, MF 69410.

${ }^{262}$ Protokoll über die Sitzung des Sonderausschusses für das Entschädigungsgesetz am 13.11. 1947, BayMJ, $1101 b$, H. 1.

263 Begründung des Entwurfs des Haftentschädigungsgesetzes, Vormerkung an Leusser (bayer. Staatskanzlei), (Absender unleserlich), 5.2. 1948, BayHStA, MA 130345.

264 Er kündigte nach der Sitzung des Sonderausschusses für das Entschädigungsgesetz vom 13.11. 1947 das Gesetz in der Öffentlichkeit und gegenüber den Verfolgtenverbänden als „Lex Auerbach“ an. Vgl. Küster an Trabold, 15. 11. 1947; BayHStA, MF 69410. 
zudem einen finanziellen Ausgleich unter den einzelnen Ländern ${ }^{265}$. Ministerialdirigent Ringelmann vom bayerischen Finanzministerium und der hessische Länderratsbevollmächtige Graf von Wedel versuchten dem Sonderausschuß für das Entschädigungsgesetz überdies nahezubringen, daß ein vorläufiger Aufschub der Haftentschädigung nur zum besten der Verfolgten sei, da man ihnen vor der bevorstehenden Währungsreform kein schlechtes Geld auszahlen wolle. Dies war kein bloß rhetorisches Argument: Bedenken gegen eine Auszahlung der Haftentschädigung in der reichlich vorhandenen inflationären Reichsmark bestanden auch in Verfolgtenkreisen selbst ${ }^{266}$.

Während der Sonderausschuß daraufhin an dem Gesetz festhalten wollte, um es unmittelbar nach der Währungsreform zu verabschieden ${ }^{267}$, beschloß das Direktorium, daß es erst zusammen mit dem allgemeinen Entschädigungsgesetz kommen sollte ${ }^{268}$. Der Kern des Haftentschädigungsgesetzes wurde schließlich in dessen Entwurf aufgenommen. Unter dem Druck der Finanzverwaltungen wurde dabei noch einmal kräftig gekürzt: So wurden bei diesen Beratungen aus der Haftentschädigung zuletzt bescheidene 150 DM pro Monat, das heißt fünf DM pro Tag KZ-Haft ${ }^{269}$.

\section{c) Konflikte um die Finanzierung}

Seit Beginn der Verhandlungen im Sonderausschuß für das Entschädigungsgesetz war die Frage der Finanzierung einer der Brennpunkte der Diskussion. Dabei standen theoretisch zwei Möglichkeiten zur Wahl, die mit gegensätzlichen gesellschaftspolitischen Implikationen behaftet waren. Die erste Variante, die auch in den deutschen Plänen vor Kriegsende dominiert hatte, zielte darauf ab, „die“ Nationalsozialisten für die Wiedergutmachung zahlen zu lassen. Wiedergutmachung bildete hier einen funktionalen Zusammenhang mit der Entnazifizierung. Bei der zweiten Variante sollten die Kosten dagegen der Allgemeinheit auferlegt und öffentliche Haushaltsmittel in Anspruch genommen werden. Das Sonderfondsgesetz, das in erster Linie aus den bei der Durchführung der Entnazifizierung anfallenden Bußgeldern sowie anderem NS-Vermögen finanziert werden sollte, hatte sich hauptsächlich an der ersten Alternative orientiert. Beim Entschädigungsgesetz wurde nun auch die Möglichkeit, Haushaltsmittel heranzuziehen, stärker diskutiert.

Die Anhänger des Prinzips, nur „die“ Nationalsozialisten mit den Kosten zu belasten, fanden sich vornehmlich unter den deutschen Verfolgtenverbänden. Eine exemplarische Erklärung der VVN Württemberg-Badens zum Entwurf des Haftentschädigungsgesetzes forderte, „daß die Mittel für dieses Gesetz, wie auch für die weiteren Gesetze der Wiedergutmachung für die politisch, rassisch und religiös Verfolgten und Geschädigten, einzig und allein von den Schuldigen und Nutznießern des Dritten Reiches getragen werden müssen". Neben denen, die unter die Entnazifizierung fielen, wurden auch diejenigen darunter gefaßt, „die sich gegen das Gesetz menschlicher Moral

\footnotetext{
${ }^{265}$ Protokoll der Sitzung des Länderrats-Direktoriums am 12.2. 1948, BA, Z 1, Bd. 1296.

266 Protokoll über die Sitzung des Landesausschusses der politisch Verfolgten, Württemberg-Baden am 9. 10. 1947, VVN/BW-Archiv, Geschichte/Dokumente der VVN.

${ }^{267}$ Niederschrift über die Sitzung des Sonderausschusses für das Entschädigungsgesetz am 24.2. 1948, BayMJ, $1101 \mathrm{~b}$, H. 1.

268 Protokoll der Sitzung des Länderrats-Direktoriums am 26. 2. 1948, BA, Z 1, Bd. 1296.

${ }^{269}$ Niederschrift über die Sitzung des Sonderausschusses für das Entschädigungsgesetz am 6. 8. 1948, BayMJ, 1101b, H. 2.
} 
verstoßen haben, indem sie durch den Krieg Millionen-Vermögen verdient haben, die Kriegsgewinnler als Nutznießer des Naziregimes “270.

Die politisch Verfolgten lehnten somit ausdrücklich eine Kollektivschuld ab und unterschieden zwischen Nutznießern und Betroffenen des Systems ${ }^{271}$, wozu sie sich auch durch ihr eigenes Schicksal legitimiert fühlten. Zudem entsprach die hier geforderte Finanzierung durch das Vermögen von Kriegsgewinnlern und Nutznießern des NSRegimes sowohl der Analyse des nationalsozialistischen Systems als auch den gesellschaftlichen Zielvorstellungen sozialistischer oder kommunistischer Art. Hier zeigten sich auch Unterschiede zwischen den deutschen und ausländischen Verfolgtenorganisationen. Bei den amerikanischen jüdischen Organisationen hatte niemals große Sympathie für diese Betrachtungsweise bestanden; Nehemiah Robinson hatte bereits während des Krieges kritisiert, daß die Differenzierung zwischen „guten“ und „bösen“ Deutschen dazu diene, die Gesamtbelastung zu verkleinern ${ }^{272}$.

Zudem wollte die VVN durch die Vermeidung einer allgemeinen Steuerbelastung zur Finanzierung der Wiedergutmachung dem Unmut und Neid in der Bevölkerung gegen eine angeblich privilegierte Stellung der Verfolgten entgegenwirken. Deshalb nahmen auch die Bemühungen der Verfolgtenorganisationen zu, sich mit anderen Geschädigtengruppen zu solidarisieren, indem eine Interessengemeinschaft behauptet wurde: „Gleichzeitig erklären wir uns, die Verfolgten des Naziregimes, als ein Teil unseres Volkes, solidarisch mit den durch die Nazipolitik in Not geratenen unbelasteten Neubürgern, Fliegergeschädigten, Kriegsversehrten, den Witwen und Waisen als indirekte Opfer des durch den Nationalsozialismus verschuldeten, verbrecherischen Krieges. “ 273 Ein besonders rühriger Verfechter des Grundsatzes der direkten Verantwortung der Nationalsozialisten und ihrer Nutznießer war Philipp Auerbach ${ }^{274}$, der ständig neue Ideen zur Finanzierung der Wiedergutmachung produzierte. Charakteristisch für seine Pläne war, daß sie in gleicher Weise auf die Interessen der Verfolgten als auch auf die des bayerischen Staates Rücksicht zu nehmen versuchten - ein schwieriges Unterfangen, daß ihm zwar viele Freunde, aber auch zahlreiche Feinde einbrachte. So schlug Auerbach vor, ehemaliges NS-Vermögen zur Finanzierung der Wiedergutmachung heranzuziehen. Im Zusammenhang des von ihm vorgelegten Entwurfes für ein Haftentschädungsgesetz hatte er auch gefordert, das Vermögen der ehemaligen Konzentrationslager den früheren Häftlingen in Anrechnung auf ihre Wiedergutmachungsansprüche zur genossenschaftlichen Nutzung zu überlassen. Neben der Erfüllung berechtigter Ansprüche der ehemaligen Häftlinge würden dadurch auch, so Auerbach, „Lasten vom unschuldigen Steuerzahler" abgewendet ${ }^{275}$.

270 Erklärung der VVN Württemberg-Baden zum Gesetz über vordringliche Entschädigung für die unter nationalsozialistischer Gewaltherrschaft erlittene Haft und der allgemeinen Wiedergutmachung, ca. Januar 1948, VVN/BW-Archiv, Wiedergutmachung - Entschädigungsgesetz.

271 Ebenda.

272 Nehemiah Robinson, Indemnifications and Reparations. Jewish Aspects, New York 1944, S. 224. Vgl. auch Erstes Kapitel, Abschnitt I. 4.

273 Erklärung der VVN Württemberg-Baden zum Gesetz über vordringliche Entschädigung (Anm. 270).

274 Siehe etwa „Vorschlag des Staatskommissars für rassisch, religiös und politisch Verfolgte zur Regelung der Wiedergutmachung", 19.1. 1948, WNRC, RG 260, OMGUS Property Division, 103-1/3. Dort heißt es unter anderem: „Wir gehen von dem Gesichtspunkte aus, daß diejenigen, die das Unglück über den vorbezeichneten Personenkreis und über Deutschland hereingebracht haben, sei es durch ihre Mitgliedschaft, sei es durch ihre aktive Unterstützung oder Nutznießung des Nazi-Regimes, mit ihrem Vermögen haftbar sind.“

275 Niederschrift über die Sitzung des Sonderausschusses für das Entschädigungsgesetz am 5. 9. 1947, BayMJ, $1101 \mathrm{~b}$, H. 1. 
Nicht nur die VVN, sondern auch etwa das bayerische Finanzministerium sympathisierte mit manchen Vorschlägen Auerbachs, versprachen derartige Pläne doch eine Entlastung der öffentlichen Kassen. Ministerialdirektor Ringelmann erklärte später, man hätte in seinem Ministerium „die stolze Hoffnung gehabt, daß es möglich sein werde, die Kosten der Wiedergutmachung allein aus dem beschlagnahmten nationalsozialistischen Gut zu decken “276. In den anderen Ländern der US-Zone zeigte man sich diesen Modellen gegenüber zurückhaltender und verwies stärker auf die Notwendigkeit, Haushaltsmittel zur Finanzierung der Wiedergutmachung heranzuziehen.

Bezeichnend war eine Diskussion im Sonderausschuß für das Entschädigungsgesetz Anfang 1948, in deren Verlauf Auerbach forderte, daß man allen Nutznießern des Naziregimes ihre Gewinne wegsteuern sollte. Zudem sollten alle ehemalige NSDAPMitglieder eine Steuer in doppelter Höhe ihres ehemaligen Mitgliedsbeitrages entrichten und überdies die Guthaben der SS und der SA für diesen Zweck zur Verfügung gestellt werden. Der Vertreter der jüdischen Gemeinden, Benno Ostertag, lehnte diese Vorschläge aus "Gründen der staatsmännischen Führung des Landes“ ab. Durch so scharfe Maßnahmen werde „eine Majorität geschaffen, die dem Staat feindlich gegenüber stehe “277. Der Ausschuß übernahm schließlich die Forderungen Auerbachs zum Teil und beschloß, die Aufbringung der erforderlichen Mittel für die Entschädigung dürfe nicht zu Lasten der Allgemeinheit gehen: „Zu diesem Zweck muß in erster Linie der Vermögenszuwachs der in die Gruppen I-IV (sci. des Befreiungsgesetzes) eingereihten Personen einschließlich der Nutznießer aus den Jahren 1933-1945 im Vorrang vor der Inanspruchnahme für Zwecke der Wähırungsreform für die Wiedergutmachung in Anspruch genommen werden. “278

Aus mehreren Gründen geriet aber die Forderung, daß die Entschädigung in erster Linie aus dem nationalsozialistischen Vermögen bzw. durch ehemalige Nationalsozialisten und ihre Nutznießer zu bezahlen sei, allmählich immer stärker ins Abseits. Einmal konnte nicht ohne weiteres von deutscher Seite über alle avisierten Werte verfügt werden, da sie zum Teil unter alliierter Kontrolle standen. Bei den real zur Verfügung stehenden Werten handelte es sich dagegen in erster Linie um Immobilien. Deren Verwertung war aber nicht so schnell möglich, wie man erhofft hatte, da es sonst zu einem Preisverfall auf dem Grundstücksmarkt gekommen wäre ${ }^{279}$ - ein Effekt, der sich bereits bei der „Arisierung“ gezeigt hatte. Zudem war das in Frage kommende Vermögen nicht gleichmäßig über die Länder verteilt. Ein Großteil der Werte aus dem Vermögen der ehemaligen Konzentrationslager befand sich auf bayerischem Boden, weshalb Bayern in dieser Hinsicht eine gewisse Sonderstellung einnahm ${ }^{280}$.

Zu diesen mehr praktischen Schwierigkeiten trat eine grundsätzliche gesellschaftliche Frage hinzu. Die Anwendung des Prinzips der „direkten Verantwortung“ setzte einen Konsens darüber voraus, wer „die Nazis“ und ihre Nutznießer waren und erforderte darüber hinaus den allgemeinen Willen zu deren Bestrafung. Schien dies etwa im Exil

276 Aussage Richard Ringelmann, Protokoll des Untersuchungsausschusses zur Prüfung der Vorgänge im Landesentschädigungsamt am 23. 8. 1951, S. 75, BayLt-Archiv.

277 Protokoll über die Sitzung des Sonderausschusses für das Entschädigungsgesetz am 20.1. 1948, BA, Z 1, Bd. 1296.

278 Ebenda.

279 Aussage Ringelmann, Protokoll des Untersuchungsausschusses zur Prüfung der Vorgänge im Landesentschädigungsamt am 23.8. 1951, S. 75, BayLt-Archiv.

280 Niederschrift über die Sitzung des Sonderausschusses für das Entschädigungsgesetz am 5.9. 1947, BayMJ, $1101 b$, H. 1. 
noch einfach zu sein, hatte sich das im Zuge der Diskreditierung der Entnazifizierung geändert. So blieb auch das finanzielle Ergebnis der Entnazifizierung zugunsten der Wiedergutmachung weit hinter den ursprünglich an sie gesteckten Erwartungen zurück $^{281}$. Zugleich geriet der Ruf nach Bestrafung der Nationalsozialisten zur Finanzierung der Wiedergutmachung in zunehmendem Maße in Konflikt mit der wachsenden Sehnsucht nach der „Ruhe zum Wiederaufbau“.

Bezeichnend dafür war das Schicksal der im Entwurf des Entschädigungsgesetzes ursprünglich vorgesehenen Regelung, eine zivilrechtliche Wiedergutmachungspflicht von Denunzianten, gehässigen aktivistischen Personen des öffentlichen Dienstes sowie Personen, die sich sittenwidrig an der „Arisierung“ und ähnlichen Vorgängen bereichert hatten, festzulegen. Josef Müller, neuer bayerischer Justizminister und stellvertretender Ministerpräsident, forderte im Sommer 1948 die Streichung der damit zusammenhängenden Abschnitte. Müller warnte, diese Regelung würde zu „zahlreichen, auf persönlicher Gehässigkeit beruhenden unbegründeten Klagen angeblich Verfolgter gegen Beamte und sonstige in der Vergangenheit im öffentlichen Leben gestandene Personen verleiten und nicht zuletzt auch zu einem von bestimmten Stellen inszenierten politischen Kesseltreiben gegen jetzt wieder im öffentlichen Leben stehende Personen mißbraucht werden können.“ Als Folge einer von Müller prophezeiten Hexenjagd „würde aber eine schwere Beunruhigung in weite Volkskreise getragen und auch für den neuen demokratischen Staat die Arbeits- und Verantwortungsfreude der im öffentlichen Dienst Stehenden in bedenklicher Weise gefährdet werden “282. Die Intervention hatte Erfolg: Der Sonderausschuß für das Entschädigungsgesetz strich den betreffenden Artikel, dessen staatszersetzende Wirkung Müller so eindrucksvoll geschildert hatte, und verwies die Geschädigten auf die Vorschriften des Bürgerlichen Gesetzbuches ${ }^{283}$. Die abklingende Entnazifizierung sollte somit nicht im Zuge der Entschädigung für Verfolgte des Nationalsozialismus wieder zum Leben erweckt werden.

Eine Zäsur für alle Finanzierungspläne bildete die Währungsreform in den westlichen Besatzungszonen am 20. Juni 1948, in deren Folge sich sowohl die Rückerstattung als auch die Entschädigung „von dem Parteivermögen weg auf den Staat " ${ }^{284}$ verlagerten. So wurden die im Sonderfonds für die Zwecke der Wiedergutmachung gesammelten Geldbeträge aus Parteivermögen und Entnazifizierungsbußen, auf die insbesondere in Bayern große Hoffnungen gesetzt worden war, auf 6,5 Prozent ihres ursprünglichen Betrages abgewertet und schrumpften dadurch zu marginaler Bedeutung. Vorstöße Auerbachs bei der Militärregierung, eine günstigere Quote zu erreichen, blieben erfolglos ${ }^{285}$. Auch waren die öffentlichen Kassen durch den Währungsschnitt leergefegt, während die Länder vorher noch relativ reichlich über Reichsmark verfügt hatten. Zugleich

281 Küster bei einer Aussprache mit Karl Hauff und Alfred Hausser (beide VVN Württemberg-Baden) am 8.6. 1949, Aufzeichnung in VVN/BW-Archiv, Wiedergutmachung - Entschädigungsgesetz.

282 Josef Müller an die Justiz- und Finanzministerien der US-Zone, 19.8. 1947, BA, Z 1, Bd. 1297. Möglicherweise dachte Müller dabei auch an sich selbst, hatte er sich doch im Dritten Reich als Anwalt tatkräftig an "Arisierungen“ beteiligt. Vgl. Johannes Ludwig, Boykott - Enteigung - Mord. Die „Entjudung“ der deutschen Wirtschaft, Hamburg u. München 1989.

283 Protokoll über die Sitzung des Sonderausschusses für das Entschädigungsgesetz am 26.8. 1948, BayMJ, $1101 \mathrm{~b}$, H. 2.

284 Sebastian Endres (Bayerisches Landesamt für Vermögensverwaltung und Wiedergutmachung) an Hartlieb (Landeszentralbank), 3. 7. 1948, BayMF, 1949, Az. IV-N-402.

285 Murphy an Jack Bennett (Financial Advisor Clays), 13. 10. 1948, IfZ-Archiv, OMGUS, AG 1948/45/4. 
setzte eine breite Debatte über den inneren Ausgleich der durch den Krieg entstandenen Schäden des deutschen Volkes ein. Seit Ende August arbeitete eine trizonale Gutachterkommission, der sogenannte "15-er Ausschuß“, an einem Entwurf für einen Lastenausgleich, in dem die Ansprüche von Flüchtlingen, Vertriebenen, Bombengeschädigten, aber auch von Hinterbliebenen, Kriegsgeschädigten sowie auch der Verfolgten des Nationalsozialismus geregelt werden sollten ${ }^{286}$. Infolgedessen gerieten die Entschädigungsansprüche der Verfolgten verstärkt in Konkurrenz zu den Ansprüchen anderer Geschädigtengruppen.

Aus dieser Entwicklung ergab sich die Frage, wie sich Lastenausgleich und Entschädigung für Opfer des Nationalsozialismus zueinander verhalten sollten. Der bayerische Ministerpräsident Ehard unterstrich, man könne den Lastenausgleich und die Entschädigung nicht getrennt voneinander betrachten. Letztlich müßten beide aus demselben Topf bezahlt werden. Zudem vertrat er die Auffassung, daß die Entschädigung nicht für eine Zone gesondert geregelt werden könne ${ }^{287}$. Sowohl die bayerische Regierung als auch die Württemberg-Badens und Großhessens neigten zu diesem Zeitpunkt dazu, die Entschädigung erst einmal bis zu dem bevorstehenden Lastenausgleich aufzuschieben und statt dessen mit einem modifizierten Sonderfondsgesetz die dringendsten Notstände unter den Verfolgten aufzufangen ${ }^{288}$. Die Länder akzeptierten nur widerwillig eine Verpflichtung, die nach ihrer Auffassung eigentlich dem Rechtsnachfolger des Deutschen Reiches zukam. Zudem wurde gerade in Bayern unter Berufung auf die überproportional große Zahl der dort lebenden ehemaligen Verfolgten ein Finanzausgleich unter den Ländern für dringend erforderlich gehalten ${ }^{289}$.

Die Finanzminister der US-Zone erklärten deshalb am 13. September, daß „die Mittel der Wiedergutmachungsfonds und die verfügbaren Haushaltsmittel auch nicht entfernt zur Befriedigung der auf Grund dieses Gesetzes zu erwartenden Wiedergutmachungsansprüche" ausreichend seien. Zugleich stellten sie fest, daß die Entschädigungsansprüche der Verfolgten nur im Rahmen der im Lastenausgleich zu regelnden Ansprüche berücksichtigt werden könnten und das Entschädigungsgesetz keinesfalls vor dem Lastenausgleich in Kraft treten könne ${ }^{290}$. Daraufhin schränkte das Länderrats-Direktorium die im abschließenden Entwurf für ein Entschädigungsgesetz des Sonderausschusses vom 26. August vorgesehenen Leistungen zum Teil drastisch ein. Unter anderem wurde die Anerkennungsquote von Vermögensschäden von 30 auf 10 Prozent gesenkt bei gleichzeitiger Limitierung des Höchstbetrages auf $75.000 \mathrm{DM}$, und nicht zuletzt strich man nunmehr die DP's aus dem Entwurf heraus ${ }^{291}$.

Der Sonderausschuß für das Entschädigungsgesetz, in dem nach Auffassung etwa des bayerischen Finanzministeriums ohnehin die Verfolgteninteressen dominierten ${ }^{292}$, wurde hierzu gar nicht mehr befragt. Dort hatte sich auch von Anfang an Widerspruch

\footnotetext{
286 Vgl. Reinhold Schillinger, Der Entscheidungsprozeß beim Lastenausgleichsgesetz 1945-1952, St. Katharinen 1985, S. $121 \mathrm{ff}$.

287 Protokoll der Sitzung des bayerischen Ministerrats am 8.9. 1947, BayStK-Archiv.

288 Ebenda; Beschlußprotokoll über die Sitzung des großhessischen Kabinetts am 18. 8. 1948, HessHStA, Abt. 503, Nr. 2853.

289 Josef Müller in Protokoll der Sitzung des bayerischen Ministerrats vom 27.9. 1948, BayStK-Archiv.

290 Beschluß des Finanzausschusses der Länderrates vom 13.9. 1948, BA, Z 1, Bd. 1298.

291 Protokoll der Sitzung des Länderrats-Direktoriums am 17.9. und 23. 9. 1948, BA, Z 1, Bd. 1298.

292 Vormerkung aus dem bayerischen Finanzministerium an Ministerpräsident Ehard, 13.2. 1948, BayHStA, MA 130345.
} 
dagegen artikuliert, daß die Entschädigungsansprüche der Verfolgten als Teilregelung des Reichsschuldenproblems behandelt und so diese Ansprüche auf eine Stufe mit denen der Flüchtlinge und Bombengeschädigten gestellt würden ${ }^{293}$. Auerbach und die von ihm initiierte Interministerielle Arbeitsgemeinschaft der Sachbearbeiter für Fragen der Betreuung und Wiedergutmachung der drei westlichen Zonen forderten deshalb nunmehr eine bevorrechtigte Stellung der Verfolgten im Zusammenhang des geplanten Lastenausgleichs. Doch sollten deren Ansprüche keinesfalls innerhalb des Lastenausgleichsgesetzes, sondern in einem eigenen Entschädigungsgesetz geregelt werden. Kernstück der Vorschläge der Arbeitsgemeinschaft war deshalb, daß zehn Prozent des Aufkommens aus dem Lastenausgleich zur Finanzierung des Entschädigungsgesetzes verwendet werden sollten ${ }^{294}$.

Diese Forderung gelangte in das Entschädigungsgesetz und wurde dort unter den Deckungsmitteln aufgeführt ${ }^{295}$. Tatsächlich sollten aber niemals Mittel aus dieser Quelle in die Entschädigung fließen. Demgegenüber war es nur zweitrangig, daß im Ersten Lastenausgleichsgesetz vom 8. August 1949 selbst, das dem endgültigen Lastenausgleichsgesetz vom August 1952 vorausging, die Verfolgten des Nationalsozialismus schließlich nur am Rande berücksichtigt wurden. Auf Einspruch der Militärregierung hin wurde es als „Soforthilfegesetz“ beschlossen und der Sozialleistungscharakter stärker in den Vordergrund gerückt ${ }^{296}$. Demnach konnten bedürftige politisch Verfolgte, die am 21. Juni 1948 im Bereich der DM lebten, Unterhaltshilfe beanspruchen, sofern ihnen nicht Ansprüche aufgrund landesgesetzlicher Entschädigungsgesetze gewährt würden ${ }^{297}$.

Im Zuge der Auseinandersetzung um die Finanzierung der Entschädigung und ihres Zusammenhangs mit dem Lastenausgleich wurde schließlich der dritte Abschnitt, der die Rangfolge der Leistungen und die verfügbaren Deckungsmittel bestimmte, zum Dreh- und Angelpunkt des ganzen Entwurfes ${ }^{298}$. Die Ansprüche der Verfolgten wurden in drei Klassen eingeteilt, die "nach Maßgabe der verfügbaren Deckungsmittel“ innerhalb verschiedener Fristen zur Auszahlung vorgesehen waren. In der ersten Klasse, die möglichst sofort ausbezahlt werden sollte, befanden sich Kosten für Heilverfahren und Renten an gesundheitlich Geschädigte und Hinterbliebene, Versorgungsbezüge an Beamte und ein Teil der Haftentschädigung. Unter Klasse II fielen der Rest der Haftentschädigung sowie ein erster Teil der Entschädigung für Vermögensschäden, alle übrigen Leistungen in Klasse III. Ansprüche in Klasse II sollten innerhalb der nächsten fünf Jahre und die in Klasse III innerhalb der weiteren fünf Jahre befriedigt werden. Als Deckungsmittel wurde erstens der Sonderfonds für die Zwecke der Wiedergutmachung genannt, durch den man weiterhin über eine haushaltsunabhängige Finanzierungsquelle zu verfügen hoffte. Daneben standen Haushaltsmittel sowie die erhofften Mittel aus

293 Auerbach an Ehard, 7.8. 1947, BayMJ, 1101b, H. I.

294 Bayerisches Staatskommissariat für rassisch, religiös und politisch Verfolgte, Grundforderungen zum Lastenausgleich betreffend die Opfer der politischen, rassischen und religiösen Verfolgung, beschlossen auf der 2. interministeriellen Tagung der Wiedergutmachungsreferenten der drei westlichen Zonen in Frankfurt am 15. 8. 1948, BayMJ, 1101b, H. 2.

295 \39, USEG.

296 Vgl. Schillinger, Entscheidungsprozeß beim Lastenausgleich, S. 140f.

297 Gesetz zur Milderung sozialer Notstände (Soforthilfegesetz - SHG), in: Gesetzblatt der Verwaltung des Vereinigten Wirtschaftsgebietes, Nr. 28, 18. 8. 1949, S. 205-230.

298 Siehe auch Ministerialrat Baer, Protokoll der Sitzung des bayerischen Ministerrates am 27. 9. 1948, BayStKArchiv. 
dem Lastenausgleich, an deren Verfügbarkeit der Großteil der Leistungen in Klasse II und III geknüpft wurde ${ }^{299}$.

Damit wurde die Befriedigung der Entschädigungsforderungen zum Teil bis zu zehn Jahre hinausgeschoben und überdies von einer unsicheren Finanzierungsgrundlage abhängig gemacht. Eine derartige Praxis wurde keiner anderen Geschädigtengruppe zugemutet. Deshalb protestierten die Verfolgten, daß ehemalige Nationalsozialisten und Militaristen Pensionen erhielten, die durch den Nationalsozialismus Geschädigten aber immer weiter vertröstet würden ${ }^{300}$. Hermann Brill, nunmehr Leiter der hessischen Staatskanzlei, erklärte dazu gegenüber Vertretern der VVN, daß nach der Währungsreform „bei den Finanzgewaltigen der einzelnen Länder eine Stimmung geherrscht (habe), die nur als psychopathisch bezeichnet werden könne" ${ }^{301}$. Daß also wie Féaux de la Croix erklärt, „bei Beginn einer zentralen Entschädigungspolitik die Priorität der Wiedergutmachung bereits wie ein Dogma feststand", darf mit Kreikamp zu Recht bezweifelt werden ${ }^{302}$. Doch muß man in Rechnung stellen, daß nach der Währungsreform die sozialpolitische Sprengkraft des Flüchtlingsproblems um vieles größer war als die der Entschädigung für Verfolgte des Nationalsozialismus.

d) Das Entschädigungsgesetz der US-Zone als Präjudiz für die Bundesrepublik?

In der gegenüber dem Entwurf des Sonderausschusses vom 26. August reichlich beschnittenen Fassung verabschiedete das Länderrats-Direktorium am 28. September den Entwurf des Entschädigungsgesetzes und legte ihn der amerikanischen Militärregierung zur Genehmigung vor ${ }^{303}$. Dort kam die Maschinerie nur schwerfällig in Gang. Ein Gutachten William Habers, Clays damaligem Jewish Advisor, das auch dem Länderrat zugespielt wurde, übte indes deutliche Kritik. Haber hatte den Entwurf mit jüdischen Organisationen sowie der IRO diskutiert, weshalb er vor allem den zuletzt erfolgten Ausschluß der DP's aus dem Berechtigtenkreis bemängelte. Aber auch einige andere Regelungen, bei denen offensichtlich der Rechenstift über das Gerechtigkeitsempfinden gesiegt hatte, wurden kritisiert, so etwa die vorgesehene Umtauschrate von zehn zu eins für geldliche Ansprüche, die Erbenstellung der Länder für zu spät angemeldete Ansprüche - es wurde statt dessen analog zur Rückerstattung die Erbenstellung jüdischer Nachfolgeorganisationen gefordert - und die Obergrenze von 75.000 DM für geldliche Forderungen. Gleichzeitig verlangte Haber auch, die gesamte Haftentschädigung in die Klasse I aufzunehmen sowie die Streichung aller Hinweise auf eine Finanzierung durch den Lastenausgleich ${ }^{304}$.

Auf der Grundlage des Haberschen sowie weiterer Gutachten verschiedener OMGUS-Abteilungen wurde der Entwurf am 18./19. Januar 1949 vom Legislation Review Board der amerikanischen Militärregierung gründlich besprochen. Der Ausschuß

299 Entwurf und Begründung eines Gesetzes zur Wiedergutmachung nationalsozialistischen Unrechts, Fassung vom 26. 8. 1948, BayMJ, 110lb, H. 2.

300 Staatskommissar Epstein (Hessen), Protokoll über die Sitzung des Sonderausschusses für das Entschädigungsgesetz am 26. 8. 1948, BayMJ, 110 b, H. 2.; Auerbach an Fraktionen im Süddeutschen Länderrat, 23.9. 1948, BA, Z 1, Bd. 1298.

301 Niederschrift über die am 25.1. 1949 in Friedrichshof, Wiesbaden, stattgefundene außerordentliche Delegiertenkonferenz der VVN, HessHStA, Abt. 502, Nr. 2772c.

302 Vgl. Ernst Féaux de la Croix, Vom Unrecht zur Entschädigung: Der Weg des Entschädigungsrechts, in: ders. u. Ernst Rumpf, Der Werdegang des Entschädigungsrechts unter national- und völkerrechtlichem und politologischem Aspekt, München 1985, S.44; Kreikamp, Entstehung des Entschädigungsgesetzes, S. 72.

303 Protokoll der 34. Tagung des Länderrats am 28.9. 1948, BA, Z 1, Bd. 1298.

304 Memorandum von William Haber, 10.12. 1948, BadWürtHStA, EA1/014, Bü. 249. 
machte sich die meisten Kritikpunkte des Jewish Advisors zu eigen, allen voran wiederum den Ausschluß der DP's. Erhebliche Bedenken bestanden zudem wegen der sehr vagen Aussagen über die Finanzierung des Gesetzes ${ }^{305}$ - eine Sorge, die durch die zusätzlichen Forderungen Habers nicht geringer wurde. Dem Länderrat wurde deshalb Mitte März mitgeteilt, daß der Entwurf in dieser Form nicht genehmigt werden kön$n \mathrm{e}^{306}$. Offiziell nannte man dem Länderrat nur die Nichteinbeziehung der DP's als Ablehnungsgrund, während die übrigen beanstandeten Punkte der deutschen Seite nur inoffiziell zur Kenntnis gebracht wurden ${ }^{307}$. Der Sonderausschuß für das Entschädigungsgesetz beriet den Entwurf deshalb von neuem und kam dabei nicht nur der ausdrücklichen Aufforderung nach Einbeziehung der DP's nach, sondern berücksichtigte auch eine ganze Reihe der inoffiziellen Beanstandungen. Da auf deutscher Seite allein durch die DP-Regelung mit einer Verdoppelung der Kosten des Gesetzes gerechnet wurde, forderte der Sonderausschuß zugleich eine Anzahl von finanzpolitischen Schritten, die zur Kostendeckung beitragen sollten ${ }^{308}$.

Als der Länderrat am 26. April seinen überarbeiteten Entwurf vorlegte ${ }^{309}$, war OMGUS zunächst angenehm überrascht. Deshalb empfahl Edward H. Litchfield, Chef der Civil Administration Division, nun die Zustimmung, wenngleich unter einigen Vorbehalten, die die wackelige Finanzierungsbasis des Entschädigungsgesetzes betrafen ${ }^{310}$. Doch türmte sich jetzt ein neues, unerwartetes Hindernis auf. Die amerikanische Militärregierung hatte den Entwurf zu Informationszwecken auch den britischen und französischen Kollegen zukommen lassen. Das führte jedoch dazu, daß die britischen Kontrollratsvertreter durch das Foreign Office beauftragt wurden, gegen den geplanten einzonalen Erlaß des Entschädigungsgesetzes zu intervenieren. London gab sich besorgt, daß nichts geschehen dürfe, was eine ordentliche Regelung des Problems auf der Ebene der kurz vor ihrer Gründung stehenden Bundesrepublik verhindere ${ }^{311}$. Durch die britische Intervention gewannen bei OMGUS die ohnehin vorhandenen Bedenken bezüglich der Finanzierung des Entschädigungsgesetzes die Oberhand. Clay, der das Gesetz befürwortet hatte, war am 15. Mai in die USA zurückgekehrt und als Interimsnachfolger amtierte nun sein bisheriger Stellvertreter General George P. Hays. Dieser antwortete seinem britischen Kollegen postwendend, er werde dem Länderrat mitteilen, daß die Frage des Entschädigungsgesetzes der zukünftigen Bundesrepublik zur Entscheidung vorbehalten bliebe ${ }^{312}$.

So fand sich der Länderrat durch die Mitteilung der amerikanische Militärregierung vom 29. Juni in einer eigentümlichen Lage. Der Entwurf wurde ohne Anerkennung oder Ablehnung zurückgestellt. OMGUS lobte ausdrücklich die Bemühungen des Länderrats und den Zweck des Entwurfes. Zugleich aber hieß es, daß wegen des grundsätzlichen Charakters des Entschädigungsgesetzes und der erheblichen daraus herrühren-

${ }^{305}$ Minutes of the Legislative Review Board Meeting, 18./19.1. 1949, IfZ-Archiv, MF 260, OMGUS 17/256-1/ 1; Memorandum v. E.H. Schwenk, 20.1. 1949, ebenda.

306 Hemken (Rechtsabteilung des Länderrats) an die Ministerpräsidenten der US-Zone, 18.3. 1949, BayMJ, $110 \mathrm{Ib}, \mathrm{H} .2$.

307 Aktennotiz Seidel über Telefongespräch mit Radluff (OMGUS) am 22.3. 1949, BA, Z 1, Bd. 1298; von Wedel an Mitglieder des Sonderausschusses für das Entschädigungsgesetz, 25. 3. 1949, BayMJ, 1101b, H. 2.

308 Protokoll über die Sitzung des Sonderausschusses für das Entschädigungsgesetz am 28.3. 1949, BayMJ, $110 \mathrm{lb}$, H. 2.

309 Länderrat request L 36-6, 26.4. 1949, IfZ-Archiv, MF 260, OMGUS, AG 1949/10/5.

310 Litchfield an Chief of Staff, 1.6. 1949, IfZ-Archiv, MF 260, OMGUS-CAD 17/256-2/23.

311 Kenneth McLean an Hays, 20.6. 1949, IfZ-Archiv, MF 260, OMGUS, AG 1949/10/5.

312 Hays an McLean, 21.6. 1949, IfZ-Archiv, MF 260, OMGUS, AG 1949/10/5. 
den finanziellen Belastung die künftige Bundesregierung darüber entscheiden müsse. Zudem sei es politisch ungünstig, einen Monat nach Verkündung des Grundgesetzes ein solches Gesetz durch die gesetzgebende Gewalt der Militärregierung zu erlassen ${ }^{313}$. Die inneralliierten Hintergründe dieser Entscheidung waren zu diesem Zeitpunkt auf deutscher Seite nicht bekannt und die offensichtlich vorgeschobene offizielle Begründung konnte wenig überzeugen. Es erhob sich eine Welle von Protesten, die von enttäuschten Vertretern des Länderrats über die Verfolgtenorganisationen bis zu den Landesparlamenten der US-Zone reichte. Zugleich begannen nun Planungen, den Entwurf alternativ auf Länderebene zu beschließen. „Mit Rücksicht auf die Stimmung der Landtage" sollten allerdings bei dieser Gelegenheit die DP's wieder aus dem Entwurf herausgestrichen werden ${ }^{314}$. Doch als Nachrichten durchsickerten, daß der designierte amerikanische Hohe Kommissar John J. McCloy die Entscheidung noch einmal revidieren wolle, wurden die Planungen für eigene Ländergesetze auf Eis gelegt ${ }^{315}$, und am 23. Juli beantragte der Länderrat schließlich bei der Militärregierung, ob das Gesetz nicht doch genehmigt werden könnte ${ }^{316}$.

Mit dem Eintreffen McCloys in Berlin Anfang Juli vollzog sich eine erneute und nun endgültige Kurskorrektur. Bereits vor seiner Abreise nach Deutschland hatte er auf Vermittlung Präsident Trumans zweimal mit dem Komitee der amerikanischen jüdischen Organisationen unter anderem über das Rückerstattungs- und das Entschädigungsgesetz konferiert ${ }^{317}$. Bei dieser Gelegenheit hatte sich gezeigt, daß McCloy noch keine Ahnung von dieser Materie hatte ${ }^{318}$, doch erkannte er schnell die Wichtigkeit der Frage und nahm fortan entscheidenden Einfluß auf den weiteren Gang der Dinge. Eine Denkschrift des neuen Jewish Advisors Harry Greenstein vom 16. Juli gab den letzten Anstoß dafür, daß McCloy sich entschloß, dem Entschädigungsgesetz zur Annahme zu verhelfen. Greenstein hielt den finanziellen Bedenken den politischen und moralischen Primat dieser Forderungen entgegen: „I know of no claim on Germany's resources that has a higher priority than the claims that the proposed law seeks to honor. "319 Was nun folgte, bezeichnete später Jack Raymond in der New York Times als "außergewöhnliche Ein-Mann-Schlacht“ ${ }^{320}$. McCloy mußte zugleich Widerstände in seiner eigenen Administration, in Washington und bei der britischen Militärregierung überwinden, um dem Entschädigungsgesetz zum Durchbruch zu verhelfen. Dabei stand er unter großem Zeitdruck, denn er wünschte jetzt das Gesetz noch vor den ersten westdeutschen Bundestagswahlen am 14. August in Kraft gesetzt zu sehen.

Seine Bitte an Washington um Zustimmung für dieses Gesetz unterstrich McCloy

${ }^{313}$ Frederick A. Sturm an Rossmann (Generalsekretär des Länderrats), 29.6. 1949, IfZ-Archiv, MF 260, OMGUS, AG 1949/10/5.

${ }^{314}$ Beyerle an Staatsministerium, 13.7. 1949, BadWürtHStA, EA 1/920, Bü. 709. Aber auch die VVN hatte gegen die Einbeziehung der DP's agitiert. Vgl. Diskussionsentwurf der VVN Württemberg-Baden zur Ablehnung des Entschädigungsgesetzes durch OMGUS, 22.3. 1949, VVN/BW-Archiv, Wiedergutmachung - Entschädigungsgesetz.

315 Auszug aus Protokoll der Sitzung des großhessischen Kabinetts am 20.7. 1949, HessHStA, Abt. 503, Nr. 502.

316 Länderrats-Antrag INT-36, 23.7. 1949, BayHStA, MA 130345.

317 Jacob Blaustein an Harry Greenstein, 3. 9. 1947, YIVO-Archiv, AJC-files, RG 347, GEN-12, Box 22.

318 Report on the Meeting between Mr. John McCloy and Representatives of the American Jewish Committee, American Joint Distribution Committee, Jewish Agency for Palestine and the World Jewish Congress, 14.6. 1949 in Washington, YIVO-Archiv, RG 347, AJC Records, GEN-10, Box 291.

319 Greenstein an McCloy, 16. 7. 1949, IfZ-Archiv, MF 260, OMGUS, AG 1949/10/5.

320 Jack Raymond, McCloy Orders Aid to Nazis' Victims, in: New York Times, 9. 8. 1949. 
mit düsteren Prophezeiungen. Demnach sei „die Hoffnung auf die Annahme einer allgemeinen Entschädigungsgesetzgebung diesen Charakters durch die neue deutsche Regierung beinahe gleich Null, sofern nicht schwerster Druck durch die alliierten Mächte auf die neue Regierung ausgeübt“ werde, doch zweifelte er „an der rechtlichen Grundlage einer solchen Einmischung unter dem neuen Besatzungsstatut.“ Und indem er dem britischen Wunsch nach Nicht-Präjudizierung geradezu eine Haltung des bewußten Präjudiz entgegensetzte, fuhr McCloy fort: "Taking action now in US Zone will force consideration by other Laender and eventually by Federal Gov(ernmen)t of this issue. “ ${ }^{321}$ Auf diese Weise erhielt das Entschädigungsgesetz der US-Zone in der Politik McCloys die Funktion eines Schrittmachers für eine zukünftige bundesweite Regelung der Entschädigung für Verfolgte des Nationalsozialismus.

Die endgültige Entscheidung fiel schließlich bei persönlichen Gesprächen McCloys mit den Verantwortlichen im State und War Department in Washington. Am 4. August gelang ihm der Durchbruch ${ }^{322}$, so daß er sofort nach Berlin telegraphierte: „Go ahead with general claims law“ ${ }^{323}$. Doch hatte McCloy dazu erhebliche Bedenken überwinden müssen. Auch in Washington wurde bemängelt, daß weder die Kosten noch die Finanzierungsgrundlagen des Entschädigungsgesetzes klar waren, und auch mögliche zukünftige Rückwirkungen auf die Devisenlage Westdeutschlands riefen Besorgnis hervor $^{324}$. Aber angesichts des früheren Drängens des State Departments auf eine allgemeine Entschädigungsgesetzgebung wurde eingeräumt, daß man sich die Gedanken über die ökonomischen Auswirkungen früher hätte machen müssen. Zum gegenwärtigen Zeitpunkt seien die Auswirkungen einer ablehnenden Entscheidung jedenfalls verheerend: "To disapprove it would place the US in the position of blocking the only substantive move the Germans have made toward indemnification of this sort." 325 Großen Eindruck hinterließ aber vor allem McCloys Argumentation, daß das Entschädigungsgesetz der US-Zone die Bundesregierung sowie auch seine britischen und französischen Kollegen bestimmen könnte, eine bundesweite Gesetzgebung voranzutreiben $^{326}$. Damit verkehrt sich die Annahme Kreikamps, der hier eine „Politik der NichtPräjudizierung der künftigen westdeutschen Sozialpolitik “ ${ }^{327}$ sah, in ihr glattes Gegenteil. Die Bedenken der Briten hatte McCloy hingegen mit einem politischen Kuhhandel beschwichtigt. Er verhandelte die Angelegenheit persönlich mit dem Chef der britischen Militärregierung, Sir Brian H. Robertson, und verknüpfte dabei die britische Zustimmung zum US-Zonen-Entschädigungsgesetz mit dem amerikanischen "Ja“ zum Soforthilfegesetz des bizonalen Wirtschaftsrates, an dem umgekehrt den Briten sehr gelegen war $^{328}$.

Nun entwickelten sich die Dinge in einem erstaunlichen Tempo weiter. Noch am selben Tag, an dem McCloy der Durchbruch in Washington gelungen war, wurde dem

321 McCloy an Department of Army, 20.7. 1949, IfZ-Archiv, MF 260, OMGUS, AG 1949/10/5.

322 Das Tagebuch McCloys verzeichnet für den 4.8. 1949 ein Gespräch mit Tracy S. Voorhees (War Department), bei dem offensichtlich der Durchbruch gelang. Vgl. Washington Journal, 4.8. 1949, WNRC, RG 466, Records of the U.S. High Commissioner for Germany (McCloy Papers), Box 1.

323 McCloy an Hays, 4. 8. 1949, IfZ-Archiv, MF 260, OMGUS, AG 1949/10/5.

${ }^{324}$ Voorhees an McCloy, 29.7. 1949, IfZ-Archiv, MF 260, OMGUS, AG 1949/10/5.

325 Memorandum von Geoffrey W. Lewis (stellvertr. Leiter der Deutschlandabteilung des State Department) an Murphy, 27. 7. 1949, USNA, RG 59, 462.11/7-2749.

326 Ebenda.

327 Kreikamp, Entstehung des Entschädigungsgesetzes, S. 74.

328 Robertson an Hays, 21.7. 1949, WNRC, RG 466, McCloy Papers, Box 1; McCloy an Hays, 4.8. 1949 (Anm. 323). 
Länderrat mitgeteilt, daß das Entschädigungsgesetz jetzt doch genehmigt werde. Formell wurde die erneute Wende um 180 Grad damit begründet, daß entgegen den bisherigen Befürchtungen doch keine Überschneidungen mit dem als Teil des Lastenausgleichs erlassenen bizonalen Soforthilfegesetz auftreten würden. Ausdrücklich hieß es aber, daß mit der nun erfolgenden amerikanischen Zustimmung keine Billigung der von den Deutschen vorgeschlagenen Finanzierungsmethoden verbunden sei. Jetzt sah sich der Länderrat gedrängt, das Gesetz noch vor Bildung der Bundesregierung zu verkünden $^{329}$. Dies geschah noch im August, so daß das Entschädigungsgesetz rückwirkend zum 26. April 1949 in Bayern, Württemberg-Baden, Hessen und Bremen in Kraft trat $^{330}$. Anders als das Rückerstattungsgesetz war dies nun ein Gesetz, das weitgehend auf den deutschen Vorarbeiten beruhte, auch wenn die amerikanische Militärregierung wesentliche Impulse für das Zustandekommen gegeben hatte.

329 Sturm an Rossmann, 4. 8. 1949, IfZ-Archiv, MF 260, OMGUS, AG 1949/10/5.

330 Bayern: BayGVOBI, Nr. 20, 29.8. 1949, S. 195-205. Bremen: Gesetzblatt der Freien Hansestadt Bremen, Nr. 41, 27.8. 1949, S. 159-166. Hessen: HessGVOBl, Nr. 26/27, 18.8. 1949, S. 101-111. Württemberg-Baden: WBRegBl, Nr. 20, 1.9. 1949, S. 187-196. 